Atmos. Chem. Phys., 14, 1587-1633, 2014

www.atmos-chem-phys.net/14/1587/2014/

doi:10.5194/acp-14-1587-2014

(c) Author(s) 2014. CC Attribution 3.0 License.

\title{
A review of air-ice chemical and physical interactions (AICI): liquids, quasi-liquids, and solids in snow
}

T. Bartels-Rausch ${ }^{1}$, H.-W. Jacobi ${ }^{2,3}$, T. F. Kahan ${ }^{4}$, J. L. Thomas ${ }^{5,6}$, E. S. Thomson ${ }^{7}$, J. P. D. Abbatt ${ }^{8}$, M. Ammann ${ }^{1}$, J. R. Blackford ${ }^{9}$, H. Bluhm ${ }^{10}$, C. Boxe ${ }^{11,12}$, F. Domine ${ }^{13}$, M. M. Frey ${ }^{14}$, I. Gladich ${ }^{15}$, M. I. Guzmán ${ }^{16}$, D. Heger $^{17,18}$, Th. Huthwelker ${ }^{19}$, P. Klán ${ }^{17,18}$, W. F. Kuhs ${ }^{20}$, M. H.Kuo ${ }^{21}$, S. Maus ${ }^{22}$, S. G. Moussa ${ }^{21}$, V. F. McNeill ${ }^{21}$, J. T. Newberg ${ }^{23}$, J. B. C. Pettersson ${ }^{7}$, M. Roeselová ${ }^{15}$, and J. R. Sodeau ${ }^{24}$

${ }^{1}$ Laboratory of Radio and Environmental Chemistry, Paul Scherrer Institute, 5232 Villigen PSI, Switzerland

${ }^{2}$ CNRS, Laboratoire de Glaciologie et Géophysique de l'Environnement (UMR5183), 38041 Grenoble, France

${ }^{3}$ Univ. Grenoble Alpes, LGGE (UMR5183), 38041 Grenoble, France

${ }^{4}$ Department of Chemistry, Syracuse University, 1-014 Center for Science and Technology, Syracuse, New York, USA

${ }^{5}$ UPMC Univ. Paris 06, UMR8190, CNRS/INSU - Univ. Versailles St.-Quentin, LATMOS-IPSL, Paris, France

${ }^{6}$ University of California, Los Angeles, Department of Atmospheric and Oceanic Sciences, Los Angeles, CA 90095, USA

${ }^{7}$ Department of Chemistry and Molecular Biology, Atmospheric Science, University of Gothenburg, 41296, Gothenburg,

Sweden

${ }^{8}$ Department of Chemistry, University of Toronto, 80 St. George St., Toronto, ON, M5S 3H6, Canada

${ }^{9}$ Institute for Materials and Processes, School of Engineering, King's Buildings, The University of Edinburgh, EH9 3JL, UK

${ }^{10}$ Lawrence Berkeley National Laboratory, Chemical Sciences Division, Berkeley, CA 94720, USA

${ }^{11}$ Department of Chemistry and Environmental Science, Medgar Evers College - City University of New York, Brooklyn, NY 11235, USA

${ }^{12}$ City University of New York, Graduate Center, Department of Chemistry, Department of Earth \& Environmental Sciences, Manhattan, NY 10016, USA

${ }^{13}$ Takuvik Joint International Laboratory, Université Laval and CNRS, and Department of Chemistry, 1045 avenue de la médecine, Québec, QC, G1V 0A6, Canada

${ }^{14}$ British Antarctic Survey, Natural Environment Research Council, Cambridge, UK

${ }^{15}$ Institute of Organic Chemistry and Biochemistry, Academy of Sciences of the Czech Republic, Flemingovo nam. 2,16610 Prague 6, Czech Republic

${ }^{16}$ Department of Chemistry, University of Kentucky, Lexington, KY 40506-0055, USA

${ }^{17}$ Department of Chemistry, Faculty of Science, Masaryk University, Kamenice 5/A, 62500 Brno, Czech Republic

${ }^{18}$ RECETOX, Faculty of Science, Masaryk University, Kamenice 3, 62500 Brno, Czech Republic

${ }^{19}$ SLS Swiss Light Source, Paul Scherrer Institute, 5232 Villigen PSI, Switzerland

${ }^{20}$ GZG Abt. Kristallographie, Universität Göttingen, Goldschmidtstr. 1, 37077 Göttingen, Germany

${ }^{21}$ Department of Chemical Engineering, Columbia University, New York, NY, USA

${ }^{22}$ Geophysical Institute, University Bergen, 5007 Bergen, Norway

${ }^{23}$ Department of Chemistry and Biochemistry, University of Delaware, Newark, Delaware 19716, USA

${ }^{24}$ Department of Chemistry and Environmental Research Institute, University College Cork, Cork, Ireland

Correspondence to: T. Bartels-Rausch (thorsten.bartels-rausch@psi.ch)

Received: 28 September 2012 - Published in Atmos. Chem. Phys. Discuss.: 26 November 2012

Revised: 6 November 2013 - Accepted: 13 December 2013 - Published: 12 February 2014 
Abstract. Snow in the environment acts as a host to rich chemistry and provides a matrix for physical exchange of contaminants within the ecosystem. The goal of this review is to summarise the current state of knowledge of physical processes and chemical reactivity in surface snow with relevance to polar regions. It focuses on a description of impurities in distinct compartments present in surface snow, such as snow crystals, grain boundaries, crystal surfaces, and liquid parts. It emphasises the microscopic description of the ice surface and its link with the environment. Distinct differences between the disordered air-ice interface, often termed quasi-liquid layer, and a liquid phase are highlighted. The reactivity in these different compartments of surface snow is discussed using many experimental studies, simulations, and selected snow models from the molecular to the macro-scale.

Although new experimental techniques have extended our knowledge of the surface properties of ice and their impact on some single reactions and processes, others occurring on, at or within snow grains remain unquantified. The presence of liquid or liquid-like compartments either due to the formation of brine or disorder at surfaces of snow crystals below the freezing point may strongly modify reaction rates. Therefore, future experiments should include a detailed characterisation of the surface properties of the ice matrices. A further point that remains largely unresolved is the distribution of impurities between the different domains of the condensed phase inside the snowpack, i.e. in the bulk solid, in liquid at the surface or trapped in confined pockets within or between grains, or at the surface. While surface-sensitive laboratory techniques may in the future help to resolve this point for equilibrium conditions, additional uncertainty for the environmental snowpack may be caused by the highly dynamic nature of the snowpack due to the fast metamorphism occurring under certain environmental conditions.

Due to these gaps in knowledge the first snow chemistry models have attempted to reproduce certain processes like the long-term incorporation of volatile compounds in snow and firn or the release of reactive species from the snowpack. Although so far none of the models offers a coupled approach of physical and chemical processes or a detailed representation of the different compartments, they have successfully been used to reproduce some field experiments. A fully coupled snow chemistry and physics model remains to be developed.

\section{Introduction}

Ice and snow, as present in Earth's cryosphere, are reactive media (Takenaka et al., 1992; Klán and Holoubek, 2002; Abbatt, 2003) that play an integral role in transferring trace gases to and from the atmosphere (Domine and Shepson, 2002). Surface snow can efficiently scavenge and accumulate compounds of environmental concern (Wania et al., 1998;
Dommergue et al., 2003). At the same time, snow is a highly dynamic multiphase medium. Changes in snow structure and properties critically affect both physical processes and chemical reactivity (Domine et al., 2008). Better understanding underlying processes and their relation to the Earth system is of importance to environmental chemistry, atmospheric science, and cryospheric science, as detailed in recent reviews on the uptake of acidic trace gases to ice (Abbatt, 2003; Huthwelker et al., 2006), snow chemistry (Grannas et al., 2007b), halogen chemistry (Simpson et al., 2007; Abbatt et al., 2012), fate of organics (McNeill et al., 2012; Grannas et al., 2013), and mercury in snow (Steffen et al., 2008).

\subsection{Importance of air-snow interactions}

The release of reactive compounds from the snowpack to the atmosphere is of importance for the composition and the oxidative capacity of the atmospheric boundary layer in permanently or seasonally snow-covered regions, including the polar regions (Domine and Shepson, 2002). Strikingly, the depletion of ozone in air masses from the ground up to heights of several kilometres had already been observed in the 1980s at the Arctic coast (Oltmans et al., 1989) and is linked - at least in part - to processes in surface snow and ice (Simpson et al., 2007; Abbatt et al., 2012; Pratt et al., 2013). Other substantial effects include the emission of trace gases from snowpacks. For example, in Antarctica $\mathrm{NO}_{\mathrm{x}}$ levels typical for urban conditions have been observed (e.g. Davis et al., 2001, 2004; Eisele et al., 2008; Frey et al., 2013). Snow can act as an important storage and transfer medium for pollutants from the atmosphere to aquatic environments or to the soil. Mercury and persistent organic pollutants are examples of species that may accumulate in surface snow during winter and be released during snowmelt (Wania et al., 1998; Lalonde et al., 2002). However, from a global perspective the overall removal or transfer from the atmosphere to the soil and oceans is likely smaller than the depositional fluxes, because species like nitrogen oxides (Grannas et al., 2007b) and mercury (Durnford and Dastoor, 2011) are partially re-emitted to the atmosphere due to chemical processes in the snow. For other species such as persistent organic pollutants, the transfer to the soil or to the oceans may exceed the initial deposition, as those species may be formed by postdepositional processes in surface snow (Grannas et al., 2013). To fully assess the atmosphere-to-soil or -ocean fluxes from a global perspective, the post-depositional fate of pollutants and impact of chemistry in snow need to be understood.

In addition nitrate and other species have been measured in firn and ice cores, giving detailed concentration profiles that may be related to past atmospheric composition and climate (e.g. Fuhrer et al., 1993; Anklin and Bales, 1997; Legrand and Mayewski, 1997; Sommer et al., 2000; Rothlisberger et al., 2001; Frey et al., 2006). Chemical reactions and physical exchange processes have the capacity to significantly modify the amounts and location of impurities stored 
within the snow, making the interpretation of concentration profiles impossible without the application of models (Neftel et al., 1995; Wolff, 1995).

\subsection{Impurity compartments}

The major source of impurities in surface snow is the atmosphere. Riming, the freezing of aqueous droplets, leads to the retention of soluble atmospheric trace gases (e.g. $\mathrm{SO}_{2}, \mathrm{H}_{2} \mathrm{O}_{2}$, $\mathrm{NH}_{3}, \mathrm{HNO}_{3}, \mathrm{CH}_{2} \mathrm{O}, \mathrm{CHOOH}, \mathrm{HCl}, \mathrm{Hg}(\mathrm{II})$ ) into the ice particles later found in snow samples (Snider and Huang, 1998; Long et al., 2010; Douglas et al., 2011). Thus rimed snow and ice are usually more concentrated with impurities than other types of deposited snow (Mitchell and Lamb, 1989; Poulida et al., 1998). Volatile atmospheric trace gases can also be taken up directly from the gas phase, likely affecting surface snow composition strongly (Abbatt, 2003; Huthwelker et al., 2006; Grannas et al., 2007b; Steffen et al., 2008). These adsorbed species may react rapidly to changes in the atmospheric environment, while entrapped species experience more solid-state-like processes. Figure 1 illustrates the different locations that may host impurities in surface snow, such as the ice crystals with an air-ice interface towards the gas-filled pore space and with ice-ice interfaces at grain boundaries and triple junctions (so-called veins) and quadruple points (nodes) between ice crystals. If impurities are concentrated, colligative effects result; for example dissolution of impurities may form brine and introduce liquid into the system or solids may precipitate (Fig. 1). Brines are impurity-rich liquid solutions that coexist with the solid ice phase in thermodynamic equilibrium and recently approaches have been developed to predict the impurity concentration in brine (Sect. 2.1).

Clearly, the chemical and physical environment that impurities experience varies widely between individual compartments, as for example evident from the diffusivity of water molecules in each compartment (Sect. 4.1). How do impurities distribute between the individual compartments in laboratory samples and the field (Sect. 2)? How do exchange processes of trace gases between the atmosphere and each of these individual compartments differ? Is reversible surface adsorption (Sect. 4.3), solid-state diffusion (Sect. 4.2), or uptake to the liquid fraction in snow (Sect. 4.3.5) the dominant mechanism for specific experimental conditions, and which mechanism describes field observations best (Sect. 4.4 and Sect. 4.2.3)? Similar questions about the dominating process arise in the interpretation of chemical reactivity in ice and snow samples: how and why does the reactivity differ at ice surfaces (Sect. 5.5) from that in the bulk ice (Sect. 5.2) - such as in liquid inclusions (Sects. 5.1, 5.2, 5.3)? And, how well do models capture the complex snow chemistry and what are the limiting factors (Sect. 5.6)? The situation where bulk and surface reaction might occur is very similar to other heterogeneous systems of atmospheric relevance, such as aerosols, where strategies have been developed to differentiate between the contributions of heterogeneous vs. bulk reactivity (Kolb et al., 2010; Shiraiwa et al., 2010).

Next to adsorbed and dissolved impurities, snow also contains trapped aerosol particles. These may originate from ice condensation nuclei, from scavenging during precipitation, or from deposition from air that was wind-pumped through the porous snow (see Domine et al., 2004; Beine et al., 2011; Voisin et al., 2012; Domine et al., 2013, and references therein). Recently it was shown that reactions within such aerosols in surface snow can be the main source of trace gas emissions to the overlying atmosphere (Abbatt, 2013; Pratt et al., 2013), and it has been proposed that the main absorbers of solar irradiation, driving photochemistry in snow, are in many places located in aerosol particles trapped in snow (Beine et al., 2011; Voisin et al., 2012). The reactivity of solid aerosol deposits is not further discussed in this review. However, Koop et al. (2000) noted that sea salt deposit may remain in liquid phase for typical Arctic temperatures, and reactivity in such liquid reservoirs is discussed throughout the review.

\subsection{Snow dynamics}

Temperature gradient conditions, for instance when the snowpack is warmed at its surface during the day from sun or radiatively cooled at night, are common in the environment. Temperature gradient changes can occur over a range of timescales: from fractions of seconds (Szabo and Schneebeli, 2007) to diurnally and seasonally. Field measurements have shown such alternating temperature gradients in the top $0.2 \mathrm{~m}$ of alpine and arctic snowpacks (Birkeland et al., 1998; Dadic et al., 2008). Under the influence of these gradients, morphological changes of the surface snow occur quickly (Fig. 2), and these changes of snow shape due to temperature and vapour gradients respond in complicated, subtle ways to changes in temperature and humidity (Arons and Colbeck, 1995; Schneebeli and Sokratov, 2004). Pinzer and Schneebeli (2009a, b) studied snow metamorphism under alternating temperature gradients (with $12 \mathrm{~h}$ periods) using X-raycomputed microtomography (XMT). They found that up to $60 \%$ of the total ice mass was redistributed during the $12 \mathrm{~h}$ cycle. Such high water fluxes mean that ice sublimates and condenses with a characteristic residence time of just 2-3 days (Pinzer et al., 2012). An illustrative video of their experimental observations of the metamorphism indicates that the mass fluxes are much higher than previously thought and the fate of impurities distributed within the snow is not clear (Pinzer et al., 2012).

Further, freeze-thaw cycles that are common in maritime mountain regions can also occur in the Arctic (Meyer and Wania, 2008) and lead to a redistribution of impurities (Eichler et al., 2001). How do impurities distribute between the individual compartments during the freezing process (Sect. 2.5), and how can we explain the significant reactivity and unique reaction products observed during the 


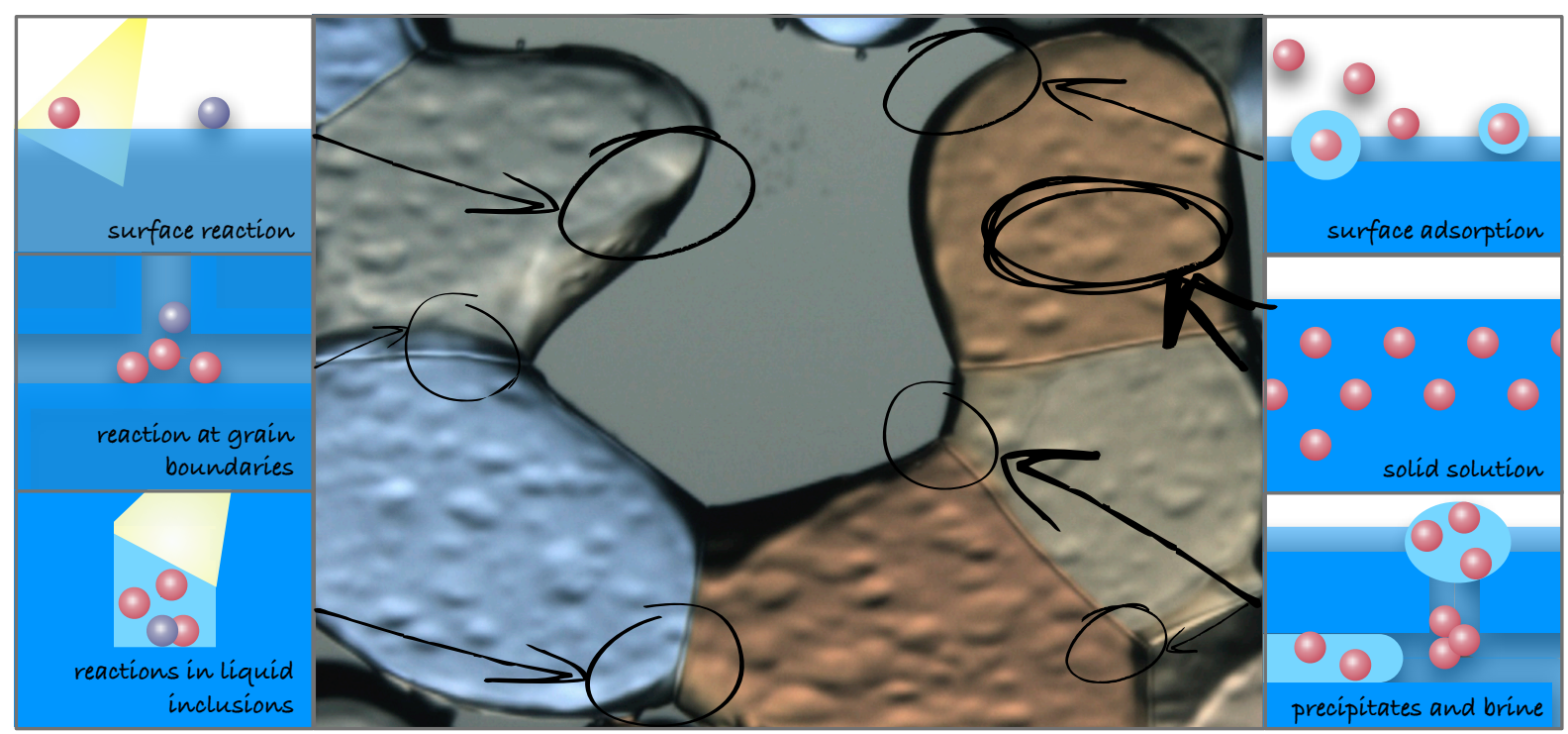

Fig. 1. Illustration of the multiple domains in snow hosting impurities and reactions. The photo shows a $\approx 1$ mm-wide picture of a thin section of alpine snow as seen under a polarised microscope. Ice crystals appear coloured, interstitial air greyish (courtesy of F. Riche and M. Schneebeli, copyright by WSL SLF Davos). The schemes illustrate impurities (red and blue spheres) and their location within the individual compartments in snow - in bulk ice (dark blue) and on its surface, interstitial air (white) and liquid brine (light blue). The disordered interface at the ice crystal's surface and its potential heterogeneity given by hydration shells surrounding impurities are illustrated as grey-bluish and light-blue areas. On the left, locations where reactions occur are sketched (top to bottom): heterogeneous (photo)reactions, (bi-molecular) reactions in grain boundaries, (photo)reactions in liquid micro-inclusions. In the right panel the different compartments are illustrated: impurities at the disordered ice surface with varying hydration shell in their vicinity, ordered arrangement of impurities in the ice crystal as solid solution, and solid precipitates and liquid brine in grain boundaries and veins.

freezing process (Sect. 5.1.1)? Pockets of liquid or liquid in grain boundaries can migrate under the influence of temperature gradients and promote transport of species at faster diffusional rates than within the solid lattice (Hoekstra and Osterkamp, 1965). Such effects have been discussed for sea ice (Harrison, 1965; Weeks and Ackley, 1986), for surface snow (Meyer and Wania, 2008), and glacial ice (Rempel et al., 2001, 2002) where the transport of species is governed by a combination of gravitation forces, diffusion and temperature gradients.

How impurities respond to such strong rearrangements of the ice phase is not clear, but may be more important for their ultimate fate than their initial mode of incorporation. Considering the dynamic character of the ice matrix, the location of impurities in surface snow is not necessarily reflective of the way they have initially been incorporated in fresh snow. Further, adsorbing species might be trapped by water molecules that grow the ice from the gas phase (Sect. 4.3.7), leading to an enhanced uptake and capacity to trap these gases.

\subsection{Structure of the snow surface}

At surfaces, both internal and at the air-ice interface, the crystal structure of ice is necessarily modified because of the outer layer's missing bonds and subsequent reconstructions and relaxations of the surficial molecular layers to min- imise free energy. This is a well-established phenomenon in surface physics of ice (Frenkel, 1946; Henson and Robinson, 2004; Henson et al., 2005; Hobbs, 2010) and other solid materials such as colloids (Alsayed et al., 2005), ceramics (Clarke, 1987), and metals (Frenken and van der Veen, 1985). Henson and Robinson (2004) have compiled studies of this phenomenon for different materials that span triplepoint temperatures from 25 to $933 \mathrm{~K}$, illustrating that surface disorder is a ubiquitous property of crystals (Fig. 3). Henson and Robinson (2004) also proposed a functional dependency (solid and dashed lines in Fig. 3). This relationship is however based on crude assumptions treating the surface disorder analogously to multi-layer adsorption; also, as the authors note, only some selected studies were included in the compilation, and particularly for ice considerable disagreement with many other studies exists. More recent approaches to derive functional relationships and a complete discussion of experimental observations are given in Sect. 3.1 and Sect. 3.3.

Such molecular disorder at the surface is frequently referred to as a quasi-liquid or liquid-like layer. The use of these synonyms has provoked some controversy and confusion (Baker and Dash, 1996; Knight, 1996b, a; Domine et al., 2013). In this review, the terms surface disorder and disordered interface $(D I)$ are used to stress that the molecular disorder is an inherent interfacial property of crystals. 


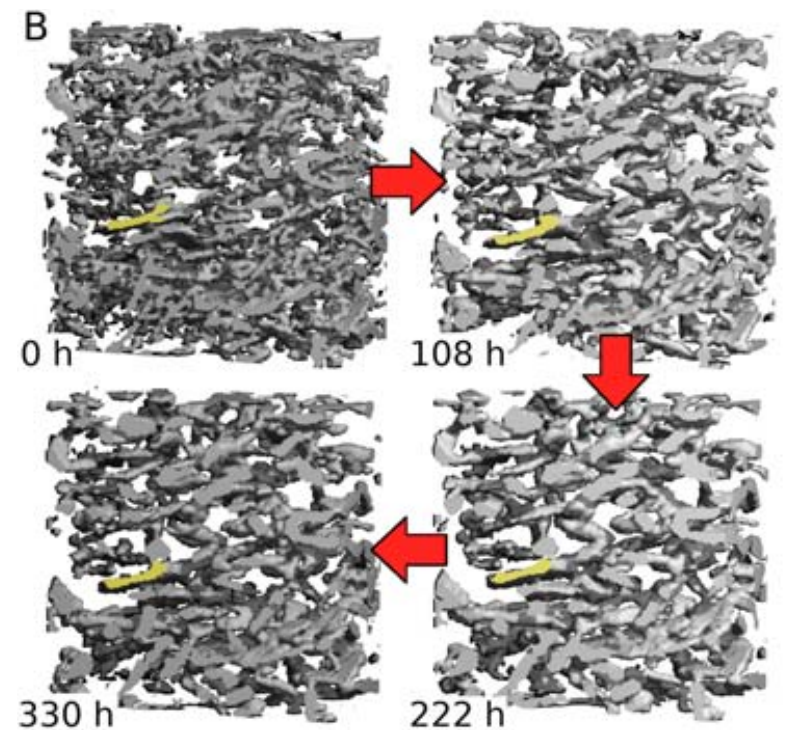

Fig. 2. Morphological evolution of snow during metamorphosis under the influence of a temperature gradient. Three-dimensional Xray-computed microtomography reconstructions after $0,108,330$, and $220 \mathrm{~h}$ are shown. Between each image, the sample was exposed to more than four sinusoidal temperature gradient cycles on the order of $90 \mathrm{Km}^{-1}$. The size of each image is $3.6 \mathrm{~mm} \times 1.8 \mathrm{~mm} \times$ $3.6 \mathrm{~mm}$. One structural element has been marked yellow for orientation. Reprinted with permission from Pinzer and Schneebeli (2009b). Copyright (2009) by John Wiley and Sons.

Note that we avoid the use of the term premelting, even though it is commonly used synonymously with surface disorder in material science, because we believe it invites confusion with the formation of a true melt. A motivation of this review is to highlight clear differences and analogies in the behaviour of disordered ice surfaces to that of a liquid phase. Further, we address the question of how chemical processes (Sect. 5.5), physical exchange processes (Sect. 4.3.3), and diffusion (Sect. 4.1.2) are affected by increasing surface disorder. Central to answering these questions is the ability to quantify the disordered fraction of ice. Recent molecular dynamic simulations (Sect. 3.2), thermodynamic considerations (Sect. 3.1), and experimental observations (Sect. 3.3) of the properties and extent of the disorder are reviewed. As impurities are ubiquitous in environmental snow, this review addresses how impurities impact the disordered interface in great detail (Sects. 3.2.2 and 3.3.1).

\section{Chemical impurities in multiphase snow}

The liquid nature of sulphuric acid solutions in triple junctions of Antarctic ice has been shown using Raman microscopy by Fukazawa et al. (1998). Koop et al. (2000) concluded that sea salt particles remain liquid under environmentally relevant temperatures both as aerosol in the bound-

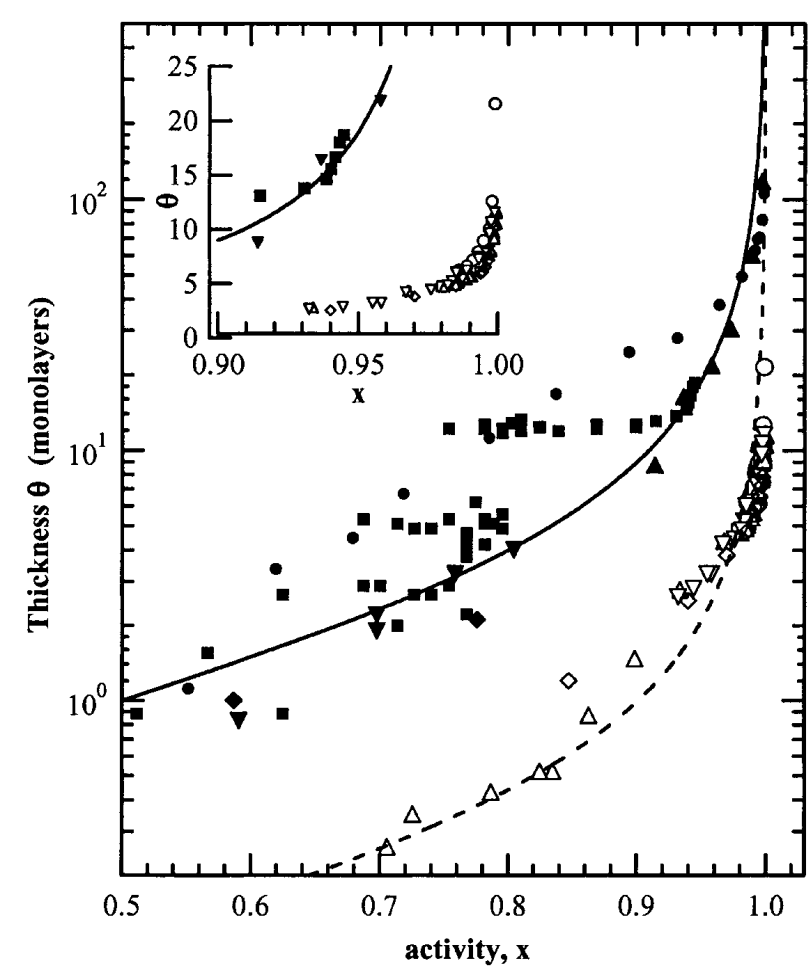

Fig. 3. Empirical correlation between the thickness of the disordered interface and the thermodynamic activity for different solids. Open symbols denote atomic, and filled symbols molecular, systems. Data include neon with a triple point of $\sim 25 \mathrm{~K}$ (open circles), aluminium (934 K, open bottom-down triangles), oxygen $(54 \mathrm{~K}$, filled bottom-down triangles), and biphenyl (filled circles, $343 \mathrm{~K}$ ). The lines give simple functional dependences for each data set; see text for details. Reprinted with permission from Henson and Robinson (2004). Copyright (2004) by the American Physical Society.

ary layer as well as in the form of deposits on snow. This is caused by the low eutectic temperatures of constituent solutes, as illustrated in the phase diagram in Fig. 4. Next to ice and to liquid solutions, solid precipitates might occur in environmental snow samples, when the solubility limit of solutes is reached (Thomas and Dieckmann, 2009). A noteworthy environmental signature of solutes and precipitates in such multiphase frozen systems are ozone depletion events. The release of bromine, acting as a catalyst for the destruction of tropospheric ozone, from surface snow has been outlined in recent years (Simpson et al., 2007; Abbatt et al., 2012). The bromine emissions are suggested to be a consequence of bromide precipitation at lower temperatures than chloride and may be enhanced (bromine explosion) by a reduced buffering capacity of brine in salty snow due to calcite precipitation (Sander et al., 2006). In the case of precipitation of calcium as ikaite $\left(\mathrm{CaCO}_{3} \cdot 6 \mathrm{H}_{2} \mathrm{O}\right)$, supported by recent observations, this effect is not expected (Dieckmann et al., 2008; Morin et al., 2008). Recent measurements of $\mathrm{pH}$ changes at the surface of freezing sea salt solutions suggest that buffering is 


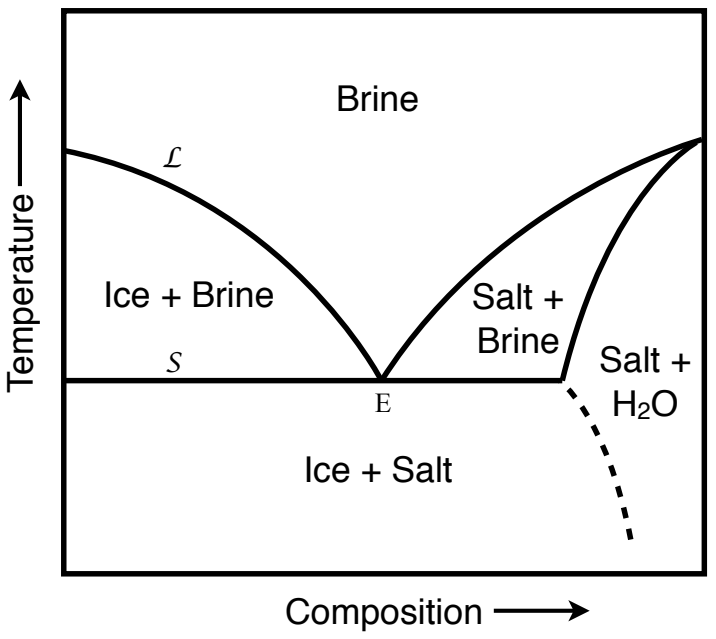

Fig. 4. An example of an equilibrium phase diagram for a binary solution comprised of two components, water and a typical soluble mineral salt. The lines separate regions of different phases. The liquidus $(\mathcal{L})$ separates the region in which the system is completely liquid, with salt completely dissolved in liquid water forming a brine, from a region in which solid and liquid coexist. Likewise, the solidus $(\mathcal{S})$ separates the latter region from the region where all of the material is solid. These two lines intersect at the eutectic point E. At salt concentrations above the eutectic water may be found in liquid brine, ice, or molecularly incorporated into salt crystals $\left(\right.$ salt $\left.+\mathrm{H}_{2} \mathrm{O}\right)$.

maintained in the brine layer in contact with the atmosphere (Wren and Donaldson, 2012a).

Recent research has focused on detecting and predicting the presence and composition of solutes in multiphase snow. How solutes distribute in snow samples has received particular attention. They might be incorporated into the ice crystal, in liquid inclusions within bulk ice, or remain at ice surfaces or in grain boundaries (Hobbs, 2010). This is of interest particularly for the freezing process, given that in many laboratory-based studies samples prepared by freezing solutions were used.

\subsection{Amount and concentration of brine}

The salinity of liquid in coexistence with ice adjusts to maintain thermodynamic phase equilibrium as illustrated in Fig. 4. Above eutectic temperatures Cho et al. (2002) confirmed that liquid $\mathrm{NaCl}$ concentrations are well described by the phase diagram. In these NMR studies, they derived the brine concentration at various temperatures for samples in thermodynamic equilibrium, and developed a parameterisation to calculate the amount of liquid in freezing systems. This approach was expanded by Kuo et al. (2011), who substituted concentrations with activities and included two additional solutal loss processes during freezing, (i) the solubility

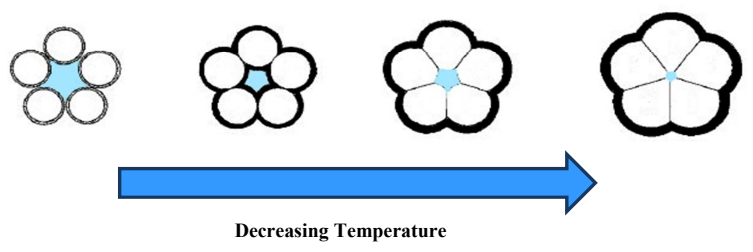

Fig. 5. Schematic representation of how the amount of liquid represented by the blue area adjusts to temperature and how it may be trapped in veins forming micro-inclusions (O'Concubhair and Sodeau, 2013). Reprinted with permission from Takenaka et al. (1996). Copyright (1996) by the American Chemical Society.

of solutes in the ice crystal and (ii) release to the gas phase. With this approach the total amount and concentration of the solution can be predicted during the freezing process of solutions containing salts or inorganic, volatile acids, as long as the freezing is not kinetically hindered. In an earlier NMR study the liquid fraction of natural sea ice with a more complex chemical composition was well described based on the eutectic concentrations of salts (Richardson, 1976). The total volume of liquid in coexistence is thus given and can be predicted by the amount of solutes (Fig. 4). Obviously, the volume of liquid in coexistence with ice drastically shrinks with decreasing temperatures, leading to highly concentrated liquid pockets in growing ice (Fig. 5), which provide a unique and highly reactive medium (Sect. 5.1.1).

In addition to colligative solute effects, geometric constraints can stabilise liquids in confined reservoirs, as theoretically treated by Nye (1991). If inclusions of liquid are small, with radii in the nanometre range, the Gibbs-Thomson effect leads to a substantial melting point depression. The Gibbs-Thomson effect states that the melting point depression $(\mathrm{d} T)$ depends on the radius $(r)$ of a particle, or inclusion: $\mathrm{d} T \sim 1 / r$. Melting point depressions of $15-40 \mathrm{~K}$ have been found for water and solutes in nanometre-sized confinements (Aristov et al., 1997; Christenson, 2001). The theoretical treatment presented by Nye (1991) combines both the Gibbs-Thomson effect and solution theory.

\subsection{Solubility limits}

The key to predicting the amount of liquid in cold, multiphase systems is the precise knowledge of the amount of solutes. At low temperatures and high concentration, the solubility limits of major solutes can be reached (Fig. 4). For example, from the six major ions present in seawater, sulphate and sodium start to precipitate in the form of mirabilite $\left(\mathrm{Na}_{2} \mathrm{SO}_{4} \cdot 10 \mathrm{H}_{2} \mathrm{O}\right)$ at $266 \mathrm{~K}$, while sodium chloride precipitates at $250 \mathrm{~K}$ and calcium carbonate at $271 \mathrm{~K}$ (Thomas and Dieckmann, 2009). Such solubility limits, which may significantly lower the salinity of brine, are not yet included in the models by Cho et al. (2002) and Kuo et al. (2011). If liquid brine and solid precipitates are separated, the distribution of 
ions in bulk snow will also change. Further, buffer capacity and $\mathrm{pH}$ may change upon precipitation of solutes, with direct consequences for air-ice chemical exchanges and the chemical reactivity in this compartment.

\subsection{Below the eutectic composition}

Surprisingly and in contrast with expectations from the phase diagram, the NMR investigations by Cho et al. (2002), Guzmán et al. (2006) and Robinson et al. (2006) have revealed the existence of liquid $\mathrm{NaCl}$ and $\left(\mathrm{NH}_{4}\right)_{2} \mathrm{SO}_{4}$ solutions well below the respective eutectic temperatures. Cho et al. (2002) argued that kinetic limitations leading to supercooled solutions could not explain the observations, because the amount of liquid closely followed the temperature during warming periods toward the eutectic temperature. Freezing of emulsions that resemble water droplets in the atmosphere can be kinetically hindered so that a meta-stable liquid phase exists well below the eutectic temperature (Koop et al., 2000; Bogdan, 2010). Using surface-sensitive, synchrotron-based X-ray spectroscopy, Křepelová et al. (2010a) found no evidence for liquid on the surface of frozen solutions of $\mathrm{NaCl}$ below the eutectic. This technique probes the local, chemical environment of the chloride anions and does not rely on assumptions based on bulk properties to derive conclusions about the physical state of the probe. One difference between the two studies is that Křpelová et al. (2010a) exclusively probed the upper surface, while Cho et al. (2002) also probed the bulk ice. We propose here that geometric constraints to the liquid volume kept in the micro-pockets might explain the observed freezing point depression (Sect. 2.1). As the size and number of these micro-pockets strongly depend on the impurity concentration and the freezing rate (Sect. 2.5), the extrapolation to environmental snow with its low impurity levels and different origin than these laboratory ice samples might be questioned.

\subsection{Spread and agglomerates of impurities}

At grain boundaries and at the air-ice interface, liquid can spread in channels or form isolated agglomerates (Fig. 6). Whether the liquid is trapped in such isolated patches (also referred to as micro-pockets), or if it wets the grains possibly forming interconnected channels, depends on the surface energies (Nye and Frank, 1973; Waff and Bulau, 1979). These surface energies are highly compound-specific.

There have been a number of studies using lowtemperature scanning electron microscopy (LTSEM) which have identified solid particles such as dust and salt impurities like sodium chloride and sulphate, in snow and ice (e.g. Mulvaney et al., 1988; Cullen and Baker, 2001; Barnes et al., 2002; Baker et al., 2003; Obbard et al., 2003; Barnes and Wolff, 2004; Lomonaco et al., 2011; Spaulding et al., 2011). In preparation for the LTSEM, brine is solidified, direct information on the phase of the impurities in the sample are thus

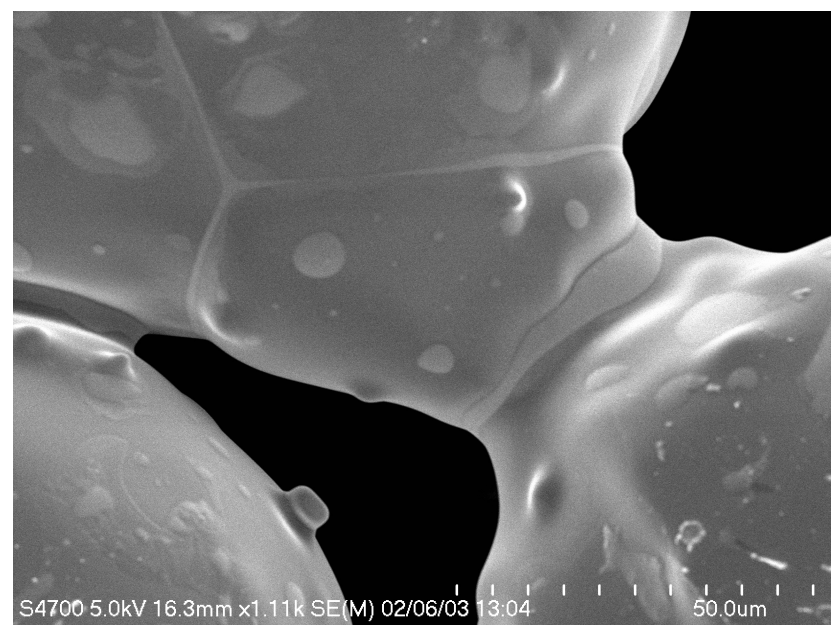

Fig. 6. Low temperature scanning electron microscopy image of ice particles containing salt. The lighter-grey regions along grain boundaries and as isolated patches are $\mathrm{NaCl} \cdot 2 \mathrm{H}_{2} \mathrm{O}$. The darkergrey areas show ice. Reprinted with permission from Blackford et al. (2007).

lost. State-of-the-art LTSEM instruments have a resolution of $5 \mathrm{~nm}$, which makes SEM ideal to study impurity agglomerates, rather than deriving molecular level information. Also, SEM is not suitable for lighter elements such as carbon or nitrogen. The first direct observation of sulfuric acid, concentrated in triple junctions and to a lesser extent at grain boundaries, in Antarctic ice was made using an electron dispersive (EDS) X-ray detector analysis in LTSEM (Mulvaney et al., 1988). Since this first observation there have been a number of LTSEM studies of polar ice with EDS analysis of impurities indicating that impurities are preferentially located in disconnected regions along the grain boundaries (see Blackford, 2007, for studies prior to 2007). Yet, a clear quantitative analysis based on statistically significant data is still lacking. More studies characterising the material structure of ice are needed to be able to interpret the results in an atmospheric context. Morphology and surface energy in the ice- $\mathrm{NaCl}$ system have been studied by LTSEM using ice particles doped with $\mathrm{NaCl}$ frozen in liquid nitrogen (Blackford et al., 2007). Figure 6 shows the shape of the ice and the liquid NaCl-rich brine phase after etching of the ice matrix. The brine concentrates in vein structures where three or more grains meet and as inclusions in grain boundaries and at the air-ice interface that appear as small mushroom-like features in the image. These images are rich in detail and provide qualitative structural information, which in itself is useful - as interconnected paths or isolated pockets of second-phase liquid can be detected.

Most studies have focused on glacial ice, which is different from surface snow, making extrapolations of impurity distributions from those findings to snow questionable for a number of reasons: (i) glacial ice is more dense than snow and 
temperature gradients are reduced, resulting in less sintering and ice mass transport; (ii) glacial ice is much older than surface snow and impurities have had more time to be transported through the ice matrix. Recently, an extensive LTSEM microstructural characterisation of Antarctic firn has been made by Spaulding et al. (2011). They observed distinct impurity patterns and claimed that the impurities control the microstructure found at those locations. This finding would be important, if true, as it means that the chemical species in the ice influence the structure, and the chemical reactions themselves are influenced by the structure. However, the relevant processes during densification and evolution of firn structure and their timescales were not studied, and the observed patterns might also simply be due to different impurity sources. $\mathrm{X}$-ray-computed microtomography (XMT) allows in situ observations of the arrangement of snow crystals in snowpack samples (e.g. Schneebeli and Sokratov, 2004; Heggli et al., 2011) and polar firn (Freitag et al., 2004) at 5-40 $\mu \mathrm{m}$ resolution. It has furthermore been claimed that brine networks have been imaged in sea ice by XMT (Obbard et al., 2009) and in natural marine ice-gas-hydrate mixtures (Murshed et al., 2008), which would make XMT a promising method to investigate the distribution of brine in porous snow samples. Yet, using XMT is difficult when liquid is present, due to the small difference in absorption of liquid solutions and of solid ice. Hence it seems likely that the liquid features documented by Obbard et al. (2009) and Murshed et al. (2008) are to a certain degree sea salts that have precipitated at their imaging temperature of $263 \mathrm{~K}$. A contrast agent may be added to enhance the brine-ice absorption contrast when studying saline ice grown in the laboratory (Golden et al., 2007), although laboratory ice may differ from natural sea ice. In future studies the problems with the ice-brine contrast may be overcome by means of phase-contrast-based XMT (McDonald et al., 2011) enabling the observation of brine and void air simultaneously.

\subsection{Solutes during the freezing process}

The rejection of solutes from the growing ice crystal lattice during the freezing of salt solutions, as predicted by the phase diagram (Fig. 4), is generally a good approximation, because solubility of solutes in ice is low (Hobbs, 2010). Molecular dynamics simulations of ice growth from supercooled salt solutions have revealed the microscopic mechanism whereby ions and neutral species are excluded from growing ice (Vrbka and Jungwirth, 2005; Carignano et al., 2006, 2007; Bauerecker et al., 2008; Liyana-Arachchi et al., $2012 b$, a). However, a small fraction of impurities may be incorporated within grains. In this case it has been found that ions are more readily incorporated into the ice matrix than non-ionised solutes (Hobbs, 2010). Large organic molecules such as glucose (Halde, 1980), carboxymethyl cellulose (Smith and Pounder, 1960), and alkylbenzenes (Fries et al., 2007) can also be incorporated within ice samples dur- ing freezing of liquid solutions. The formation of a solid solution, which is most likely highly supersaturated, is consistent with the kinetic model of Domine and Thibert (1996). Recent spectroscopic investigations have started to assess whether solutes end up in the bulk (brine inclusions and grain boundaries) or at the air-ice interface during freezing. Wren and Donaldson (2011) reported only a minor increase in nitrate concentration at the ice surface and suggested that nitrate might be favourably incorporated into pockets or grain boundaries inside bulk ice at 258-268 K. A similar tendency of nitrite to be captured in liquid reservoirs inside growing ice was suggested earlier (Takenaka et al., 1996). Using surfacesensitive spectroscopy Křepelová et al. (2010a) showed that frozen solutions of $\mathrm{NaCl}$ above the eutectic exhibited a composition on the ice surface consistent with the phase diagram of the bulk solution. This is in agreement with earlier work by Döppenschmidt and Butt (2000) where solid $\mathrm{NaCl}$ crystals were identified at the ice surface at temperatures below the eutectic using AFM. Wren and Donaldson (2011) suggested that the preference to be trapped in pockets is a compoundspecific effect. Further, Cheng et al. (2010) have shown that the presence of electrolytes can trigger the occurrence of random inclusions at high concentrations, whereas at lower concentrations solutions tend to freeze and thereby form connected channels. Next to concentrations, also the freezing rates, which have a large effect on the incorporation of solutes (see below), might have been different in both experiments and also as compared to natural snow. Certainly, more studies are needed to address the environmental significance of these observations.

The selective incorporation of ions into the ice matrix can lead to the generation of a charge imbalance at the freezing front (Workman and Reynolds, 1950). The charge imbalance creates a large electrical potential, when the product of the growth rate and electrolyte concentration at the freezing front exceeds a critical value that depends on $\mathrm{pH}$ (Bronshteyn and Chernov, 1991; Sola and Corti, 1993). Workman and Reynolds (1950) found that the potential is larger for diluted solutions and report potentials of up to $200 \mathrm{~V}$, for solutions of $10^{-5} \mathrm{M}$. The potential is a function of the time, freezing rate, concentration of salt(s) as well as other solutes and crystal orientation. In follow-up studies (Lodge et al., 1956; Cobb and Gross, 1969; Murphy, 1970), the magnitudes of the freezing potentials of identical solutions were scattered because these factors were not kept constant. Measuring freezing potentials across the interface between single crystals and electrolyte solutions significantly improved reproducibility (Wilson and Haymet, 2008). Even though the absolute values of freezing potentials are poorly reproduced due to the technical difficulties, the phenomenon uncovers important micro-structural behaviour during freezing. A freezing potential originates from unequal distribution coefficients between the solution and the ice. Thus its measurement may be one of the few options of how to access the fraction of ions incorporated into the ice lattice. Overall, the effects of 
freezing potential may be of importance whenever the distribution coefficients of cations and anions are not equal, which is expected to be the most common case for freezing of environmental solutions.

\subsection{Modelling liquids in snow}

Physical snow models solve the energy budget of the snowpack and have been used to simulate the amount and redistribution of liquid in snowpacks exposed to temperature cycles. To understand and predict the distribution of impurities in snow, predicting the drainage of water through the snowpack is of importance, because these movements of the liquid phase can redistribute solutes (Eichler et al., 2001). Bulk snowpack models treat the liquid water content as a bulk parameter, while in 1-D models different layers can have different capacities to store liquid water. Typically, a snow layer can retain up to $10 \%$ of its mass in the form of liquid water before it drains to deeper layers due to gravitational flow (Brun et al., 1992). In the most complex 1-D snow models existing today the vertical transport of liquid in the snow is simulated using a bucket-like approach, where each snow layer is filled up with liquid water up to its maximum retention capacity before excessive liquid is drained to the next layer below (Brun et al., 1992; Bartelt and Lehning, 2002). This is certainly an oversimplification since water movement in the snow can also occur under non-saturated conditions, while capillary barriers and effects can limit or stop the liquid water flow. Recent attempts have been made to improve the simulation of water movement in the snowpack based on established models for the calculation of water flow through soils (e.g. Hirashima et al., 2010). Nevertheless, the simulation of liquid water still requires attention in the future. So far, no attempts have been made to model the impact of liquid water on the redistribution of impurities inside the snowpack.

\subsection{Conclusions about the multiphase structure}

The location and chemical state of impurities in (multiphase) snow remain an unresolved issue. This issue is essential to assess the chemical reactivity and the exchange with the overlying air, and to compare results from studies with different types of ice or snow samples. Significant progress has been made during recent years towards analysing and describing the physical state and distribution of impurities in snow:

1. Detailed modelling to derive the brine concentrations in frozen samples, based on the thermodynamic phase diagram, but also taking into account losses by release of volatile species from the brine to the gas phase and non-ideal behaviour of the brine solution, has recently been presented.

2. The total amount of solute that gets expelled from the ice during the freezing process and the precise compartment into which they get expelled are highly un- certain: brine may end up at the air-ice interface, in grain boundaries, or trapped in micro-pockets in the bulk ice. Observing the electrical potential that builds up during the freezing of solutions at the ice-solution interface gives a quantitative measure to estimate the influence of the freezing rate and of solute concentrations on the distribution of solutes between the ice surface and the bulk ice. Better understanding the freezing process is particularly important to compare individual laboratory-based studies and to extrapolate to field conditions as concentrations and freezing rates might vary widely between different experiments and compared to the field.

3. Observing liquid water and void air simultaneously in porous snow and ice samples is delicate, and continued developments of phase-contrast XMT are one way to tackle this issue. SEM studies can assess the chemical composition of agglomerates of solute in micropockets within the ice's microstructure. Such studies have shown that some impurities accumulate along grain boundaries, while others are concentrated in isolated spots. What controls the precise distribution is an area of active investigation.

4. The fate of solutes below the eutectic point is an essential, yet unexplored, question. In particular, it is currently not clear how liquid-like the environment that impurities experience in micro-pockets remains below the eutectic temperature. We argued that apparent discrepancies to the phase diagram might be due do to an additional melting point depression in nanometresized micro-pockets (Gibbs-Thomson effect).

\section{The disordered interface}

The surface of snow crystals hosts chemical reactions and is the interface at which exchange with the gas phase takes place. The role of the disordered interface in promoting chemical reactions and exchange processes has been intensively discussed for decades (Smith and Pounder, 1960; Wang, 1961, 1964; Gross et al., 1987; Dash et al., 1995; Cohen et al., 1996; Finnegan and Pitter, 1997; Petrenko and Whitworth, 1999; Giannelli et al., 2001; Cho et al., 2002; Heger et al., 2005; Vrbka and Jungwirth, 2005; Kahan et al., 2007; Wren and Donaldson, 2011). A key question that leads to some controversy is whether or not describing the surface in analogy to liquid phase and parameterising processes occurring there based on liquid phase-processes is a valid and realistic picture.

Most studies have dealt with the disordered interface at clean ice surfaces, i.e. without doping the surface with impurities, and studies that have dealt with the thickness and the properties of the ice surface will be reviewed in this section. Key questions are the following: does surface disorder spread 


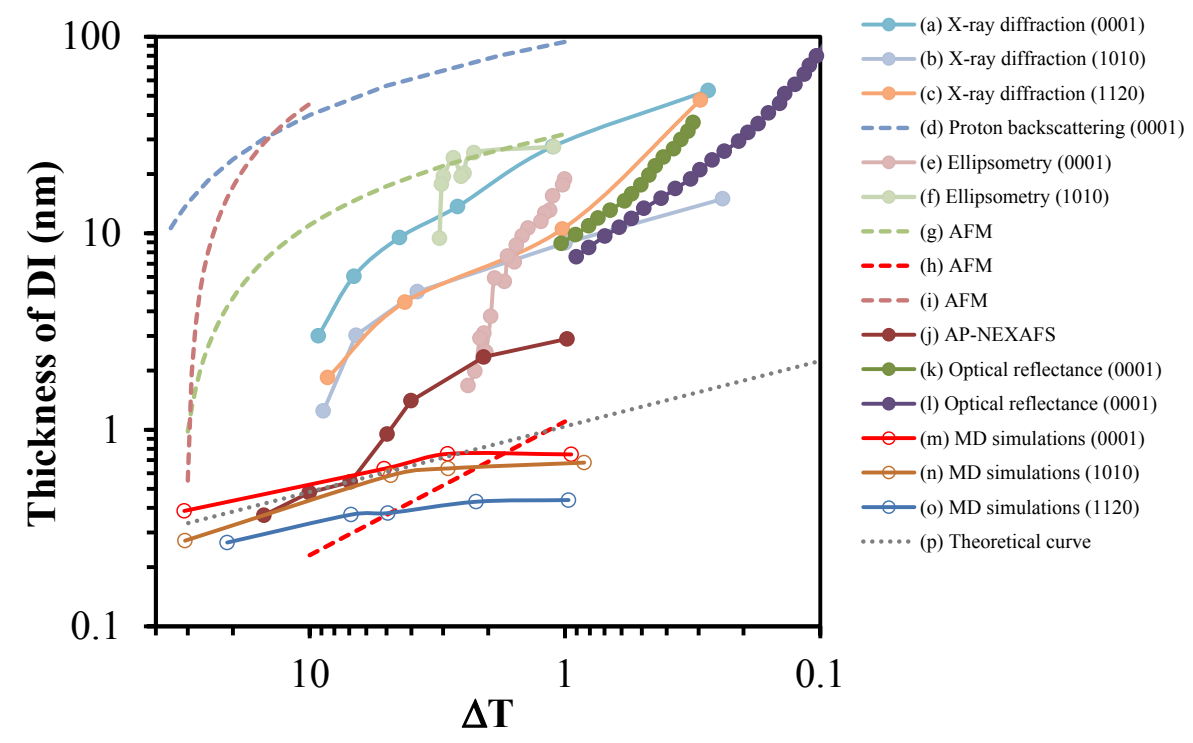

Fig. 7. Comparison of different methods to derive the thickness of the disordered interface (DI) at the free ice surface versus $\Delta T=T_{\mathrm{m}}-T$ obtained using different methods. Solid circles are measured data, while dashed lines are results from reported equations fit to experimental data. Molecular dynamics (MD) simulations are represented by open circles. Glancing-angle X-ray diffraction (Dosch et al., 1995) on (a) basal and $(\mathbf{b}, \mathbf{c})$ prismatic crystal surfaces, (d) proton backscattering (Golecki and Jaccard, 1978) on basal ice, ellipsometry (Furukawa and Nada, 1997) on (e) basal and (f) prismatic crystal surfaces, (g) atomic force microscopy (AFM) (Döppenschmidt and Butt, 2000) on a 100 ml frozen droplet and vapour deposited on mica, (h) AFM (Pittenger et al., 2001) for vapour-deposited ice on metal, (i) AFM (Goertz et al., 2009) for ice frozen on a metal substrate, (j) ambient pressure near-edge X-ray absorption fine structure (Bluhm et al., 2002) for vapourdeposited ice on metal, HeNe laser optical reflectance (Elbaum et al., 1993) on basal crystals in the presence of (k) water vapour and (l) 30 Torr air, TIP4P/Ice MD simulations (Conde et al., 2008) for (m) basal and (n, o) prismatic crystals, (p) general thermodynamic solution (Dash et al., 2006)

evenly along the air-ice interface? Is the disordered interface homogeneous along its depth? Is it a feature restricted to the upper few monolayers or does it stretch deep into the ice crystal at environmentally relevant temperatures? Figure 7 compiles measurements and estimates of the thickness of the disordered interface on clean ice surfaces and includes results from experimental studies, molecular dynamics simulations, and thermodynamic calculations. It is important to note that the thickness is not a direct observable in any of the experimental studies and the given values represent average values over the entire probing area. In particular, this explains values below $0.3 \mathrm{~nm}$, which is the diameter of a water molecule and sets the lower limit of a physically meaningful thickness. Additional uncertainties due to translating the observables to layer thicknesses may also partially explain low values.

Some of these studies have shown that the presence of impurities can significantly impact the disordered interface. More recent spectroscopic studies allow a picture to develop of how impurities impact the hydrogen-bonding network at the ice surface. These studies, reviewed in Sect. 3.3, aim at answering the following questions: does the presence of impurities change the hydrogen-bonding network only locally, does the disorder reach deeper into the ice crystal lattice, and does the effect depend on the type and concentration of impurities and on temperature?

\subsection{Thermodynamics of surface disorder}

Theoretically, the disorder can be thought of by analogy to wetting behaviour, and complete thermodynamic descriptions of the disordered interface have been developed and are best found in dedicated reviews on the topic (Dash et al., 2006; Luo and Chiang, 2008). As in wetting, a disordered interface, here represented with liquid properties, will exist on a solid ice surface in equilibrium if it lowers the free energy of the system - that is, if by its existence an intermediate layer of thickness $d$ reduces the total excess surface free energy $F_{\mathrm{S}}$ (Israelachvili, 1991; Dash et al., 2006).

$F_{\mathrm{S}}=\left(s_{\mathrm{lv}}+s_{\mathrm{ls}}-s_{\mathrm{SV}}\right)=f(d)+s_{\mathrm{SV}}$

Here $s_{\mathrm{lv}}, s_{\mathrm{ls}}$ and $s_{\mathrm{sv}}$ are the surface energies of the liquidvapour, liquid-solid and solid-vapour interface, respectively. Theoretically the functional dependence of the surface energy $f(d)$ comes from knowledge of the intermolecular forces at the interface. In the case of ice and other molecular materials it is most common to use van der Waals forces whose long-range potential falls off with the square of the 
distance. The resulting thickness-versus-temperature prediction is shown in Fig. 7 for a clean ice surface and compared with experimental results. It is important to point out that the wetting theory treats the disordered interface as a liquid phase and input values for the calculations are those of liquid water. This approach may thus provide a unified approach to describe the disordered interface and melting in one model, but the ability to clearly differentiate between these physically distinct phenomena is lost. This approach is also in contrast to other theoretical predictions and to some experimental evidence. Consequently, this simplified picture has provoked some discussion (Baker and Dash, 1996; Knight, 1996a).

In systems with impurities or with surface charge, exponentially decaying electrostatic Coulomb interactions can be used to model the interactions between charged particles (Israelachvili, 1991), in addition to the common colligative depression of the melting temperature, which results in additional liquid (Beaglehole, 1991). Thus the theoretical treatment predicts that the temperature dependence of the layer thickness varies depending on which interactions are dominating (Wettlaufer, 1999; Dash et al., 2006). As a consequence of these predictions in certain cases thickness can behave non-monotonically with respect to temperature and/or impurity level (Benatov and Wettlaufer, 2004; Thomson, 2010; Thomson et al., 2013).

\subsection{Molecular simulations of surface disorder}

Molecular dynamics (MD) simulations provide a useful tool to study the surface disorder of ice with resolution at the molecular level. These simulations are particularly useful for following the development of surface disorder from initiation to its macroscopic extent, molecule by molecule (Fig. 8). They are, however, often limited to total sample thicknesses below $10 \mathrm{~nm}$. Only recently have efficient coarse-grained MD simulations allowed simulating systems with thicknesses of $16 \mathrm{~nm}$ (Shepherd et al., 2012). Similar limitations also apply to the lateral dimensions of the sample. To overcome this issue, periodic boundary conditions are typically used and the simulations are, thus, effectively performed for infinite flat surfaces of single crystals. Simulations of a polycrystalline ice surface involving multiple grain boundaries are yet to be undertaken. Simulations are also time-limited, with standard classical MD simulations covering timescales up to several microseconds.

In spite of the prevailing spatial and temporal limitations of molecular simulations, important new results concerning the structure and dynamics of the ice-vapour interface have been obtained during the last decade since the pioneering work summarised in a review by Girardet and Toubin (2001). Critical to any simulation is how well the underlying potentials used to parameterise the intra- and inter-molecular interactions capture the physics of the system. Recently, much progress has been made developing and critically evaluating water models, including their ability to adequately describe the general features of water over the entirety of phase space, including fundamental quantities such as the melting point of ice (Vega et al., 2009; Vega and Abascal, 2011). While no model is perfect and universally accepted, their drawbacks are known and can be accounted for. One other approach is the use of first-principle MD simulations that do not rely on the assumption of underlying potentials (Mantz et al., 2000, 2001a, b). Such simulations have been used to study molecular-level disorder with and without impurities. Here we review the primary findings of MD simulation efforts. To account for inter-model differences all temperatures are given relative to the individual model melting point $\left(T_{\mathrm{m}}\right)$.

\subsubsection{Simulations of disorder on pure ice}

Molecular dynamics simulations show that a disordered layer develops spontaneously at the free surface of ice at temperatures below the melting point (Fig. 8). This has been observed regardless of the water model and the crystallographic plane exposed to the vapour phase (Bolton and Pettersson, 2000; Picaud, 2006; Vega et al., 2006; Bishop et al., 2009; Neshyba et al., 2009; Pereyra and Carignano, 2009; Pfalzgraff et al., 2011; Shepherd et al., 2012). The onset temperature of disorder is found to depend on the crystal facet exposed to the vapour phase; for example on the basal plane, the first sign of interfacial disorder occurs about $100 \mathrm{~K}$ below the melting point, whereas on the prism plane disorder was observed around $T_{\mathrm{m}}-80 \mathrm{~K}$ (Conde et al., 2008). The thickness of the disordered interface also shows small differences for different crystal facets (Conde et al., 2008; Pfalzgraff et al., 2011). It appears that the disorder on the basal plane is slightly thicker; a similar trend can also be observed in experiments (Sect. 3.3). Simulations reveal that the surface disorder begins with a small fraction of water molecules leaving the outermost crystalline layer of ice and becoming mobile as adsorbed molecules on the crystal lattice (Bishop et al., 2009; Pfalzgraff et al., 2011). With increasing temperature, the number of vacancies in the outermost crystalline layer increases, giving rise to aggregates of (increasingly mobile) adsorbed molecules on top of the crystal and, at the same time, resulting in higher disorder and mobility of molecules within the outermost crystalline layer itself. While the number of disordered molecules grows steadily with temperature, the disordered interface remains up to about $T_{\mathrm{m}}-10 \mathrm{~K}$ limited to the outermost molecular layer of the ice. Only at higher temperatures does the disorder propagate to additional ice layers, and the thickness of the disordered interface increases to about $0.5 \mathrm{~nm}$ (Fig. 7). It is important to note that different water models yield practically the same thickness when compared at the same degree of undercooling relative to the model melting points (Vega et al., 2006; Paesani and Voth, 2008; Bishop et al., 2009; Neshyba et al., 2009; Muchová et al., 2011; Pfalzgraff et al., 2011). A recent large-scale, long-time simulation employing a coarse-grained model of 

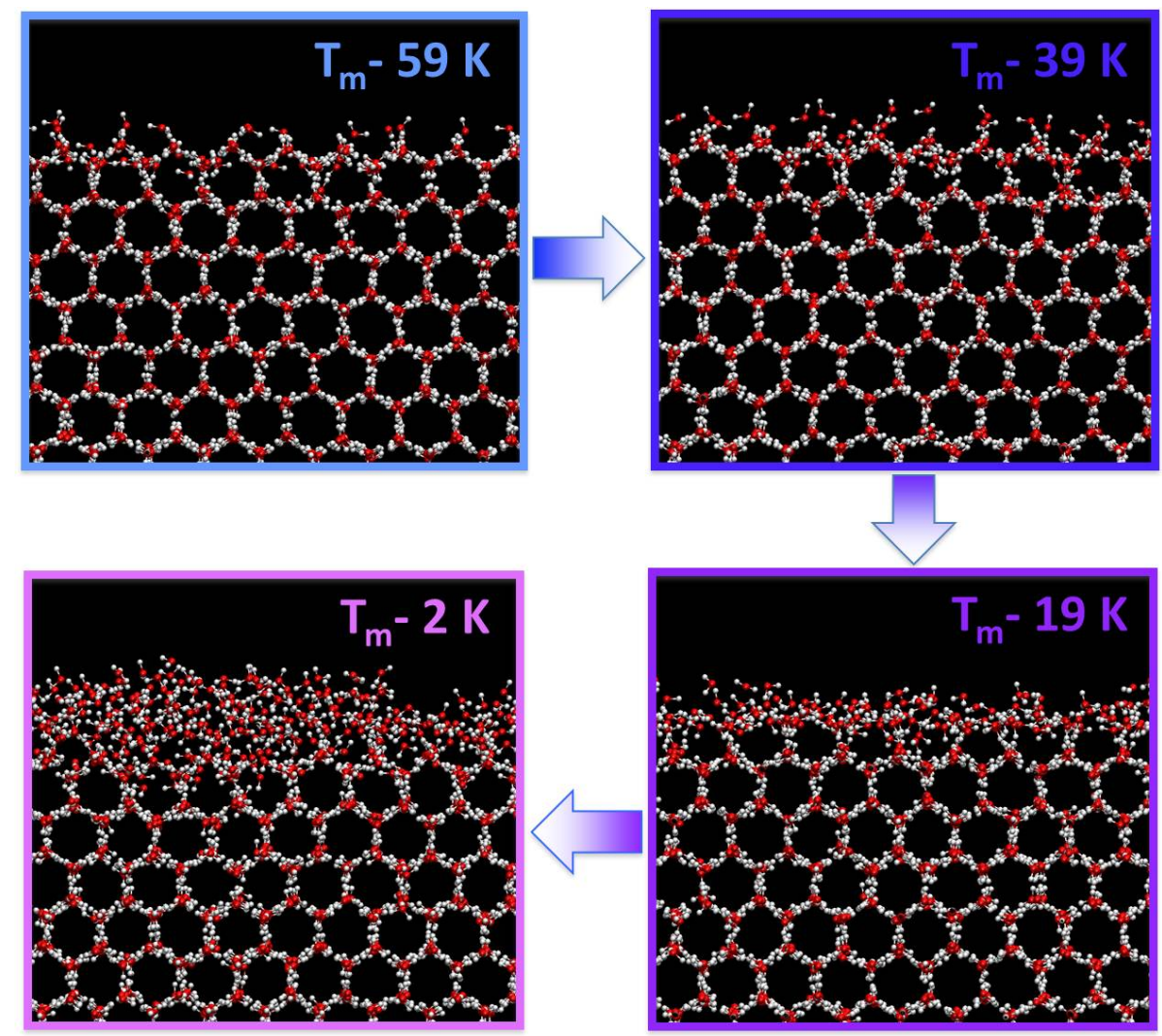

Fig. 8. Snapshots of the prismatic air-ice interface for selected simulations. The simulation temperatures correspond to undercooling of $-59 \mathrm{~K}$ through $-2 \mathrm{~K}$ relative to the melting point of the water model (NE6, $T_{\mathrm{m}}=289 \mathrm{~K}$ ). Reproduced from Gladich et al. (2011) with permission from the PCCP Owner Societies.

water (Molinero and Moore, 2009) further corroborated this molecular picture of the ice surface (Shepherd et al., 2012). However, at $T_{\mathrm{m}}-1 \mathrm{~K}$ their simulations show larger fluctuations of the disordered interface's thickness, with increases of its thickness of about $2 \mathrm{~nm}$ for periods of about $50 \mathrm{~ns}$, than do previous smaller-scale, atomistic simulations. Thus, apart from temperatures very close to $T_{\mathrm{m}}$, molecular simulations provide a consistent and robust picture of the surface disorder, independent of a specific water model used in the simulation. In addition to the spatial and temporal limitations of current molecular simulations, obtaining reliable results at temperatures just below the melting point is further complicated by the fact that the melting point of the model ice is typically subject to an uncertainty of $\pm 2 \mathrm{~K}$. Large-scale simulations and more-accurate estimates of the melting point of models will be needed to increase accuracy within this environmentally relevant temperature region.

\subsubsection{Simulation of disorder induced by ionic impurities}

MD simulations of ice growth from supercooled salt solutions have revealed that the presence of ions increases the thickness of the interfacial disorder compared to pure ice both at the free ice surface and at the grain boundaries
(Vrbka and Jungwirth, 2005; Carignano et al., 2006, 2007; Bauerecker et al., 2008). The same conclusion has been drawn for some small organics; we refer the reader to the recent review by McNeill et al. (2012) for an in-depth discussion on organics. Current molecular simulation studies are limited in terms of the size of the systems and, hence, the spatial scale of inhomogeneity that can be investigated. Nevertheless, the existence of a uniform disordered interfacial layer is not likely in the presence of ions. Instead, a pronounced tendency for ion clustering has been seen upon freezing salt solutions, resulting in the coexistence of thick ion-containing disordered regions and regions of pure ice with thin layers of interfacial disorder. This picture agrees with recent observations of impurity-induced disorder using surface-sensitive spectroscopy (Sect. 3.3). So far, only a few MD studies using selected concentrations of $\mathrm{NaCl}$ at defined temperatures have been performed. More simulation work is needed to obtain quantitative results regarding the effects of temperature, salt concentration, and ionic composition on the thickness and character of the disordered interface. Uncertainty also remains as to the distribution of various ions within the disordered layer and their propensity for either the ice-liquid 
or the liquid-vapour interfaces, or for the interior of the unfrozen liquid.

\subsection{Observation of surface disorder}

The disordered interface on ice surfaces has been investigated using many techniques (Li and Somorjai, 2007). Either these techniques are based on observations of properties of the ice surface that change with the degree of molecular order or the structure at the surface is probed directly (see $\mathrm{Li}$ and Somorjai, 2007, for a complete list of individual studies).

\subsubsection{The thickness and effect of impurities}

Experimental results for ice-vapour interfaces are summarised in Fig. 7, showing that the measured thicknesses vary widely between different studies. There are several factors contributing to this variability.

Different techniques have inherently different probing depths and examine different physical properties of the surface layer. For example, proton channelling is elementspecific and probes atomic positions in the interfacial region, while ellipsometry probes changes of the refractive index and extinction coefficient with the use of an appropriate optical model. The different probing depth is critical in measurements of the disordered interface, because the ice surface's properties vary over depth (Sects. 3.2 and 4.1). Some techniques also interact with the surface more than others, thereby adding uncertainty to the observations. In addition to wide variations in observed or predicted thicknesses, the onset temperature at which surface disorder is observed varies between different techniques. Sum frequency generation (SFG) probes anisotropic surface vibrational modes of water. Although it is difficult to quantitatively assess the thickness with this technique, it is inherently surface sensitive and observes an onset in surface disorder of the interfacial water molecules near $198 \mathrm{~K}$ (Wei et al., 2001). In contrast to these results, proton backscattering observes onsets at $233 \mathrm{~K}$ (Golecki and Jaccard, 1978) and ellipsometry at $243 \mathrm{~K}$ and $268 \mathrm{~K}$ (Furukawa and Nada, 1997; McNeill et al., 2006).

As seen in Fig. 7, different ice crystal orientations give rise to different thickness results in otherwise identical experiments (Furukawa et al., 1987; Sazaki et al., 2012), consistent with molecular dynamics simulations (see Sect. 3.2).

Surface disorder is also affected by the presence of impurities, as theoretically predicted (Sects. 3.1 and 3.2), and experimentally verified by optical reflectance (Elbaum et al., 1993), by ellipsometry (McNeill et al., 2006, 2007), and directly by partial electron yield near-edge X-ray absorption fine structure (NEXAFS) (Bluhm et al., 2002). Observations of impurity-amplified or -induced disorder at ice surfaces depend on experimental conditions, the method of experimental probing, and on the type of impurity. Using synchrotron-based, surface-sensitive NEXAFS Křepelová et al. (2010b) reported that only about $20 \%$ of the interfa-

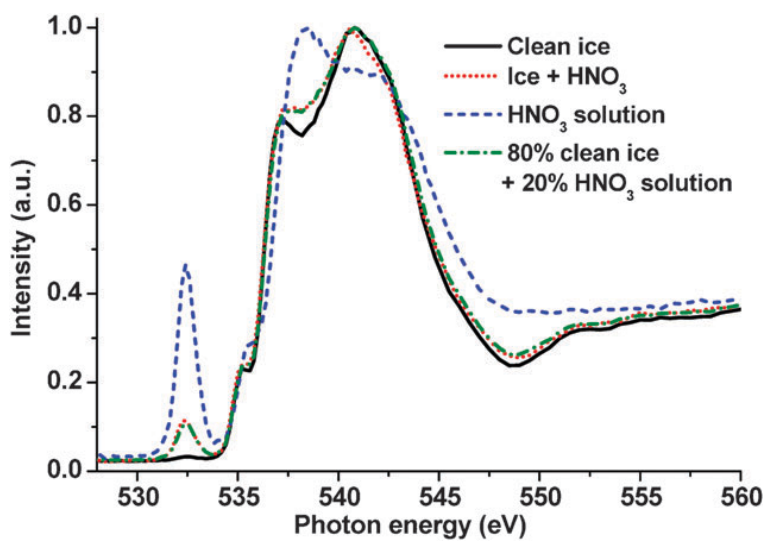

Fig. 9. NEXAFS spectra probing the oxygen of nitrate and ice at the surface at the upper few nanometres of the sample and showing little change to the structure of ice in the presence of adsorbed nitrate (red dotted line) compared to pure ice (black solid line) at $230 \mathrm{~K}$. Reproduced from Křepelová et al. (2010b) with permission from the PCCP Owner Societies.

cial $\mathrm{H}_{2} \mathrm{O}$ molecules form a hydration shell in the presence of nitrate molecules in sub-monolayer coverage on ice at $230 \mathrm{~K}$ (Fig. 9). The majority of the water molecules show no change in their hydrogen-bonding network in the presence of nitrate. Minor amounts of $\mathrm{H}_{2} \mathrm{O}$ hydrating sub-monolayer concentrations of acetic acid were observed at temperatures of $\sim 230-245 \mathrm{~K}$, while no changes at all were observable for acetone on ice (Starr et al., 2011; Křepelová et al., 2013). NEXAFS probes the upper few nanometres of an ice sample, and, thus, the observation of ordered ice suggests that disorder does not spread throughout the entire upper few nanometres, but leaves room for disorder on the scale of a few molecular layers. The observations of hydration shells surrounding the nitrate molecules on ice just as they would be in aqueous solution indicates some heterogeneity of the disordered interface at low surface coverage of nitrate where pronounced disorder, with liquid-like properties, is limited to the vicinity of the impurities. The emerging picture of the locally restricted and compound-specific changes to the hydrogenbonding network is illustrated in the surface adsorption panel of Fig. 1.

Other potential sources of thickness variability may stem from ice preparation (vapour deposition versus cleavage of a single crystal) and different ambient vapour environments (air or some inert gas versus pure water vapour). Thus, thickness measurements from identical experimental techniques (e.g. atomic force microscopy (AFM); see Fig. 7) can vary by more than an order of magnitude, likely due to some combination of the aforementioned variability as well as, in the case of AFM, variation in the AFM tip temperature and composition (Döppenschmidt and Butt, 2000; Pittenger et al., 2001; Goertz et al., 2009). 


\subsubsection{Observation of properties}

Is there a gradual change from the disordered interface to liquid water, as the melting temperature is approached and crossed? Spectroscopic studies give clear indications that, with the onset of melting, the properties at the surface change abruptly and that the disordered interface has structural features that are very different from supercooled water (Lied et al., 1994; Wei et al., 2001). Furthermore, sum frequency generation (SFG) (Wei et al., 2001), proton channelling (Golecki and Jaccard, 1978), and glancing-angle Xray studies (Lied et al., 1994) show that the disordered interface is not homogeneous perpendicular to the air-ice interface. Rather its properties gradually change with depth. This suggests that simple models that parameterise the disordered interface as a thin, homogenous water-like layer are questionable and contradict AFM measurements, where a sharp border between the disordered interface and the bulk ice has been found (Döppenschmidt and Butt, 2000).

While the thickness variation in the disordered interface has been heavily studied, few observations exist with regard to how the disorder is distributed laterally on a molecular level at the ice-vapour interface. This is a very challenging task from an experimental perspective, considering that most surface-sensitive techniques detect average thicknesses over large sample areas. Further, this question must be asked with the understanding that, under ambient conditions, the lateral distribution of water molecules evolves on short timescales, making their structure difficult to probe. Sazaki et al. (2012) recently reported pioneering observations in this direction. They used laser confocal microscopy to monitor the ice surface close to its melting point and observed two types of disordered interfaces with different morphologies and dynamics. Droplets moving over the surface and their collision and coalescence were observed in both cases, with a lateral resolution on the order of $\approx 1 \mu \mathrm{m}$. Thus, while the molecularlevel information is not observed in the lateral direction, these interesting results challenge the current understanding of disordered interface observations, from which a homogeneous distribution of the disordered thickness is derived. A further indication of a heterogeneous distribution of surface disorder comes from surface-sensitive studies that probe impurities on ice surfaces (Sect. 3.3.1). The work by Sazaki et al. (2012) further revealed that growing steps on the basal plane of ice crystals can be observed up to the melting point. This shows that surface disorder for a wide temperature range - except within a fraction of a degree from melting - may preserve some long-range order. Considering that the temperature during some experiments was close to the melting point, one might caution that the observations are - at least partially influenced by melting of the sample.

\subsection{Conclusions about the disordered interface}

Even though surface disorder is a general interfacial phenomenon of crystals, it is most controversially discussed in the context of ice and snow. The debate is centred on the analogy to the liquid phase that is often used to describe and parameterise the surface disorder and its interaction with impurities. Recent MD simulations and experimental observations give little support for this analogy and establish a rather differentiated picture of the disordered interface:

1. To give an exact parameterisation of the thicknessversus-temperature dependence of the disordered interface even on clean ice is still not possible. Individual observations of the onset temperature, the thickness, and the functional dependence of this disordered interface with temperature differ widely, as do simulations and thermodynamic calculations based upon varying initial assumptions. What is evident from Fig. 7 is that interpreting and generalising observations of surface disorder remain difficult.

2. There are clear indications that the disordered interface is different from a supercooled liquid phase. First, the disordered interface is not homogeneous perpendicular to the surface. Secondly, some studies indicate that its structure does not continuously evolve into the structure of the liquid with increasing temperatures. Third, a very recent study even claims to have successfully observed isolated disordered regions on ice surfaces (Sazaki et al., 2012) indicating some spatial heterogeneity of the disordered interface.

3. Even small levels of impurities induce surface disorder, with its extent critically depending on the type of impurity and on temperature. Additionally, there are indications from observations and from MD simulations that impurity-induced changes to the hydrogenbonding network are most pronounced in the immediate vicinity of impurities, leading to some heterogeneity of the disordered interface. Spectroscopic studies indicate that the hydrogen-bonding network surrounding the impurity is indistinguishable from that of an aqueous solution.

4. Thermodynamic treatments of the disordered interface can directly incorporate colligative effects allowing single unified models, for the two regimes to be treated under environmental temperature and impurity conditions. The validity of treating the disordered interface as a separate phase and the importance of ignoring any micro-scale inhomogeneity of the disordered interface in these macroscopic thermodynamic models is debated. 

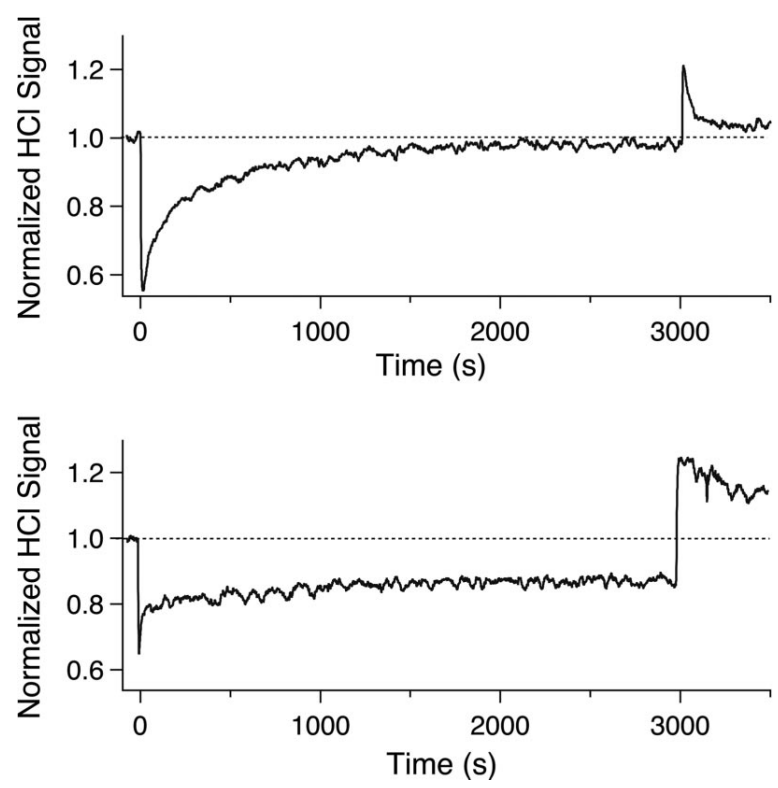

Fig. 10. Uptake of $\mathrm{HCl}$ on ice films as a function of time. Upper panel: Langmuir-type adsorption at $214 \mathrm{~K}$ with a surface coverage of $1 \times 10^{15}$ molec $\mathrm{cm}^{-2}$. Lower panel: long-lasting flux into the disordered interface of $5 \times 10^{11}$ molec $\mathrm{cm}^{-2} \mathrm{~s}^{-1}$ at $\sim 196 \mathrm{~K}$. This example shows how changing the experimental conditions can lead to significantly different uptake behaviour on ice, even of the same species; see text for details. Reprinted from McNeill et al. (2006). Copyright (2006) National Academy of Sciences, USA.

\section{Physical exchange processes}

Uptake and migration of trace gases and impurities in snow and ice have important environmental implications. They affect the chronology of ice core records (Barnes and Wolff, 2004), the composition of snow (Grannas et al., 2007b), the budget of atmospheric trace gases (Domine and Shepson, 2002) and the fluxes of volatile trace gases through snow (Herbert et al., 2006; Seok et al., 2009; Pinzer et al., 2010; Bartels-Rausch et al., 2013). The observational basis of such large-scale effects in polar and even in alpine areas as well as in the upper troposphere is sound; but despite intensive research over recent decades, a quantitative description of the underlying processes leading to the large-scale observables can often not be given.

Clearly, exchange of trace gases between the snow and the gas phase can be driven by (i) surface adsorption, (ii) uptake into the bulk (Abbatt, 2003; Huthwelker et al., 2006; Bartels-Rausch et al., 2012), (iii) or by a combination of both. Bulk refers to the interior crystal structure, grain boundaries, micro-pockets, or the disordered interface (Fig. 1). Both types of interaction show distinct differences: surface adsorption operates at shorter timescales and, thus, responds faster to changes of environmental conditions. The total capacity to accommodate trace species by adsorption is limited

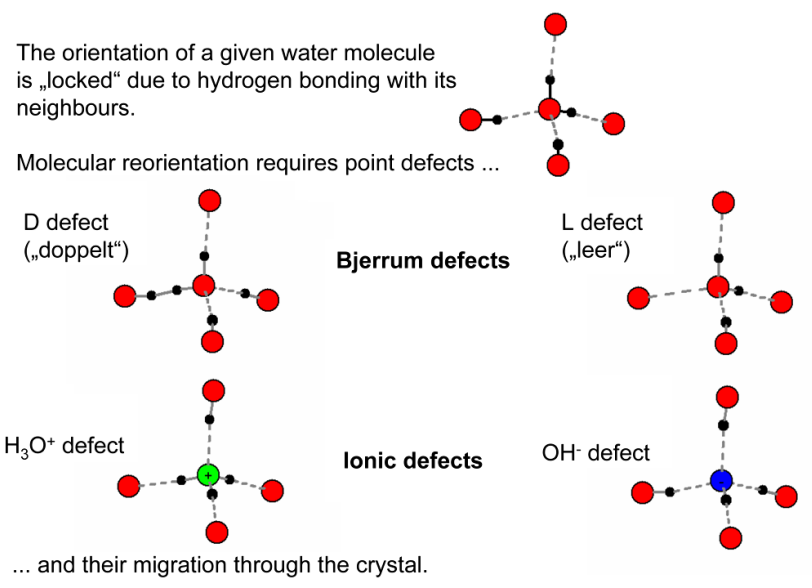

Fig. 11. Sketch of possible point defects in ice. Reproduced from Bartels-Rausch et al. (2012).

to the surface and is smaller than for bulk processes. As long as it is unknown which process dominates the exchange of trace gases with ice, it is impossible to estimate the exchange of trace gases under environmental conditions and to quantify the uptake and release that is crucial for snow chemical models. A limitation is that most of the recent studies give no direct evidence of the exchange process or of the compartment (Fig. 1) to which the uptake is occurring. Rather, the time profile of the exchange process is used to differentiate between surface adsorption and other processes. Figure 10 shows an example of such time profiles and how changing the experimental conditions can lead to significantly different uptake behaviour on ice, even for the same species. In the upper panel, the gas-phase concentration of the acidic trace gas recovers to its initial concentration at $\approx 1500 \mathrm{~s}$ after exposure of the gas phase to an ice sample (starting at $t=0 \mathrm{~s}$ ). Such an uptake profile is well described by surface adsorption. Long-lasting uptake, as shown in the lower panel, has been observed for strong acids, such as $\mathrm{HNO}_{3}$ (Abbatt, 1997), $\mathrm{HCl}$ (Huthwelker et al., 2004), $\mathrm{SO}_{2}$ (Sommerfeld and Lamb, 1986; Clapsaddle and Lamb, 1989), $\mathrm{CF}_{3} \mathrm{COOH}$ (Symington et al., 2010), HONO, a weak inorganic acid (Kerbrat et al., 2010b), and the small organic molecule formaldehyde (Barret et al., 2011b). It has been interpreted as diffusion into the ice crystal forming a solid solution, diffusion along grain boundaries, and dissolution into the liquid fraction of the snow. Also, surface restructuring processes induced by the dopant have been invoked to explain the uptake, for example in the study by McNeill et al. (2006) shown in Fig. 10. Each of these processes is reviewed in the following. Another interpretation leading to the long-lasting uptake is the formation of hydrates (Symington et al., 2010), which is not further considered here. 


\subsection{Diffusion of water in pure ice}

Before we start to deal with the mobility of guest species in ice it is worth considering the intrinsic mobility of water molecules in bulk ice. The reason is that in general the water molecules' mobility is important for the uptake of foreign molecular species in ice; a notable exception exists for very small species like $\mathrm{H}_{2}$ and $\mathrm{He}$, which can diffuse within the perfect ice Ih lattice (Strauss et al., 1994; Satoh et al., 1996; Ikeda-Fukazawa and Kawamura, 2004) without any water rearrangements. The mobility of water molecules and protons in bulk ice has been studied intensely for more than $50 \mathrm{yr}(\mathrm{Pe}-$ trenko and Whitworth, 1999) and we now have an in-depth view on their mobility in bulk ice, while the processes on the surface and along grain boundaries are less well understood. It turns out that a number of defects within the perfect ice crystal play a central role, most prominently vacancies and interstitials together with orientational (Bjerrum) and ionic defects (Fig. 11); water transport in bulk ice cannot be understood without the presence of these defects.

\subsubsection{Diffusion of water in the ice crystal}

Water molecules in ice are generally immobile as long as they occupy fully bonded stable crystal sites. Therefore, transport properties of water molecules in ice are thought to be determined by mobile defects. To summarise the large body of work in bulk ice, the following may be stated: at high temperatures, above $230-240 \mathrm{~K}$, the long-range transport of protons is of interstitial nature and is achieved by the transport of intact water molecules via intrinsic defects in the crystal lattice (Geil et al., 2005; Kawada, 1978); intrinsic defects (as shown in Fig. 11) exist also in the purest ice for entropic reasons and their numbers increase with temperature. On average, a water molecule traverses 1.5-4 interstitial cavities of the ice structure in a jump before it readsorbs on a regular lattice site (Geil et al., 2005). An interstitial mechanism for water self-diffusion is also strongly supported by the observation of moving dislocations (Goto et al., 1986). The water molecules' diffusion coefficients, summarised in Petrenko and Whitworth (1999), decrease from $\approx 2$ to $0.22 \times 10^{-15} \mathrm{~m}^{2} \mathrm{~s}^{-1}$ between $263 \mathrm{~K}$ and $233 \mathrm{~K}$, in good agreement with tracer diffusion work (Blicks et al., 1966; Delibaltas et al., 1966; Ramseier, 1967) and direct observations by synchrotron X-ray tomography (Ramseier, 1967). Whether water molecules migrate in the bulk below $230 \mathrm{~K}$ preferentially via a vacancy mechanism as suggested by Livingston and George (2002) remains an open question; very little indeed is known about vacancies in hexagonal ice (Petrenko and Whitworth, 1999). Bjerrum and ionic defects may be injected into the bulk from the disordered ice surface (Devlin and Buch, 2007) where they are more abundant. Bjerrum defects (in terms of their concentration and mobility) play an important role for the re-insertion of water molecules into the crystalline frame at the end of an intersti- tial jump (Geil et al., 2005). This observation illustrates that the various point defects in ice interact with each other and cannot be understood without this interplay (Petrenko and Whitworth, 1999).

\subsubsection{Diffusion of water at the ice surface}

Much less is known about the corresponding water or (connected) proton mobility on the ice surface, along grain boundaries and other imperfections of the ice lattice. Using the technique of groove formation time (Mullins, 1957) in polycrystalline ice to deduce surface diffusivity, values of $3.5 \times 10^{-9} \mathrm{~m}^{2} \mathrm{~s}^{-1}$ and $3 \times 10^{-10} \mathrm{~m}^{2} \mathrm{~s}^{-1}$ at $271 \mathrm{~K}$ and $263 \mathrm{~K}$, respectively, were obtained (Nasello et al., 2007). These numbers are about two orders of magnitude greater than in single crystalline bulk ice and quite close to the values of supercooled water with a value of $\approx 7 \times 10^{-10} \mathrm{~m}^{2} \mathrm{~s}^{-1}$ (Gillen et al., 1972; Price et al., 1999). It is noteworthy that molecular dynamics simulations that evaluated diffusivities for surface water molecules in the disordered interface of ice agree with available experimental data by Nasello et al. (2007) to within the quoted precision for the entire temperature range: at a temperature of $T_{\mathrm{m}}-9 \mathrm{~K}$ a diffusivity of $\approx 8 \times 10^{-10} \mathrm{~m}^{2} \mathrm{~s}^{-1}$ was obtained, and $59 \mathrm{~K}$ below melting this value drops to $1.8 \times 10^{-11} \mathrm{~m}^{2} \mathrm{~s}^{-1}$ (Gladich et al., 2011). The finding that the coefficient of self-diffusion on the ice surface is similar to that of supercooled liquid casts some doubts on the earlier results by Mizuno and Hanafusa (1987) using nuclear magnetic resonance work on ice to deduce diffusivities. The water molecule self-diffusion coefficient was established for the temperature range from $253 \mathrm{~K}$ to the melting point and amounts to $2.2 \times 10^{-13} \mathrm{~m}^{2} \mathrm{~s}^{-1}$ at $263 \mathrm{~K}$, i.e. clearly slower than in supercooled liquid water. Ironically, the water mobility in the surface layer of ice situated between those of bulk ice and supercooled water thus appeared to justify the name quasi-liquid layer (QLL). One should, however, note that in the experiment of Mizuno and Hanafusa (1987) some sintering of the particles may have occurred so that the diffusivities are likely not to represent true surface values.

The discrepancy also illustrates one of the pertinent problems in work on the disordered interface: the results often depend on the method used. Clear differences in mobility between the outermost and the inner water layers were established in the work by Nada and Furukawa (1997) and are, in fact, a ubiquitous feature of ice surfaces over a large range of temperatures (Bolton and Pettersson, 2000; Toubin et al., 2001; Grecea et al., 2004; Park et al., 2010). Consequently, techniques sensitive to the outermost surface layers will always get a higher water mobility than methods looking at the bulk of the disordered interface or at grain boundaries; the differences may well span orders of magnitude. Molecular dynamics work by Pfalzgraff et al. $(2010,2011)$ and Gladich et al. (2011) confirmed the enhanced mobility of water molecules on free ice surfaces in the temperature range from $230 \mathrm{~K}$ to the melting point and provided more details 
regarding the diffusion mechanism at different temperatures. An Arrhenius analysis of MD-simulated self-diffusion coefficients on ice yielded a positive Arrhenius curvature, implying a change in the mechanism of self-diffusion with an increase in energy of activation from low to high temperature. Since supercooled water is known to exhibit the opposite Arrhenius curvature, i.e. the energy of activation is a decreasing function of temperature, it implies that selfdiffusion on the ice surface occurs by significantly different mechanisms compared to bulk self-diffusion in supercooled water. A rather sharp transition to isotropic diffusivity is observed in the temperature range of 240-250 K; self-diffusion at higher temperatures, which occurs within an increasingly thick disordered layer, is governed by quasi-3-dimensional liquid-like mechanisms that are isotropic regardless of the geometry of the underlying crystalline ice matrix. In such a thick interface the ions display free diffusion, while in a thin layer the ions are strongly affected by the underlying crystalline ice and move by an ice surface hopping mechanism (Carignano et al., 2007). For the ions to diffuse freely following a Brownian pattern, the interfacial liquid layer must be at least three full molecular layers thick.

For experimental studies of surface diffusivities at temperatures well below $200 \mathrm{~K}$ other techniques have been developed and were reviewed more recently (Park et al., 2010). There is evidence that a translational surface mobility in the outer ice layers is preserved down to temperatures of $100 \mathrm{~K}$ (Verdaguer et al., 2006; Lee et al., 2007; Jung et al., 2004).

\subsubsection{Diffusion of water in grain boundaries}

Interestingly, the water mobility across grain boundaries is two orders of magnitude smaller than the mobility at the ice surface (Nasello et al., 2005) approaching the values of Mizuno and Hanafusa (1987) discussed above. Thus, it seems that the water molecules' mobility at the surface and in grain boundaries are quite different, while the latter are still enhanced by more than 3 orders of magnitude over the bulk values (Mullins, 1957; Nasello et al., 2005). The intermediate diffusivity in grain boundaries between that of crystalline ice and water was later confirmed by Lu et al. (2009) (Fig. 12).

\subsection{Diffusion of impurities in pure ice}

Reliable data on the diffusion and solubility of impurities in ice are scarce because these are extremely difficult to measure due to numerous experimental artefacts that can arise. In particular, dopant concentrations may be high enough to form hydrates in the ice, and hence direct applications to the diffusion of diluted trace gases in the thermodynamic stability domain of ice solid solutions cannot be done. Moreover it is a challenge to isolate and quantitatively measure individual processes such as surface adsorption, diffusion into grain boundaries, or the bulk ice crystal lattice. Huthwelker

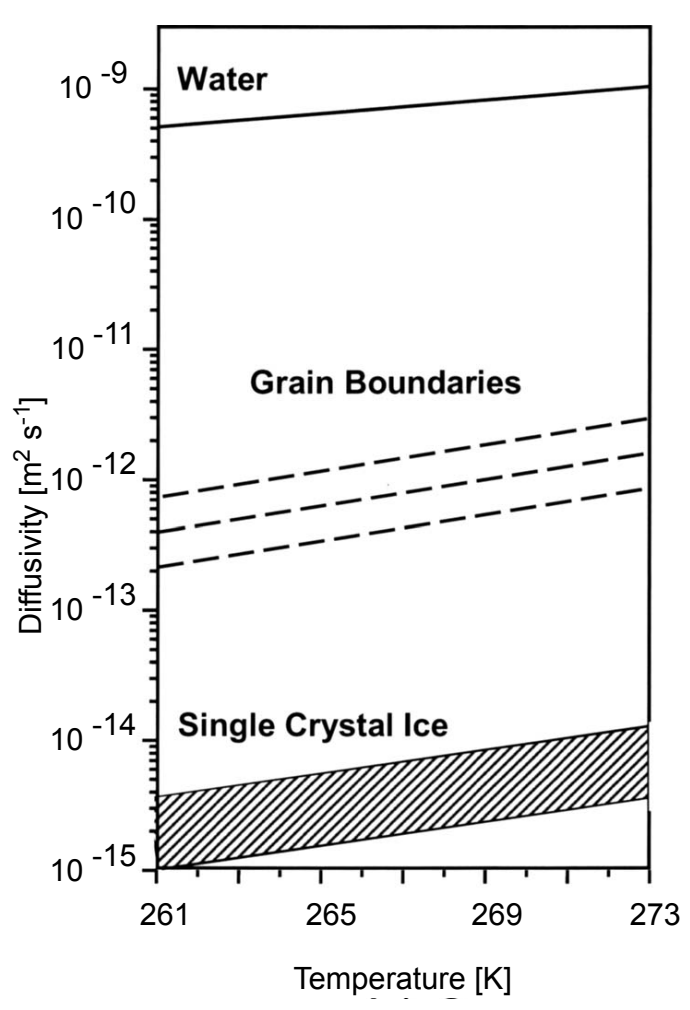

Fig. 12. Diffusivities of water molecules in ice and supercooled water. Adapted with permission from Lu et al. (2009). Copyright (2009) AIP Publishing LLC.

et al. (2006) presented a detailed discussion of such pitfalls and carefully re-analysed existing data. Doing so, the scatter of for example $\mathrm{HCl}$ diffusion measurements can be reduced from 10 to 2 orders of magnitude (Huthwelker et al., 2006). Certain impurities like $\mathrm{HF}, \mathrm{HCl}$, or $\mathrm{NH}_{3}$, which in principle have the possibility to substitute water molecules in the ice lattice, increase the number of point defects (see Fig. 11) in ice. This in turn affects the mobility of the water molecules and of the inserted species as well as the electric properties of ice (Petrenko and Whitworth, 1999).

\subsubsection{Diffusion of impurities in the ice crystal}

Thibert and Domine (1997) exposed single ice crystals to a well-controlled atmosphere of diluted trace gases. After exposure for periods of days to weeks, the diffusion profile of the trace gas was obtained by serial sectioning of the ice crystals and subsequent chemical analysis. From these profiles, taken at different temperatures, the thermodynamic solubility in ice and diffusion coefficients were derived. While this method is limited to species with sufficient solubility in ice, it is applicable to species of atmospheric relevance. This method provides diffusion constants at $253 \mathrm{~K}$ for $\mathrm{HCl}, \mathrm{HNO}_{3}$, and formaldehyde (Thibert and Domine, 1997, 1998; Barret et al., 2011b) of $\approx 3 \times 10^{-16}, 7 \times 10^{-15}$, and $6 \times 10^{-16} \mathrm{~m}^{2} \mathrm{~s}^{-1}$, respectively. These measurements are 
technically demanding as discussed in the original work and from a broader perspective in Huthwelker et al. (2006).

Infrared laser resonant desorption has also been used to study diffusion of $\mathrm{HCl}$ in ice (Livingston et al., 2000). The beauty of the technique is that laser ablation resolves sub$\mu \mathrm{m}$ ice thicknesses, compared to $\approx 20 \mu \mathrm{m}$ for serial sectioning of crystals mechanically. Hence, experiments on shorter timescales seem possible. In the experiments presented by Livingston et al. (2000) $\mathrm{HCl}$ dopant concentrations were high enough to form hydrates in the ice, and hence cannot be directly applied to the diffusion of dilute trace gases in the thermodynamic stability domain of ice. This was corroborated by the work of Domine et al. (2001), who used infrared spectroscopy to show that the high concentrations used considerably perturb the ice structure, rendering it almost amorphous, so that the diffusion coefficients measured are not those of crystalline ice. Indeed, Livingston et al. (2000) report $D_{\mathrm{HCl}}=5 \times 10^{-14} \mathrm{~m}^{2} \mathrm{~s}^{-1}$ at $170 \mathrm{~K}$, an unrealistically high value, compared to values in the range $10^{-16}$ to $10^{-15} \mathrm{~m}^{2} \mathrm{~s}^{-1}$ at $238-265 \mathrm{~K}$ found by Thibert and Domine (1997). The profiling techniques discussed above are destructive, rendering direct in situ observation of the diffusion process difficult. Here, accelerator-based techniques, such as Rutherford backscattering (RBS), might become viable tools. In an RBS experiment, $\mathrm{He}^{2+}$ ions are shot into ice and the energy spectrum of the backscattered ions is a direct measure of the depth profile of the impurities in ice. It has been demonstrated that this technique can be used to follow the diffusion of $\mathrm{HBr}$ into ice in situ at $\mathrm{HBr}$ vapour pressures in the stability domain of ice and with a depth resolution of some $100 \mathrm{~nm}$ (Huthwelker et al., 2002; Krieger et al., 2002). In these studies the ice sample was not a well-defined single crystal as in the studies by Thibert and Domine $(1997,1998)$ and Barret et al. (2011b). Ballenegger et al. (2006) estimated the diffusion coefficient of formaldehyde in ice using molecular dynamics calculations. They obtained a value of $4 \times 10^{-11} \mathrm{~m}^{2} \mathrm{~s}^{-1}$ at $260 \mathrm{~K}$, orders of magnitude larger than the values derived from measurements (Barret et al., 2011a). The overestimation of the modelled diffusion constants might be due to limitations of the model. Such limitations may include an imperfect representation of the ice structure for diffusion processes, and molecular structures that are too rigid to predict sites where formaldehyde would, in fact, be stabilised and reside longer than computed. Also, hydration of formaldehyde may take place in bulk ice, which would intuitively slow down diffusion because of increased molecular size. This process was not taken into account in the MD model. One may speculate that, due to the finite size typically used in molecular dynamics studies, the model might still not simulate a thermodynamically stable ice lattice, but rather ice in a confined reservoir, where the diffusion is expected to be enhanced, compared to the one in a perfect crystal lattice.

\subsubsection{Diffusion of impurities into grain boundaries}

Diffusion measurements of trace elements in grain boundaries are virtually non-existent, because it is already very difficult to prove the existence of impurities in these reservoirs and because it is not easy to differentiate diffusion in defects and in bulk ice (Domine et al., 1994). Grain boundaries, the contact area between two ice crystals, and other defects in the ice such as dislocations and small-angle boundaries, which are formed by a 2-D network of regrouped dislocations, can act as diffusion short-circuits (Domine et al., 1994; Thibert and Domine, 1997; Barret et al., 2011a). Similarly, the triple junctions (so-called veins) and quadruple points (nodes) between ice crystals are candidates for such diffusion short cuts. One way to assess the impact of grain boundaries on the diffusion through ice is to perform the same experiment using different types of ice. Indeed, there is evidence that polycrystallinity enhances diffusion. For example, Aguzzi et al. (2003) found $\mathrm{HCl}$ and $\mathrm{HBr}$ to diffuse an order of magnitude faster in polycrystalline ice compared to single crystal ice at 200 K. In contrast, Satoh et al. (1996) measured the diffusion coefficients of $\mathrm{He}$ and of $\mathrm{Ne}$ by exposing single and polycrystals of ice to the gas of interest and monitoring pressure changes. They found that those gases did not diffuse faster in polycrystalline ice compared to single crystals.

\subsubsection{Diffusion in field samples}

The above suggests that solid-state diffusion can be important for understanding the composition of environmental ice and snow and its evolution, such as migration of species in ice cores and the partitioning of highly soluble species between snow and the atmosphere. The following examples illustrate the complexity of migration in natural snow and ice, where diffusion into the solid ice crystal or liquid diffusion in grain boundaries can dominate.

Peak widening and shifts in ice core signals have been observed for soluble inorganic and organic species (De Angelis and Legrand, 1994; Pasteur and Mulvaney, 2000). De Angelis and Legrand (1994) studied the volcanic signal in Greenland ice cores, and in particular the $\mathrm{SO}_{4}^{2-}, \mathrm{F}^{-}$and $\mathrm{Cl}^{-}$signals. They noted that in some layers ascribed to volcanic eruptions the three signals coincided well, while in others the $\mathrm{F}^{-}$peak was shifted relative to the other two. Shifting did not occur when an (alkaline) ash layer fixing the $\mathrm{F}^{-}$was present. In the absence of ash, $\mathrm{F}^{-}$was excluded from the volcanic acidic layer. The author proposed that migration took place in the upper part of the firn by diffusion of HF in the gas phase of the interstitial air. Solid-state diffusion of HF is also proposed to account for peak widening over the years. By comparing peak width at $1210 \mathrm{~m}$ depth (age $7400 \mathrm{yr}$ ) to those of recent eruptions, the authors proposed a diffusion coefficient for HF of $1.9 \times 10^{-12} \mathrm{~m}^{2} \mathrm{~s}^{-1}$ in ice. This value compares well with the coefficient of HF measured in laboratory ice, $5 \times 10^{-12} \mathrm{~m}^{2} \mathrm{~s}^{-1}$ (Kopp et al., 1965). 
Pasteur and Mulvaney (2000) observed the migration of methanesulfonate (MSA), a product of the atmospheric oxidation of dimethylsulfide, in firn and ice cores. MSA deposition occurs in summer, but at some sites migration to the winter layer is observed after a site-dependent number of years. An interesting observation is that the migration leads to very good coincidence with the dominant $\mathrm{Na}^{+}$ions that deposit mostly in winter. The authors analysed several hypotheses, and their favoured mechanism is "the migration of MSA in the snowpack via an initial diffusion in either the vapour or liquid phase which is halted by precipitation in the winter layer when the MSA forms an insoluble salt with a cation". However, it is not clear why the summer sulphate peak does not migrate with the same mechanism. For sulphate, Traversi et al. (2009) postulated that the mobility depends on the presence of other ions forming soluble, and thus very mobile, salts. Rempel et al. (2002) elaborated on that explanation. They suggested that most water-soluble species found in ice cores were, in fact, concentrated in triple junctions (veins) and quadruple points (nodes) between ice crystals, where they formed a concentrated liquid solution (Sect. 2.1). At the specific conditions of that study, there are more impurities in the winter layers, so that liquid in veins and nodes is more abundant. MSA is less concentrated in the winter layers and, therefore, migrates there through the liquid veins, simply by virtue of the concentration gradient. Since there is more liquid in the winter layers and MSA concentrations are determined from bulk ice samples, eventually more MSA ends up in the winter layers and the MSA peaks essentially superimpose with the dominant $\mathrm{Na}^{+}$signal. This elegant hypothesis explains the MSA observations, although as yet it has not been applied to the $\mathrm{SO}_{4}^{2-}$ signal for further testing. In this case diffusion does not take place in crystalline ice, but in liquids. We propose here that the HF diffusion observed by De Angelis and Legrand (1994) is indeed in the solid phase because HF solubility in ice is sufficient to accommodate all the HF found in ice cores, while the solubility of large molecules in crystalline ice is extremely low so that MSA is rejected to veins and nodes, as observed also for $\mathrm{SO}_{4}^{2-}$ (Sect. 2.4). This strongly suggests that the estimation of the diffusion coefficient of MSA in solid ice by Roberts et al. (2009), $D_{\mathrm{MSA}}=4.1 \times 10^{-13} \mathrm{~m}^{2} \mathrm{~s}^{-1}$, is in fact diffusion in veins and not in ice crystals. Indeed, this value is orders of magnitude higher than the single-crystal diffusion coefficients measured for $\mathrm{HCl}, \mathrm{HNO}_{3}$, and formaldehyde (Thibert and Domine, 1997, 1998; Barret et al., 2011b) and even higher than the self-diffusion coefficient of water in ice (Sect. 4.1.1), which is extremely unlikely for such a large molecule.

\subsection{Adsorption}

Interactions between atmospheric gases and ice surfaces are initiated by adsorption. Over the last decades, numerous studies have been conducted to elucidate the nature of this

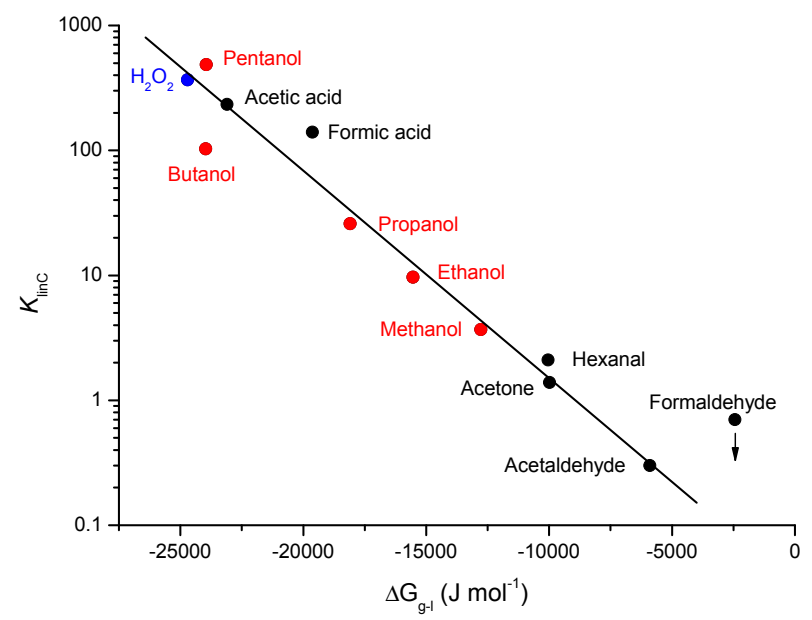

Fig. 13. Plot of $K_{\mathrm{LinC}}$ at $228 \mathrm{~K}$ versus the free energy of condensation $\left(\Delta D G_{\mathrm{g}-1}\right)$ for a range of organic alcohols (red), organic carbonyl compounds (black), and an inorganic compound (blue). The data point for formaldehyde has little confidence as argued by Pouvesle et al. (2010). Figure published with kind permission from John Crowley.

interaction (Abbatt, 2003; Huthwelker et al., 2006) and have resulted in quantitative parameterisation of the partitioning between the gas phase and the ice surface for a number of atmospherically relevant trace gases (Crowley et al., 2010). For historic reasons, most of these studies focused on temperatures relevant to the stratosphere or the upper troposphere. Surface snow and tropospheric ices, however, can be exposed to warmer conditions. At these temperatures either a disordered surface will generally exist or partial melting might occur, and recent studies have addressed the role of the disordered interface, and of liquid in gas-ice interactions. Further complexity was added to the recent fundamental studies by investigating the simultaneous adsorption of several trace gases or the adsorption to growing ice samples. Combined, these studies have led to a better understanding of trace gasice interactions under conditions that mimic environmental conditions more closely, as reviewed in the following.

\subsubsection{Langmuir isotherm}

The surface coverage as a function of both temperature and gas-phase concentration has been measured for a number of trace gases at temperatures ranging from approximately $250 \mathrm{~K}$ to below $180 \mathrm{~K}$. The adsorption isotherms of many organic and inorganic species to ice appear to be reasonably well described by a Langmuir mechanism both in laboratory experiments and theoretical calculations.

$\theta=\frac{K_{\text {LangC }}[\mathrm{X}]_{\mathrm{g}}}{1+K_{\text {LangC }}[\mathrm{X}]_{\mathrm{g}}}$ 
Equation (2) displays such a Langmuir isotherm. It allows deriving the partition coefficient, $K_{\text {LangC }}$, from measurements of surface coverage, $\theta$, as a function of gas-phase concentration, $[\mathrm{X}]_{\mathrm{g}}$. A key feature of the Langmuir isotherm is that it predicts saturation of the surface coverage $\left(N_{\max }\right)$ at high gas-phase concentrations, as the adsorbing species compete for a fixed number of adsorption sites on the surface. At atmospherically relevant low trace gas concentration, a simplified analysis using only the linear part of the adsorption isotherm is often sufficient. The partitioning coefficient, $K_{\text {LinC }}$ Eq. (3), has the advantage that knowledge of $N_{\max }$, which is often difficult to obtain experimentally due to lateral adsorbate-adsorbate interactions, is not needed.

$K_{\text {LinC }}=\frac{[\mathrm{X}]_{\mathrm{g}}}{[\mathrm{X}]_{\text {surf }}}=K_{\text {LangC }} \times N_{\text {max }}$

Such self-association, at higher concentrations outside the linear range, has been discussed mainly for those chemicals that can form common hydrogen bonds such as formic acid, acetic acid, ethanol, acetone, and some aromatics (Abbatt et al., 2008; von Hessberg et al., 2008; Symington et al., 2010; Kahan and Donaldson, 2007, 2008, 2010; Ray et al., 2011, 2013).

In 2005, Ullerstam et al. (2005) measured the first adsorption isotherms of nitric acid at atmospherically relevant partial pressures and found good fits to a Langmuir adsorption isotherm. Ullerstam et al. (2005) suggest that a Langmuir isotherm is not inconsistent with dissociative uptake, as it is possible that only the nitrate (and not the proton) requires accommodation at the ice surface. To which degree acids dissociate upon adsorption to ice at atmospherically relevant temperatures is essentially an open question (Huthwelker et al., 2006; Kahan et al., 2007; Křepelová et al., 2013). Recently, the dissociation of a weak organic acid, acetic acid, was directly probed at the ice surface at $230-240 \mathrm{~K}$ using surfacesensitive core electron spectroscopy XPS (Křepelová et al., 2013). The degree of dissociation was found to be higher on ice than in a dilute aqueous solution in equilibrium with the same acetic acid partial pressure. Wren and Donaldson (2012b) proposed that the ionisation of $\mathrm{HCl}$ is inhibited at the ice surface compared to the bulk liquid and to the surface of liquid water, based on observed changes in the fluorescence spectrum of a pH-sensitive dye. Ullerstam et al. (2005) further observed that the uptake of nitric acid at low concentration is (partially) irreversible. This indicates that a new concept to describe the adsorptive uptake might be required, as the current Langmuir isotherm and the linear relationship rely on equilibrium conditions that are in contradiction to the irreversible nature of the uptake process.

Nevertheless, for a wide range of organic and weak-acidic trace gases, the Langmuir concept gives a reliable description of surface adsorption as illustrated in Fig. 13. It shows how $K_{\text {LinC }}$ correlates with the free energy of condensation $\left(\Delta G_{\mathrm{g}-1}\right)$ at $228 \mathrm{~K}$, indicating that the adsorption process is a surface process and dominated by hydrogen bonding (Pou- vesle et al., 2010). This conclusion is in agreement with earlier MD simulations (Girardet and Toubin, 2001; Compoint et al., 2002; Picaud et al., 2005; Allouche and Bahr, 2006; von Hessberg et al., 2008) and was recently further verified experimentally using a combination of surface-sensitive Xray photoemission and partial electron yield X-ray absorption spectroscopy in a study of ice surface properties preand post-acetone adsorption (Starr et al., 2011). The measurements of acetone directly on the surface of ice at temperatures below $245 \mathrm{~K}$ confirmed that the uptake is purely a surface process and that the Langmuir model successfully described the adsorption and identified the preferred geometry of the hydrogen-bonded acetone. The correlation shown in Fig. 13 can also be used to predict the partitioning of trace gases to ice and indicates that the recent experiments by Pouvesle et al. (2010) on the reversible adsorption of $\mathrm{H}_{2} \mathrm{O}_{2}$ to ice might describe the uptake better than older results by Clegg and Abbatt (2001) (not shown in Fig. 13). The pronounced uptake observed by Pouvesle et al. (2010) makes this surface process quite significant at environmental conditions.

\subsubsection{Adsorption at higher temperatures}

A different uptake behaviour from that derived at low surface coverage and temperatures below $250 \mathrm{~K}$ has been reported at temperatures approaching the melting point in some studies. For example, benzene- and acetone-saturated surface coverages increased with increasing temperatures on ice films and artificial snows at temperatures up to $266 \mathrm{~K}$ (Abbatt et al., 2008). Early experiments on the uptake of $\mathrm{H}_{2} \mathrm{O}_{2}$ to artificial snow showed a slightly increased uptake at $270 \mathrm{~K}$ compared to $263 \mathrm{~K}$ (Conklin et al., 1993). In contrast, formaldehyde was not observed to undergo increased partitioning to ice at $268 \mathrm{~K}$ compared to $258 \mathrm{~K}$ or $238 \mathrm{~K}$ (Burkhart et al., 2002). The changes in adsorption at higher temperatures have been explained by uptake in the liquid fraction (Conklin et al., 1993) or to the disordered interface (Abbatt et al., 2008; Burkhart et al., 2002). However, surface concentrations exceeded multi-layer coverage in some experiments (Abbatt et al., 2008; Burkhart et al., 2002; Conklin et al., 1993), which might explain the deviation in uptake behaviour. Further, the formaldehyde-water phase diagram and the potential dissolution of formaldehyde into the bulk ice - as observed by Barret et al. (2011b) - was not discussed in the study by Burkhart et al. (2002), and the most likely explanation for their observation is that the partitioning of formaldehyde to ice is dominated by diffusion into the bulk.

\subsubsection{Uptake to the disordered interface}

Recently, direct laboratory evidence showed that $\mathrm{HCl}-$ and $\mathrm{HNO}_{3}$-ice interactions are highly dependent on the surface state of the ice substrate (McNeill et al., 2006, 2007; Moussa et al., 2013). This pioneering work overcomes the main limitation of the above studies, by providing a link between 
surface structure and adsorption behaviour. Surface disorder on ice exposed to $\mathrm{HCl}$ or $\mathrm{HNO}_{3}$ in the gas phase at temperatures as low as $189 \mathrm{~K}$ or $216 \mathrm{~K}$, respectively, was observed using surface-specific ellipsometry. Uptake profiles were monitored, confirming that the presence of a disordered interface at such low temperatures goes along with a substantial change in the uptake from Langmuir-type adsorption to a continuous flux of acidic trace gases to the ice (Fig. 10). This is a key finding as it would provide a feedback mechanism leading to an enhanced uptake - beyond adsorption - when the adsorbate induces surface disorder. A further key finding from these studies is that the potential of either acid to induce surface disorder and, thus, to promote the long-term uptake depends on the precise temperature and partial pressure.

Earlier studies have tried to estimate the capacity of the disordered interface to take up trace gases, based on the solubility of the impurity in aqueous solutions. Conklin et al. (1993) argued that even at temperatures close to the melting point - where the disordered interface is thick - only $20 \%$ of $\mathrm{H}_{2} \mathrm{O}_{2}$ uptake may be based on dissolution into the disordered interface. This limited capacity agrees with findings that the uptake of a larger set of non-polar organics at $266 \mathrm{~K}$ is not explained by dissolution into the disordered interface (Roth et al., 2004). Roth et al. (2004) showed that interfacial disorder of 10-50 nm thickness can only (partially) explain experimentally observed uptake, and if assumed thicknesses are below $2 \mathrm{~nm}$ the impact of dissolution is entirely negligible. Recent developments in XPS and NEXAFS setups allow deriving information on the surface structure of ice and the surface concentration of dopants in situ. Starr et al. (2011) confirmed that the uptake of acetone to ice at 218$245 \mathrm{~K}$ is a surface process and is well described by the Langmuir model. The adsorption of $\mathrm{HNO}_{3}$ was not yet studied in detail with this technique, but first results presented by Křepelová et al. (2010b) of nitrate dosed to ice surfaces indicate that the disorder induced by the nitrate is limited to the hydration shell in the vicinity of the individual dopant molecules (Sect. 3.3.1). These in situ results thus rather suggest that the uptake of trace gases to ice is not linked to the disordered interface. Certainly, more studies spanning a wider temperature and concentration range are needed.

\subsubsection{Uptake to grain boundaries}

The Langmuir model has also been found to accurately describe uptake to polycrystalline ice at temperatures below 223 K. Bartels-Rausch et al. (2004) observed indistinguishable adsorption behaviour of acetone on different types of artificial and natural snow with varying levels of inter-grain contact area, a parameter that has been shown to vary by as much as a factor of 7 in different artificial snow types (Riche et al., 2012; Bartels-Rausch et al., 2013). Interestingly, a number of $\mathrm{SO}_{2}$ uptake studies on ice spheres have shown that the uptake was enhanced at higher temperatures close to the ice melting point, in contrast to the expectations of a classical adsorption process (Sommerfeld and Lamb, 1986; Clapsaddle and Lamb, 1989; Conklin and Bales, 1993). In the later experiments, kinetics were diffusion-like for the course of hours to days, and hence inconsistent with a simple Langmuir-type uptake process on the ice surface itself. Moreover, the temperature dependence of these longlasting uptake kinetics is well described by diffusion into the veins of the highly polycrystalline ice bed (Huthwelker et al., 2001), based on the concept and thermodynamic equations suggested by Nye (1991) and Mader (1992).

\subsubsection{Uptake to brine}

A drastic change in the adsorption properties once a liquid phase is present has been seen in well-defined laboratory experiments (Abbatt, 1997; Journet et al., 2005; Kerbrat et al., 2007; Petitjean et al., 2009). In these studies the uptake of volatile organics or $\mathrm{HNO}_{3}$ on pure ice surfaces and on supercooled solutions doped with $\mathrm{HNO}_{3}$ at temperatures below $243 \mathrm{~K}$ was investigated. The findings indicated that uptake to the solutions increased enormously relative to the pure ice surface. Other early studies of $\mathrm{SO}_{2}$ uptake on ice doped with $\mathrm{NaCl}$ also found that the observed partitioning can be well described by dissolution into a liquid phase if its volume is estimated using melting point depression (Conklin and Bales, 1993). Similarly, Tasaki and Okada (2009) examined the retention of water-soluble organics in a chromatographic column packed with ice spheres. The ice was doped with $\mathrm{NaCl}$ and it was found that the retention largely increased with the formation of liquid brine. At low temperatures, in the absence of brine, adsorption to the surface was the dominant retention mechanism, while at higher temperatures partitioning to the liquid phase became more important. Interestingly, the presence of brine at the surface of frozen ice samples does also impact the dissociation of acidic trace gases upon adsorption. An inhibition of ionisation of strong acids, as observed on pure ice surfaces, was not observed in the presence of brine (Wren and Donaldson, 2012a, b). For $\mathrm{HNO}_{4}$, significantly less adsorption to ice was found in a recent study by Ulrich et al. (2012) than was deduced in an earlier study (Li et al., 1996); this was attributed to high impurity concentrations partially melting the ice film in the earlier work. This result highlights the importance of ice surface physical characteristics in air-ice interactions. It also shows that ice surface properties must be well characterised in order to correctly interpret experimental results such as the uptake equilibrium.

\subsubsection{Co-adsorption}

The Langmuir model predicts that simultaneous dosing of several trace gases to an ice surface (co-adsorption) will result in competition of the trace gases for adsorption sites. The influence of acetic acid on the uptake of HONO at temperatures up to $243 \mathrm{~K}$ (Kerbrat et al., 2010a), and 
the co-adsorption of formic and acetic acid (von Hessberg et al., 2008), and butanol and acetic acid (Sokolov and Abbatt, 2002), were well described by Langmuir's competitive adsorption model. A competition has also been observed for the strong acids $\mathrm{HCl}$ and $\mathrm{HNO}_{3} . \mathrm{HNO}_{3}$ seems to bind more strongly than $\mathrm{HCl}$ to the ice, allowing $\mathrm{HCl}$ to be displaced by $\mathrm{HNO}_{3}$ (Hynes et al., 2002; Sokolov and Abbatt, 2002; Cox et al., 2005). Co-adsorption studies of $\mathrm{HCl}$ and $\mathrm{CH}_{3} \mathrm{COOH}$ showed a twofold increase in acetic acid uptake when the partial pressure of $\mathrm{HCl}$ was increased to levels that induced surface disordering at $212 \mathrm{~K}$ (McNeill et al., 2006). This was the first study showing that inducing disorder by solutal dosing impacts the trace gas uptake at low temperatures. The fact that the increased uptake induced by co-adsorption critically depends on the experimental conditions might also explain why in other studies the presence of $\mathrm{HCl}$ did not significantly change the uptake behaviour of butanol (Sokolov and Abbatt, 2002). Enhancement of acetone uptake at temperatures lower than $245 \mathrm{~K}$ in the presence of $\mathrm{CF}_{3} \mathrm{COOH}$ was observed in co-adsorption studies of $\mathrm{CF}_{3} \mathrm{COOH}$ and acetone (Symington et al., 2010).

\subsubsection{Uptake to growing ice}

We have so far treated the ice surface as a static interface to which trace gases adsorb and establish a reversible adsorption equilibrium. However, the natural temperature gradients in snow lead to significant water vapour fluxes, resulting in an ever growing or sublimating interface (Sect. 1.3). How adsorbed species respond to these water fluxes and in particular to growing ice conditions depends on their residence time on the surface. If the residence time is long compared to the frequency of water molecules bombarding the surface, growing ice may bury adsorbed molecules (Conklin et al., 1993; Domine and Thibert, 1996; Karcher and Basko, 2004). The surface residence time may be linked to the adsorption enthalpy (Huthwelker et al., 2006; Bartels-Rausch et al., 2005). Thus, available parameterisations of trace gas adsorption obtained from experiments under equilibrium conditions may not adequately describe partitioning to snow under temperature gradient conditions for species with more negative adsorption enthalpies than water on ice. A few studies have addressed this issue for $\mathrm{HCl}$ (Domine and Rauzy, 2004), for $\mathrm{HNO}_{3}$ (Ullerstam and Abbatt, 2005) and for aromatic hydrocarbons (Fries et al., 2007). In general, the results show increased uptake of trace gases in growing ice, when compared to adsorption at equilibrium conditions. However, the interpretation of these experiments has remained difficult because ice growth rates were poorly defined or could not be varied over sufficiently large ranges.

\subsection{Modelling physical cycling of trace species}

Detailed snowpack models taking into account some of the above-described physical processes were developed for

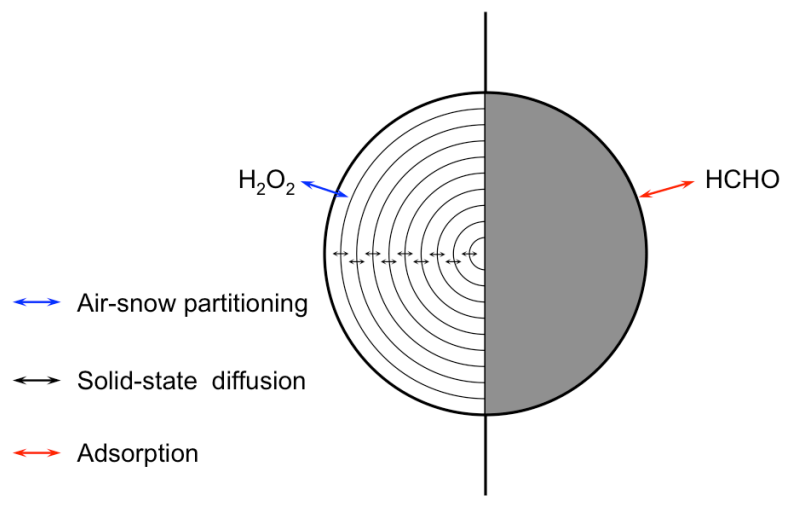

Fig. 14. Scheme illustrating two approaches to parameterise the exchange of impurities between the snow grains and the adjacent interstitial air: a transport model using spherical layers $\left(\mathrm{H}_{2} \mathrm{O}_{2}\right.$, left side). A bulk approach assuming that an uptake equilibrium between the entire ice phase and the air is established (formaldehyde, right side).

species like $\mathrm{H}_{2} \mathrm{O}_{2}$ and formaldehyde. Hutterli et al. (2003) presented atmosphere-snow models for these two species based on 1-D models previously developed by McConnell et al. (1998) and Hutterli et al. (1999). Motivation came from the knowledge that hydrogen peroxide is the only major atmospheric oxidant that is conserved in snow. The reconstruction of its atmospheric concentration from the ice core record can deliver crucial information to constrain the photochemistry of the past atmosphere (Thompson, 1995; Frey et al., 2005; Lamarque et al., 2011) and has attracted great interest (e.g. Neftel et al., 1995; Anklin and Bales, 1997; McConnell et al., 1997; Frey et al., 2006). Similar reasons led to the examination of formaldehyde in ice cores, since reconstructed atmospheric formaldehyde concentrations would constitute a strong constraint to past methane and hydroxyl radical concentrations (Staffelbach et al., 1991).

Snowpack modelling of $\mathrm{H}_{2} \mathrm{O}_{2}$ and formaldehyde was applied to conditions at Summit, Greenland, to simulate concentration profiles in surface snow for a period of six years (Hutterli et al., 2003). Transport of $\mathrm{H}_{2} \mathrm{O}_{2}$ and formaldehyde in the interstitial air, the exchange between snow grains and the adjacent interstitial air, and snow metamorphism were treated in the model. Snow temperatures were calculated using observed air temperatures (annual mean temperature $241 \mathrm{~K}$ ) and the heat conductivity of the snow. The conductivity was determined using the snow density based on a measured profile. The same density profile was used to calculate the specific surface area, which was subsequently used to estimate an average radius of the snow grains. The transport in the interstitial air took into account molecular diffusivities, which were corrected according to the snow temperature and the firn density. Fresh snow was regularly added throughout the year, corresponding to a total accumulation of $23 \mathrm{~g} \mathrm{~cm}^{-2} \mathrm{yr}^{-1}$. As a result, older snow was transferred 
into deeper layers, causing an increase of the snow density according to the employed density-depth relationship, a decrease in the specific surface area and a corresponding increase of the average grain radius. Therefore, the metamorphism of the snow is represented in the model in a simplified way.

The physical cycling - the exchange of impurities between the snow grains and the adjacent interstitial air - was calculated based on empirical correlations from field and laboratory experiments (Fig. 14) (Conklin et al., 1993; McConnell et al., 1997; Hutterli et al., 1999; Burkhart et al., 2002). In the case of HCHO, the concentrations in the condensed phase were simulated according to a bulk approach assuming that formaldehyde is mostly adsorbed at the surface of the grains. In contrast, for $\mathrm{H}_{2} \mathrm{O}_{2}$ it was assumed that it is contained in the bulk solid of the snow grains and not adsorbed at the surface (McConnell et al., 1998). Therefore, a temperature-dependent air-snow partitioning coefficient was employed to determine the equilibrium between firn air concentrations and the concentrations in the outermost layer of the assumed spherical snow grains. Inside the grains, the transport of $\mathrm{H}_{2} \mathrm{O}_{2}$ was simulated using ten spherical layers and a temperature-dependent diffusion coefficient. In the case of $\mathrm{H}_{2} \mathrm{O}_{2}$ the empirical equilibrium constant was considerably lower than the extrapolated Henry's law constant. Moreover, the constant decreased strongly from $228 \mathrm{~K}$ to approximately $261 \mathrm{~K}$, before slightly increasing at higher temperatures (Conklin et al., 1993). These different temperature dependences of the equilibrium may reflect the adsorption processes at very low temperatures and the uptake in the liquid fraction at higher temperatures.

Concentrations in the atmospheric boundary layer were used as an upper limit of interstitial air concentrations. These concentrations were derived by offline calculations using a box model with a comprehensive atmospheric chemistry mechanism. The obtained annual cycles for $\mathrm{H}_{2} \mathrm{O}_{2}$ and formaldehyde boundary layer concentrations were scaled to agree with concentrations observed at Summit. The atmospheric concentrations were used together with meteorological observations, such as temperature and humidity, to determine $\mathrm{H}_{2} \mathrm{O}_{2}$ and formaldehyde concentrations in fresh snow. Diffusional growth of snow at cloud level is thought to not introduce any fractionation between water and $\mathrm{H}_{2} \mathrm{O}_{2}$. Thus, the co-condensation model is applied to calculate the fresh snow concentrations as described in Sigg et al. (1992). The formaldehyde concentrations in the fresh snow were further scaled in order to reproduce observed firn concentrations at greater depths. The co-condensation mechanism caused a supersaturation of the fresh snow in formaldehyde and $\mathrm{H}_{2} \mathrm{O}_{2}$, and only about $50 \%$ of the formaldehyde and $\mathrm{H}_{2} \mathrm{O}_{2}$ initially present is preserved in the snowpack and firn. Previous simulations for $\mathrm{H}_{2} \mathrm{O}_{2}$ demonstrated that at the snow surface $\mathrm{H}_{2} \mathrm{O}_{2}$ in the ice phase was always out of phase with the gas phase due to fast changes in the atmospheric conditions and the snow properties resulting also in a non-uniform distribu- tion of $\mathrm{H}_{2} \mathrm{O}_{2}$ inside the grains of the older snow (McConnell et al., 1998). Sensitivity studies further revealed that only the formaldehyde concentrations were significantly affected by the transport in the interstitial air and the accumulation rates, while the effect on $\mathrm{H}_{2} \mathrm{O}_{2}$ concentrations remained small for typical Greenland conditions (Hutterli et al., 2003). Tripling Summit accumulation rates of $0.23 \mathrm{~g} \mathrm{~cm}^{-2} \mathrm{yr}^{-1}$ did not have a large impact on $\mathrm{H}_{2} \mathrm{O}_{2}$ preservation. However lower snowfall rates, like those in Antarctica (0.07 to $0.3 \mathrm{~g} \mathrm{~cm}^{-2} \mathrm{yr}^{-1}$ ) demonstrate a large impact of accumulation rate on $\mathrm{H}_{2} \mathrm{O}_{2}$ (Frey et al., 2006), suggesting that if surface snow is quickly buried the resulting concentrations can be far away from equilibrium. The modelling study by Hutterli et al. (2003) thus showed that for $\mathrm{H}_{2} \mathrm{O}_{2}$ and formaldehyde physical cycling dominates in determining concentrations although both compounds undergo photochemical reactions in the snow.

Although the presence or absence of liquid and/or a disordered interface has been neglected in the models, they have successfully been applied for a wide snow temperature range from $203 \mathrm{~K}$ to $273 \mathrm{~K}$. Since recent studies have resulted in independent and more detailed description of the equilibrium of $\mathrm{H}_{2} \mathrm{O}_{2}$ and formaldehyde between the gas phase and the snow, taking into account the adsorption at the surface and the dissolution in the bulk ice phase (Pouvesle et al., 2010; Barret et al., 2011b), new modelling studies using such data are warranted. The application of such upgraded models to the same data sets as in the previous studies based on empirical relationships may be used to investigate whether the laboratory data are sufficient to reconstruct the observed $\mathrm{H}_{2} \mathrm{O}_{2}$ and formaldehyde profiles in the snow and in the firn cores and to determine the dominant uptake process for both species. For example, the formaldehyde exchange between the atmosphere and the surface snow has recently been studied by Barret et al. (2011a), measuring formaldehyde simultaneously in the snow and the atmosphere during a $48 \mathrm{~h}$ period. They were able to reproduce the variations in formaldehyde snow concentrations using the thermodynamics of the ice-formaldehyde solid solution and by modelling diffusion in and out of snow crystals similar to the approach previously used for $\mathrm{H}_{2} \mathrm{O}_{2}$ (Fig. 14). In this study, the authors used the diffusion coefficient of formaldehyde that has been independently measured in well-controlled laboratory experiments by Barret et al. (2011b) (Sect. 4.2.1) showing that solid-state diffusion resulted in a fourfold increase in snow formaldehyde over a $48 \mathrm{~h}$ period. We refer to the review by McNeill et al. (2012) for a detailed discussion on this topic.

\subsection{Conclusions about physical processes}

Deducing the role and mechanism of surface and bulk uptake to snow and characterising it in laboratory experiments with ice remains a difficult and essential issue for most species. The main obstacle is that solutes can be taken up by different reservoirs: the ice crystal, grain boundaries, on the (disordered) surface of ice, and in liquid embedded in the snow. 
The uptake routes dominating for individual species or conditions are currently unknown, but important underlying processes have been identified and characterised:

1. On shorter timescales, typical for air-ice exchange, sorption processes usually dominate. Adsorption dominates at temperatures below $\approx 250 \mathrm{~K}$ and uptake of most trace gases can be parameterised by Langmuir adsorption, even if multiple species are present.

2. The Langmuir-type parameterisation of trace gas adsorption might not be adequate when water molecules condense to the ice surface under non-equilibrium conditions for those species with a more negative adsorption enthalpy than water on ice. Parameterising the uptake to growing ice needs future attention.

3. Less is known about the role of the disordered interface on sorption processes. Current studies focusing on typical snowpack temperatures give little to no evidence for a pronounced role of surface disorder in uptake processes.

4. In the presence of liquid, the partitioning of trace gases to snow changes drastically and the overall uptake might no longer be dominated by Langmuir-type adsorption to the ice. Possibly, Henry partitioning to the liquid fraction might be better suited to describe sorption to snow. The uptake of trace gases to such wet snows has not been systematically investigated. In particular, as the liquid fraction can be highly concentrated, it should be verified whether Henry's law constants determined using dilute solutions can be used to describe the equilibrium between the gas phase and the liquid phase present in the snow. Moreover, interactions between solutes in brine and between solutes and dissolved gases may have feedback effects on the formation and extent of brine and need to be studied in more detail.

5. Diffusion can take place in the solid ice matrix, along grain boundaries, on the surface, and in the liquid phase embedded in surface snow. The presence of impurities can significantly influence diffusion rates and solubility by preferentially trapping certain species. Formation of ice solid solutions of small molecules such as methanol and formic acid deserves investigations. $\mathrm{NH}_{3}$ is a particular case with an extremely rapid diffusion in bulk ice even at low temperatures. This makes $\mathrm{NH}_{3}$ a further candidate for uptake into the ice matrix at polar conditions, even though measurements at relevant temperatures are missing.

6. At temperatures close to the melting point, where the disordered interface is thick, the self-diffusion on the ice surface is essentially the same as that in supercooled water. Outer surface layers diffuse more rapidly than inner layers, which makes the ice surface very different from a bulk liquid. Even in thick films covering the surface, diffusion in the layers close to the surface is highly influenced by interactions with the surface molecules. Moreover, an analysis of the activation energy of the diffusion reveals the opposite temperature dependence to what has been found in liquid water, and diffusion of ions on thin disordered layers is strongly influenced by the underlying crystal. All of this indicates that the diffusion mechanism is very different in the disordered interface from diffusion in supercooled water. Describing the diffusion of water in the disordered interface as liquid-like might however be a reasonable simplification: MD simulations show a sharp transition of the diffusion mechanism above 240-250 K where the diffusion constant in the upper layer of the disordered interface approaches that of supercooled water at high temperatures.

7. Previous models to simulate the physical exchange of species like $\mathrm{H}_{2} \mathrm{O}_{2}$ and formaldehyde used empirical parameterisations to describe the equilibria between gas phase and condensed phase. These parameterisations were developed using field observations at different polar sites and reflect the overall exchange processes between the snow and the firn air. Using new experimental results and new parameterisations these exchange processes may be better specified in upgraded models and compared to available long-term observation as in the previous modelling studies. Such simulation may help to better characterise driving processes for the exchange of reactive species between the snow and the atmosphere.

\section{Chemical processes}

In recent decades numerous field and laboratory studies have established that snow hosts unique chemical reactions with large-scale impacts on air quality, climate change, and biochemical cycles (Klán and Holoubek, 2002; Grannas et al., 2007b; Simpson et al., 2007; Steffen et al., 2008). A unified picture to describe the reactivity of chemical species in snow is still missing. In particular, detailed kinetic studies are rare and, thus, the following discussion is mostly based on observed rates of product formation or the decay of the starting compound. In that sense, some reactions are accelerated compared to the unfrozen, liquid sample - with the same amount of reactants - at room temperature. Those experiments indicated that the apparent reaction rate can be enhanced up to a factor of ten (Grannas et al., 2007a; Kahan and Donaldson, 2008; Weber et al., 2009; Kahan and Donaldson, 2010). Other chemical systems displayed similar apparent reaction rates in frozen and liquid samples (Dubowski and Hoffmann, 2000; Klánová et al., 2003a, b; Ružička et al., 2005; Matykiewiczová et al., 2007a; Anastasio and Chu, 
2009; Ram and Anastasio, 2009; Galbavy et al., 2010; Kahan et al., 2010c; Beine and Anastasio, 2011; Gao and Abbatt, 2011). In addition, a third kind of systems showed up to 10-times slower reactions in snow than in liquid samples for the same total concentration of reactants (Klánová et al., 2003a; Ružička et al., 2005; Matykiewiczová et al., 2007a; Anastasio and Chu, 2009; Bartels-Rausch et al., 2011; Beine and Anastasio, 2011; Gao and Abbatt, 2011). Reactions occurring in the liquid phase during the freezing process generally show a large, up to $10^{5}$, increase of the apparent reaction rates (Pincock, 1969; Takenaka et al., 2003).

Although we are far from reaching a detailed, quantitative understanding of the chemistry occurring in snow, recent studies have identified several factors to explain the observed changes in reactivity. These factors, as discussed in the following, are the increased concentration, changes in reaction mechanisms, the temperature dependence of the reaction, the local chemical environment, and the location of the reactants. The combination of all these factors controls the observed rates in snow and the question arises of which processes dominate the overall chemical reactivity in snow.

\subsection{Local concentration}

High reactant concentrations are a major reason for the enhanced reactivity observed in snow or in ice samples used in laboratory studies to mimic environmental snow. Figure 15 shows an example in which such an enhanced concentration accelerates bimolecular reaction steps, such as the photolytic reaction between $p$-nitroanisole and pyridine (Grannas et al., 2007a).

\subsubsection{Freeze-concentration effect}

Early atmospheric chemistry work by Takenaka et al. (1992) observed a $10^{5}$ acceleration rate for the oxidation of nitrite by oxygen during freezing. This implies that a reaction that is usually slow and thus negligible in the liquid phase - such as the conversion of nitrite to nitrate by oxygen - becomes important enough to modify the composition of the sample during freezing. Takenaka et al. (1992) discarded any catalytic properties of the ice surface to produce this acceleration. The dependence of the rate on the enhanced concentration due to the volume of liquid brine reduction during freezing was later confirmed (Finnegan, 2001; Takenaka and Bandow, 2007; Grannas et al., 2007a; Wren et al., 2010). This conclusion holds for soluble species and bimolecular (or higher-order) reactions. One important consequence of this freeze concentration for environmental chemistry is that it can lead to new products and reaction pathways. Sodeau and co-workers have recently identified new reaction pathways for the release of nitric oxide and halogen species to the atmosphere from the freezing of sea salt solutions, often via trihalide ions (O'Concubhair et al., 2012; O'Driscoll et al., 2008; O'Concubhair and Sodeau, 2012; O'Sullivan

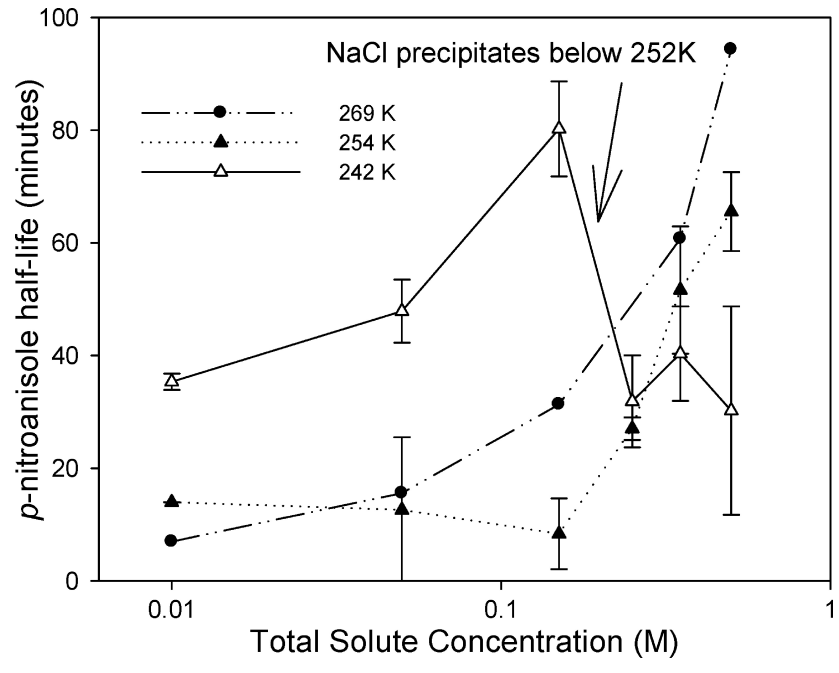

Fig. 15. Observed reactivity of p-nitroanisole in frozen aqueous solutions as a function of total solute concentration adjusted by the addition of $\mathrm{NaCl}$ at $269 \mathrm{~K}$ (filled circles), $254 \mathrm{~K}$ (filled triangles), and $242 \mathrm{~K}$ (open triangles). The lower the $\mathrm{NaCl}$ concentration, the smaller the volume of brine. The higher concentration of the bi-molecular reaction partners, $\mathrm{p}$-nitroanisole and pyridine in the smaller liquid volume might explain the apparent higher reactivity with lower total solute concentration. Reprinted with permission from Grannas et al. (2007a) Copyright (2007) American Chemical Society.

and Sodeau, 2010). Of relevance for the cryospheric community, dissolved elemental mercury is oxidised to $\mathrm{Hg}^{2+}$ when frozen in the presence of oxidants such as hydrogen peroxide, nitrous acid, or sulfuric acid and oxygen (O'Concubhair et al., 2012). The apparent rate of chemical reactions during the freezing process is further influenced by other factors, such as changes in $\mathrm{pH}$ (O'Sullivan and Sodeau, 2010).

While freezing a solution, once the temperature drops below the eutectic point, the bulk liquid solidifies if nucleation is induced. This phase change is accompanied by reactivity changes. For example, the reactivity during the freezing process was observed to cease once the sample completely solidifies, as described in the early work by Takenaka et al. (1996).

\subsubsection{Local concentration in bulk ice}

High local concentrations observed during the freezing process may prevail in frozen samples. A particular study showed that local concentrations were enhanced by $10^{6}$ in frozen samples upon slowly freezing aqueous solutions (Heger et al., 2005). High concentrations can enhance the reactivity, such as the photolytic reaction between $p$ nitroanisole and pyridine (Grannas et al., 2007a), the photodegradation of organophosphorus pesticides (Weber et al., 2009), the photolysis of polycyclic aromatic hydrocarbons (Kahan et al., 2010c), or the photoreduction of ferric ions in ice by organic molecules (Kim et al., 2010). The chemistry in 


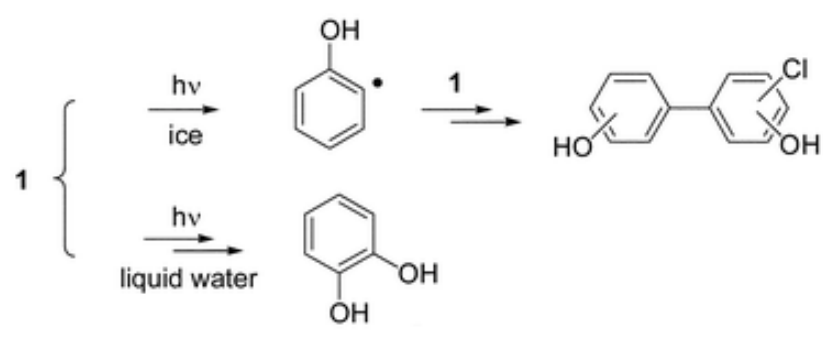

Fig. 16. Major photolysis products of 2-chlorophenol (1) in ice and in water. In ice chlorobiphenyldiol coupling products are found, in water 2-chlorophenol forms pyrocatechol. Reproduced from Klánová et al. (2003a) with permission from The Royal Society of Chemistry.

mixtures of metals and organics illustrates how the reactivity in ice is linked to the freezing process (Kim et al., 2010; Bartels-Rausch et al., 2011): during freezing the metal forms complexes with organic electron donors due to the freezeconcentration effect. Upon photolysis of the frozen sample, the newly formed ligand-metal bond absorbs the photon that initiates the intramolecular redox process. Intermolecular redox reactions could increase their efficiency towards electron transfer with higher concentrations and contribute further to enhanced reaction rates. A quantitative description of the reaction rates is often hampered because the local concentrations of reactants are unknown.

\subsubsection{Local concentration at surface}

Enhanced local concentrations of aromatic compounds such as benzene and naphthalene account for faster apparent photolysis rates at ice surfaces (Kahan and Donaldson, 2010; Kahan et al., 2010c). Considering that unimolecular reactions are not per se concentration-dependent, therefore, in such cases rather the absorption spectrum changes. In aqueous solutions, as well as in the gas phase, benzene does not absorb radiation at wavelengths longer than $\approx 290 \mathrm{~nm}$, and naphthalene absorbs only weakly. On ice, however, the absorption spectra of both molecules are redshifted compared to those in dilute solutions due to self-association of benzene and of naphthalene molecules.

\subsection{Mechanism}

Klán and co-workers observed remarkable mechanistic differences during the photoreaction of halogenated aromatic compounds in frozen and liquid aqueous solutions (Fig. 16). Dehalogenation and bimolecular (radical coupling) reactions occurred below approximately $266 \mathrm{~K}$ instead of the photosolvolysis in liquid media (Klán et al., 2000; Klán et al., 2001; Klán and Holoubek, 2002; Klánová et al., 2003a, b; Ružička et al., 2005; Matykiewiczová et al., 2007a, b). The environmental impact is related to the higher toxicity of the reaction products in ice than in water (Bláha et al., 2004). Increased local concentrations and/or the lack of sufficient water to act as a nucleophile in ice were invoked as reasons for a different reaction pathway in the frozen samples. The mechanistic change also affected the apparent reaction rates (Klánová et al., 2003a): no apparent enhanced rate was observed for these degradations in ice despite the high local concentrations. A drawback to most of these studies is that they were performed at higher concentrations than typically present in the environment; these high concentrations might contribute to the unique chemistry observed. The photochemical degradation of persistent organic compounds at environmentally relevant concentrations showed that different products were formed from those observed at higher concentrations (Matykiewiczová et al., 2007a). Remarkably, it was confirmed that solvolysis did not occur for this type of compounds in ice.

The importance of the reaction mechanism on the observed rates in ice and snow is also evident from unimolecular reactions, which are per se concentration-independent, and which often proceed with similar efficiencies in frozen and liquid solutions. For example, the production of hydroxyl radicals from the photolysis of precursors such as $\mathrm{H}_{2} \mathrm{O}_{2}(\mathrm{Chu}$ and Anastasio, 2005; Jacobi et al., 2006), $\mathrm{NO}_{3}^{-}$(Dubowski et al., 2002; Chu and Anastasio, 2003; Jacobi et al., 2006; Matykiewiczová et al., 2007b) and $\mathrm{NO}_{2}^{-}$(Jacobi et al., 2006; Chu and Anastasio, 2007; Matykiewiczová et al., 2007b) are generally reported to proceed through similar mechanisms with comparable absorption spectra and quantum yields in frozen and liquid solutions. More-recent lab studies at high surface coverages of nitrate at the air-ice interface call this result into question (Zhu et al., 2010). While the initial photolysis of these reactions is clearly a unimolecular step, it might be followed by more complex reactions such as the self-reaction of $\mathrm{HO}_{2}$ to produce $\mathrm{H}_{2} \mathrm{O}_{2}$. If such back-reactions are favoured, the overall product formation might decrease significantly (Dubowski et al., 2002; Beine and Anastasio, 2011). Such changes in the relative importance of individual reaction pathways might also explain why the two-step reduction of $\mathrm{Hg}$ (II) in the presence of organic electron donors decreases in ice compared to water (Bartels-Rausch et al., 2011).

\subsection{Reactions in the presence of solutes}

Directly comparing the reactivity in frozen systems to reactivity in liquid-solid multiphase systems has been the focus of some recent studies (Guzmán et al., 2007; Grannas et al., 2007a; Kahan et al., 2010a; Gao and Abbatt, 2011). Photolytically driven bimolecular reactions of water-soluble organics were found to proceed faster in mixtures of ice and brine compared to completely frozen systems (Grannas et al., 2007a; Gao and Abbatt, 2011). In the study by Grannas et al. (2007a) $\mathrm{NaCl}$ was added to the sample to vary the amount of brine at a given temperature (Fig. 15). Comparison of the 
rates above and below the eutectic point for a given system revealed a strong dependency on concentration: at low salt concentrations, lifetimes of water-soluble organics increased when the temperature was lowered below the eutectic; at higher concentrations the observed lifetimes were longer at temperatures above the eutectic. In contrast, water-insoluble organic aromatics were found to be photolysed faster on ice surfaces in the absence of brine (Kahan et al., 2010a). Varying the amount of brine systematically, the chemistry could be tuned from that observed at a pure ice surface (fast) to that observed in aqueous solution (slow) (Kahan et al., 2010a). The possibilities that chemistry in partially frozen samples may differ from chemistry in solid ice samples and that chemistry in brine might be more important than reactivity in completely frozen samples complicates the analysis of experiments. This becomes clear when reactions are monitored continuously during the freezing process and in the completely frozen sample. For example, Kim and Choi (2011) described an enhanced reduction of chromate and arsenite in frozen ice. Since the samples were prepared from liquid solutions and based on the observed time dependence (Kim and Choi, 2011), it is proposed here that the major part of the observed chemistry occurred during the freezing process in agreement with the freeze-concentration effect discussed.

\subsection{Chemical environments}

Ice and snow in the environment contain complex mixtures of chemicals, each of which can participate and alter chemical reactions (Grannas et al., 2007b). For example, organic chromophores act as photosensitisers that promote photochemical reactions (Bartels-Rausch et al., 2010, 2011), and produce reactive species such as $\mathrm{OH}$ radicals (Grannas et al., 2007b; Dolinová et al., 2006). They also suppress photochemical reactions by acting as a filter of light and by scavenging reactive species (Grannas et al., 2007b). The environmental importance of organic compounds in ice is discussed in detail by McNeill et al. (2012) and Grannas et al. (2013). Abida and Osthoff (2011) recently reported that organic co-solutes ranging from formate to phenol inhibited the release of gasphase $\mathrm{NO}_{2}$ from nitrate photolysis in ice, likely due to scavenging of $\mathrm{OH}$. However, halogenated phenols enhanced $\mathrm{NO}_{2}$ production. The finding was related to the acidification that the ice surface underwent following the formation of $\mathrm{HCl}$ upon oxidation of the halogenated phenol. A suppression of mercury photoreduction was observed in ice doped with halogens and organic chromophores (Bartels-Rausch et al., 2011). The observed decrease in $\operatorname{Hg}(0)$ production in the presence of chloride was attributed to the formation of oxidising halogen species or to chloride binding to mercury in concentrated brine solutions upon freezing, which might limit its reactivity (Bartels-Rausch et al., 2011). Organic cosolutes can also act as hydrogen donors upon photolysis of organic chromophores in ice (Matykiewiczová et al., 2007b). In the presence of several different types of chromophores the apparent rate of direct photolysis might be surpassed by bimolecular reactions involving photolytically produced radicals. Anthracene and naphthalene undergo photolysis at ice surfaces with no photolytic enhancement in the presence of nitrate or $\mathrm{H}_{2} \mathrm{O}_{2}$. The lack of any photolytic enhancement indicates that the indirect bimolecular degradation is slower (Kahan and Donaldson, 2008). The competition of primary photochemical processes and hydroxylation in the presence of $\mathrm{H}_{2} \mathrm{O}_{2}$ was reported (Klánová et al., 2003a; Dolinová et al., 2006). The reactivity of single reactants can change when its solubility limit is reached, resulting in physical separation of the reactants during freezing (Gao and Abbatt, 2011). In this study the reactivity of $\mathrm{OH}$ towards succinic acid in ice was lower than in aqueous solution, while no significant change was observed for malonic acid, which has the higher solubility in water of these two molecules.

Local $\mathrm{pH}$ can be significantly altered during freezing, and can affect the acid-base equilibrium as well as reactivity of the solutes. For example, the presence of organic acids can result in a 100 to $10^{4}$ increased protonation of cresol red relative to liquid solutions, which was attributed to the higher local concentration of acids at the grain boundaries due to the freeze-concentration effect during sample preparation (Heger et al., 2006). Such pH changes can significantly alter the chemistry during the freezing process, promoting pathways that do not occur in the unfrozen liquid (O'Sullivan and Sodeau, 2010). This change in local $\mathrm{pH}$ possibly affects the chemical reactions even after complete freezing. A slight increase in the apparent photolysis rate of $\mathrm{NO}_{3}^{-}$occurred with increasing $\mathrm{pH}$ (Chu and Anastasio, 2003), while the production of gas-phase $\mathrm{NO}_{2}$ increased with decreasing $\mathrm{pH}$ (Abida and Osthoff, 2011), and additional gas-phase products including $\mathrm{HONO}, \mathrm{HONO}_{2}, \mathrm{HO}_{2} \mathrm{NO}$, and $\mathrm{HO}_{2} \mathrm{NO}_{2}$ were detected at $\mathrm{pH}<4.5$ (Abida and Osthoff, 2011). The importance of these species to ice chemistry has been presented (Riordan et al., 2005; Hellebust et al., 2007, 2010). The photolysis of HONO in ice yielded approximately eight times more $\mathrm{NO}$ and $\mathrm{OH}$ than the photolysis of $\mathrm{H}_{2} \mathrm{ONO}^{+}$ in ice (Chu and Anastasio, 2007). Faster photoreduction of $\mathrm{Fe}_{3}^{+}$and $\mathrm{Cr}(\mathrm{VI})$ occurred in veins than in aqueous solution at lower $\mathrm{pH}$ due to the exclusion of protons that accompanies the freezing process (Kim et al., 2010). The release of HONO from the photosensitised reduction of of $\mathrm{NO}_{2}$ in ice doped with humic acid follows the expected $\mathrm{pH}$ dependence if freeze-induced $\mathrm{pH}$ changes are accounted for (BartelsRausch et al., 2010). The apparent photolysis rate of $\mathrm{H}_{2} \mathrm{O}_{2}$, $\mathrm{NO}_{3}^{-}$, and $\mathrm{NO}_{2}^{-}$in bulk ice samples was demonstrated to be independent of $\mathrm{pH}$ (Chu and Anastasio, 2003, 2007). Further, reaction efficiencies and product yields of halogen chemistry in ice are influenced by local $\mathrm{pH}$ as discussed in Abbatt et al. (2012). A final note here is that ammonium nitrate on ice can be photolysed to release $\mathrm{N}_{2} \mathrm{O}$, a process that is quite different from the photolysis of nitric acid on ice (Koch et al., 1996). 


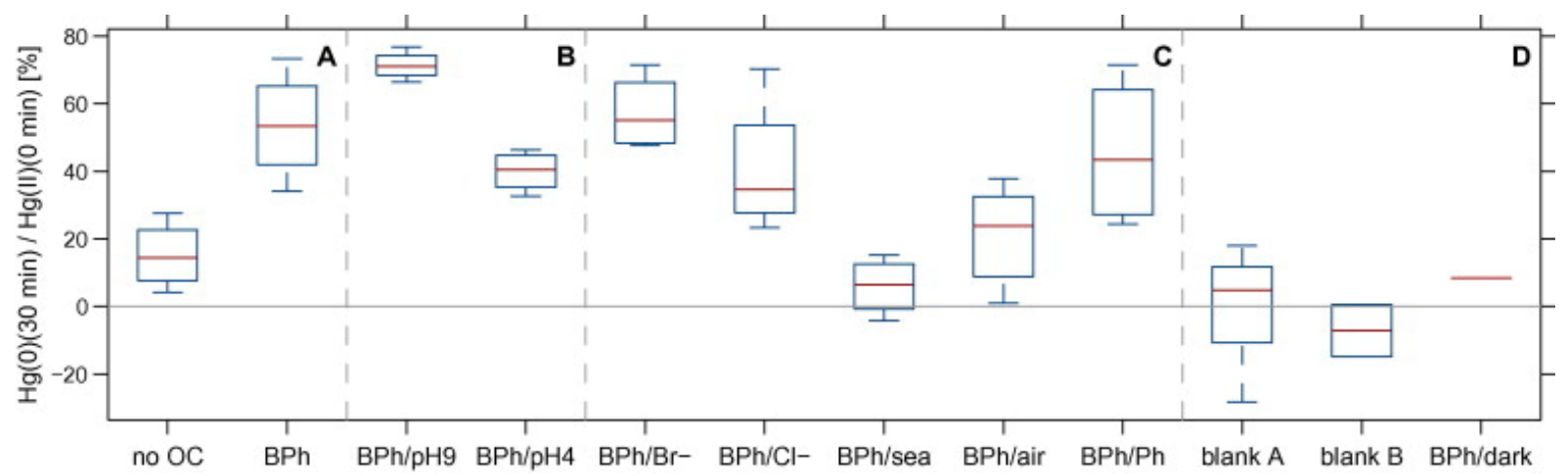

Fig. 17. The effect of a different chemical composition of the ice matrix on the photochemistry of mercury during 30 min irradiation with UVA at $258 \mathrm{~K}$ (sectors $\mathrm{A}-\mathrm{C}$ ). Also, blank experiments in the dark are shown for comparison (sector D). The solution to freeze the ice films was always doped with $\mathrm{Hg}(\mathrm{II})\left(6 \times 10^{8} \mathrm{M}\right)$ and additionally contained the following compounds as indicated: "no OC" denotes experiments of pure $\mathrm{HgO}$ solutions; "BPh" of $6 \times 10^{7} \mathrm{M}$ benzophenone in unbuffered solutions at $\mathrm{pH} 7$ (of the molten ice film); " $\mathrm{BPh} / \mathrm{pH} 9$ " and " $\mathrm{Ph} / \mathrm{pH} 4$ " $\mathrm{NaOH}$ and $\mathrm{H}_{2} \mathrm{SO}_{4}$ added to $6 \times 10^{7} \mathrm{M}$ benzophenone to reach a $\mathrm{pH}$ of 9 or of 4 , respectively; " $\mathrm{Ph} / \mathrm{Br}^{-"}$ " $6 \times 10^{7} \mathrm{M}$ benzophenone and $5 \times 10^{8} \mathrm{M}$ bromide; " $\mathrm{BPh} / \mathrm{Cl}^{-}$" $7 \times 10^{8} \mathrm{M}$ chloride, "BPh/sea" $0.5 \mathrm{M}$ chloride, $1 \mathrm{mM}$ bromide; " $\mathrm{BPh} /$ air" $6 \times 10^{7} \mathrm{M}$ benzophenone in the ice, $20 \%$ oxygen present in the carrier gas stream; "BPh/Ph" $5 \times 10^{7} \mathrm{M}$ benzophenone and $6 \times 10^{8} \mathrm{M} 2$,6-dimethoxyphenol. In each box, the central mark is the median, the edges of the box are the 25th and 75th percentiles, and the whiskers extend to the most extreme data points. Reprinted with permission from Bartels-Rausch et al. (2011). Copyright (2011) Elsevier.

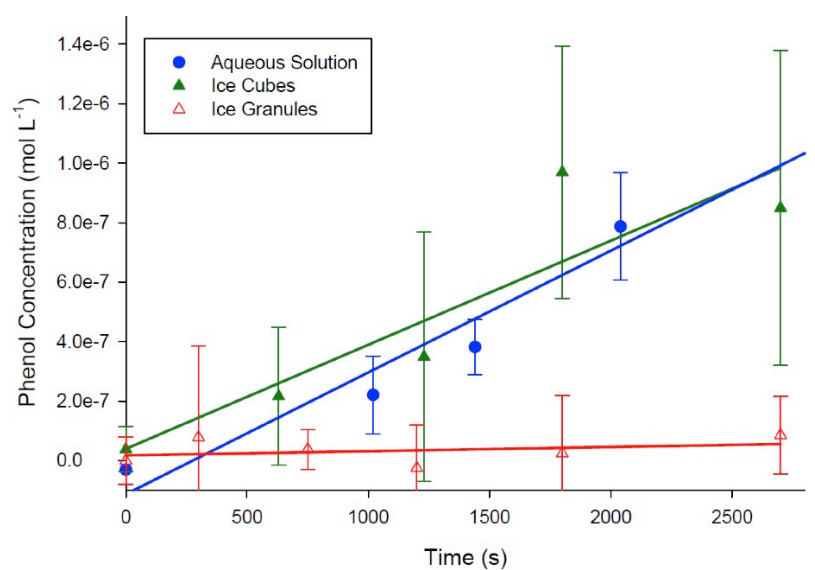

Fig. 18. Formation of phenol from in situ photolysis of $\mathrm{H}_{2} \mathrm{O}_{2}$ in the presence of benzene in liquid solution and different ice samples. Phenol concentration is plotted as a function of irradiation time for samples containing $1 \mathrm{mM}$ benzene and $0.9 \mathrm{mM} \mathrm{H}_{2} \mathrm{O}_{2}$. The solid traces are linear fits to the data, and error bars represent one standard deviation about the mean for at least three trials. Reprinted from Kahan et al. (2010b). Copyright by the authors.

\subsection{Physical environments}

Besides the local differences in concentration and chemical environment, the location where reactions occur will affect the fate of the reaction products, its distribution, and apparent rates. The previous considerations were used to describe the approximately $50 \%$ reduced photoreactivity of $\mathrm{H}_{2} \mathrm{O}_{2}$ in flash-frozen samples compared to aqueous solutions or slowly frozen samples (Beine and Anastasio, 2011).
Dubowski et al. (2001) determined that $\mathrm{NO}_{2}$ produced from $\mathrm{NO}_{3}^{-}$in the uppermost region of the spray-frozen ice samples was able to escape to the gas phase, while that produced at greater depths was photolysed to NO. Subsequent studies also concluded that the detection of $\mathrm{NO}_{2}^{-}$is only possible after the initial photo fragments (i.e. $\mathrm{NO}_{2}^{-}$and $\mathrm{O}$ ) escape the ice cage surrounding them (Chu and Anastasio, 2003, 2007; Anastasio et al., 2007). Kahan et al. (2010a, c) observed similar apparent rates for unimolecular and bimolecular reactions occurring in large ice cubes and in aqueous solution. However, the apparent reaction rates in ice granules with larger surface-to-volume ratios (formed by crushing the ice cubes) were the same as those measured in situ at ice surfaces (Kahan et al., 2010a, c) (Fig. 18). In ice cubes, reagents are located primarily in the bulk ice, and bulk kinetics govern the reactions monitored after thawing the samples. Instead, high surface area samples showed that surface processes dominate offline measurements, implying that more reagent was located at the surface (Kahan et al., 2010a, c). Similar observations were made for species doped to artificial snow from the gas phase and by freezing from solution (Ružička et al., 2005; Kurková et al., 2011)s . The high surface-area-to-volume ratio of artificial snow maximises the distribution of reagents at the surface, regardless of the sample preparation method.

From an atmospheric perspective, reactions at the icesurface-air interface are important because products are readily available to escape the ice phase. Many studies indicate that the chemistry on the ice surface is distinctly different from that observed in ice, in bulk water, and also on water surfaces. Scientists often use indirect methods to study reactions at ice surfaces, for example by probing the gas 
phase above an ice sample. We refer the reader to Huthwelker et al. (2006) for a detailed discussion on experimental methods. In those experiments probing surface reactions is usually achieved by using ice samples with a high surface-to-volume ratio (e. g. Abbatt et al., 1992; McNeill et al., 2007; BartelsRausch et al., 2010; Kurková et al., 2011). However, these studies give no direct evidence for the surface reactions, as discussed in Bartels-Rausch et al. (2011). Monitoring reactions at the ice surface requires in situ analysis, which has been done in a limited number of spectroscopic experiments in the IR (e.g. Hellebust et al., 2007) and UV/VIS (e.g. Kahan et al., 2007). The advantage of the UV/VIS spectroscopy approach is that it can be operated at temperatures typical for environmental snowpacks.

A number of recent studies show that gas-ice-surface reactions at temperatures approaching the melting point are best described as heterogenous processes, and that the rates of these reactions are very different from those in the aqueous phase or on water surfaces. The ozonation of phenanthrene and 1,1-diphenylethylene deposited from the gas phase was accelerated at ice and artificial snow grain surfaces compared to liquid water surfaces (Kahan and Donaldson, 2008; Ray et al., 2011). Recently, a remarkable and unexpected increase in the apparent ozonation rates on ice surfaces with decreasing temperature was evaluated using the LangmuirHinshelwood and Eley-Rideal kinetic models, and by estimating the apparent specific surface area of the ice grains (Ray et al., 2013). It was suggested that an increase of the number of surface reactive sites and possibly higher ozone uptake coefficients was responsible for the apparent rate acceleration of 1,1-diphenylethylene ozonation at the air-ice interface at lower temperatures. Other examples are the halogen emissions from frozen sea ice solutions upon reaction with ozone or $\mathrm{OH}$ and the heterogeneous reaction of hypohalogenic with halogen acids as recently discussed in detail (Abbatt et al., 2012). The heterogeneous photosensitised reduction of inorganic species such as $\mathrm{NO}_{2}$ has been investigated in the presence of humic substances and proxies for these species. These reactions are likely due to energy transfer from the humic substance to the reagent on the ice surface (Bartels-Rausch et al., 2010). The last study found that the reaction rate depends linearly on the concentration of the organic compounds for low total concentrations in the ice sample. There was good agreement between the extrapolation of reported reaction rates on ice and experiments on pure organic films, suggesting similar reactivity on both surfaces. For intermediate concentrations of humic acids in the ice film, the linear correlation broke presumably due to an agglomeration effect that reduced the amount of organic molecules accessible to the gas-phase $\mathrm{NO}_{2}$.

Some differences in heterogeneous reaction rates at ice and water surfaces are not easily described by known reaction mechanisms. For example, hydroxyl radicals react less efficiently with aromatic compounds at ice surfaces than at liquid water surfaces or bulk ice (Kahan et al., 2010b).
High conversion efficiencies were reported for the photolysis of aromatic compounds such as benzene, naphthalene, anthracene, and harmine (Kahan and Donaldson, 2007, 2008; Kahan et al., 2010a). The faster loss of benzene and naphthalene are due at least in part to their aggregation to form dimers at ice surfaces, where they experience a redshift in the absorption spectra as compared to aqueous solutions, but aggregation does not explain the photolysis behaviour of anthracene and harmine at ice surfaces (Kahan and Donaldson, 2007; Kahan et al., 2010a). Under the same experimental conditions, anthracene photolysis in bulk ice proceeded at the same apparent rate as in aqueous solution (Kahan et al., 2010c). The observed rates did not depend on temperature in aqueous solutions (274-297 K) or at the ice surface (257$271 \mathrm{~K}$ ) (Kahan and Donaldson, 2007). Faster photolysis rates at the ice surfaces were explained in terms of its different physicochemical properties compared to liquid water. Different absorption spectra of inorganic acids on ice and in aqueous solution make the adsorbed species more susceptible to photodissociation as discussed further in Abbatt et al. (2012). Such shifts in the absorption maxima allowed the evaluation of the nature and magnitude of the intermolecular interactions of both species in ice at 253 and $77 \mathrm{~K}$ (Heger and Klán, 2007). The presence of water in close vicinity to the probe molecules and the intermolecular interactions within the selfassembled molecular aggregations were believed to cause the observed shift of the absorption spectra. Enhanced ice-solute or solute-solute interactions have recently been visualised as a cage effect in which the boundaries of the cage are defined by the walls of the micro-pocket or vein that the reagents are trapped in. In the confined space of the cage, reagents and intermediates are unable to diffuse away from one another, so the cage effect reflects an enhanced reactivity unless an irreversible loss occurs (Ružička et al., 2005). For a detailed discussion on the photochemistry of organic molecules in ice and on the cage effect we refer the reader to McNeill et al. (2012).

McNeill et al. (2006, 2007) used ellipsometry to identify an increased surface disorder at temperatures as low as $200 \mathrm{~K}$ caused by doping the ice surface with $\mathrm{HCl}$. They reported the enhanced apparent rate when $\mathrm{HCl}$ reacted with $\mathrm{ClONO}_{2}$ for the dopant-induced disorder condition at low temperatures. At higher temperatures, surface disorder is omnipresent (Sect. 3.3). For these conditions, Kahan and Donaldson (2007) observed a constant apparent photolysis rate for anthracene on the ice surface between 257 and $271 \mathrm{~K}$. For other species, it was argued that liquid-like properties of the disordered interface facilitate heterogeneous reactions. For example, the reaction of $\mathrm{SO}_{2}$ with $\mathrm{H}_{2} \mathrm{O}_{2}$ proceeds via hydrolysis of $\mathrm{SO}_{2}$ on the ice surface (Clegg and Abbatt, 2001) and was thus suggested to be enhanced by surface disorder. Taken together, these studies show that adsorbates and molecules that were doped to the air-ice interface by freezing a solution in most cases show chemical rates that are best described by heterogeneous processes. Even at temperatures 


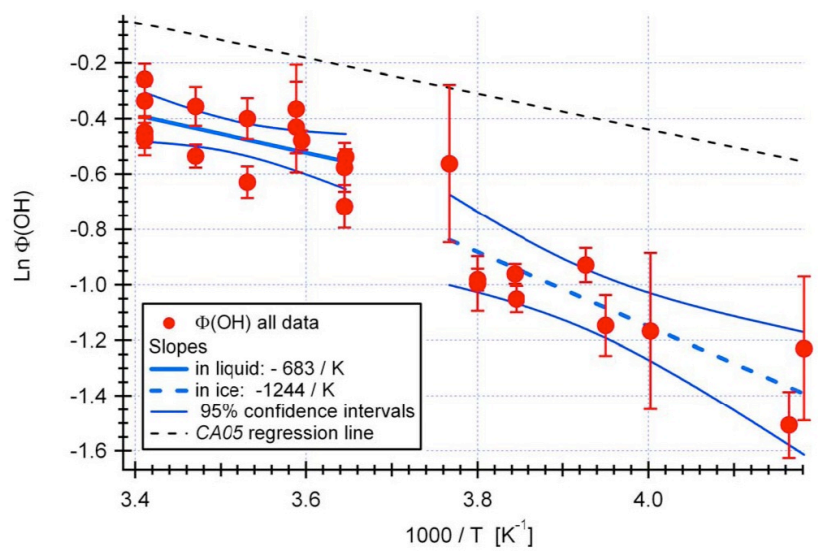

Fig. 19. Observed quantum yield of $\mathrm{OH}$ production from $\mathrm{H}_{2} \mathrm{O}_{2}$ photolysis in water and ice (red dots). The slopes for our liquid (blue solid line) and ice (blue dashed line) results are statistically different at the $87 \%$ confidence level, and the slope for the ice data shows a stronger temperature dependence. Comparison to earlier data by Chu and Anastasio (2005) (black dashed line) shows that observed kinetics critically depend on the type of ice matrix: the slope for the liquid data is identical to the earlier results for liquid and solid phases (black dashed line). The slope for the shock-frozen ice data (blue dashed line) indicates a stronger temperature dependency than results for slowly frozen ice samples (black dashed line). Reprinted from Beine and Anastasio (2011). Copyright (2011) John Wiley and Sons.

approaching the melting point $(\approx 10 \mathrm{~K}$ below eutectic temperature), chemical reactivity at the air-ice interface differs from that of the air-water interface and of bulk aqueous solutions. Thus, surface disorder seems not to justify the use of bulk rates to describe reactivity of the mostly insoluble organics studied at the air-ice interface at these high temperatures.

The reactivity of aerosol deposits at the air-ice interface has not been studied in detail in well-controlled laboratory studies. Given their reactivity throughout the troposphere (George and Abbatt, 2010), a critical role in snow chemistry as a source of volatile organic compounds has been proposed (Domine and Shepson, 2002). We refer the reader to Domine et al. (2013) for an in-depth discussion on this topic.

\subsection{Chemical processes in models}

Models that include complex snowpack chemistry are rapidly emerging. Some of these models simulate the impact of chemistry in snow on the composition of air in the boundary layer (Michalowski et al., 2000; Boxe and Saiz-Lopez, 2008; Thomas et al., 2012). Central to these models is that all chemical reactions are parameterised to occur in a liquid environment in contact with air. For example, measured liquid rate constants and Henry's law constants are applied to a liquid fraction of the snow volume and used to approximate the behaviour of the snowpack. Such an approach allowed us- ing knowledge from liquid aerosol models to develop snowchemistry models. It was further motivated by early laboratory work that showed the behaviour of some chemicals in frozen samples may be approximated by treating them analogously to solvated species (Sect. 5.2). An example is nitrate photolysis (Dubowski et al., 2002; Chu and Anastasio, 2003; Jacobi et al., 2006; Matykiewiczová et al., 2007b), even though discrepancies between model predictions based on this simplification and field observations of $\mathrm{NO}_{\mathrm{x}}$ emissions from snow remain (Frey et al., 2013). From a critical standpoint, the generalised concept of a surface disorder with liquid-like properties that is used to justify this approach at subfreezing temperatures is an over-simplification (Sects. 3 and 4.1). Clearly, the majority of chemical systems studied so far in ice samples show a distinctly different behaviour than that seen in liquid probes, so that a general use of aqueousphase chemistry may be questioned and needs to be carefully re-examined in the future (Sect. 5.2). However, it is also clear that liquid might be present in surface snow at environmental conditions (Sect. 2.1), and for those instances chemical transformations might be well captured by this model approach.

This section shows below how these models, including liquid-phase mechanisms, can capture observed fluxes and/or concentrations of trace gases measured above the snowpack. The outcome of these models can thus be used to evaluate whether snowpack chemistry alone can produce elevated concentrations of species such as bromine monoxide. Treatment of photochemistry in surface snow and ice has focused on halogens and nitrate, because laboratory and field studies have clearly shown that both reactive halogens and nitrogen oxides are emitted from irradiated snow and ice.

Liao and Tan (2008) integrated simplified chemistry in a 1D snow model aiming to simulate the formation of HONO in the snow during a 6-day period at the South Pole using prescribed and constant concentrations of nitrate and nitrite. The chemical reactions included the photolysis of $\mathrm{NO}_{3}^{-}$assumed to form directly HONO and the photolysis of HONO as its only sink. Subsequently, photolysis rates were calculated based on the simulated spectral actinic fluxes within the porous snowpack. Due to the fast photolysis of HONO in the surface layers this region did not contribute to a net production of HONO in the snow. Only with the increased vertical transport due to wind-pumping could the HONO produced in the deeper layers efficiently be transported to the surface and into the atmosphere. Overall, the photolysis of nitrate remained smaller than the HONO loss to the atmosphere. Obviously, the simplified parameterisation of snow chemistry as done in this model does not adequately describe the observations. For example, an additional source of HONO would be needed to close the reactive nitrogen budget. However, the simulation is based only on a few, selected reactions, and the results were not constrained by observations. The results were highly sensitive to $\mathrm{pH}$, the volume of the liquid fraction, and the initial $\mathrm{NO}_{2}^{-}$concentration. 
Earlier work using a multiphase box model focused on halogen activation and ozone depletion events in the coastal Arctic region (Michalowski et al., 2000). The boundary layer was modelled using aerosol- and gas-phase chemistry. Snow and aerosol chemistry was simulated with 16 reactions related to the activation of reactive bromine and chlorine species. The free troposphere was treated as an ozone reservoir, with downward mixing of ozone to the boundary layer. The four model components (liquid fraction in snow, boundary layer gas phase, aerosols, and free troposphere) were in contact using transfer coefficients. For the exchange between the boundary layer and the liquid fraction in the snow, transfer functions for $\mathrm{HOBr}, \mathrm{HOCl}, \mathrm{HBr}$, $\mathrm{HCl}$, and $\mathrm{O}_{3}$ were chosen in the range of dry deposition velocities to the snow surface. The release of volatile species from the liquid fraction of the snow back to the boundary layer occurred via two steps from the liquid to the interstitial air and from there to the boundary layer. First-order rate coefficients for transfer of molecular halogen species $\left(\mathrm{Br}_{2}, \mathrm{Cl}_{2}\right.$, and $\left.\mathrm{BrCl}\right)$ from the interstitial air to the boundary layer were also chosen similar to the dry deposition velocities. Using the boundary layer height and the snowpack depth along with the transfer coefficients, the rate of mixing between the interstitial air and boundary layer gas-phase volume was determined. This model showed for the first time emissions of halogens from the surface snow could induce a complete ozone depletion event. The predicted ozone depletion event was five days after model initialisation. The study indicated the important role of atmospheric particles in contributing to ozone depletion, because removing particles delayed the onset of the ozone depletion event by two days. The model further showed that, without the influence of the snowpack, no ozone depletion was predicted. In particular this work demonstrated that the concept to restrict chemistry in the snowpack to a liquid fraction, given that all ions were concentrated in this volume, gave reasonable results for typical coastal Arctic conditions. The sensitivity of model results to the volume of the liquid fraction showed that increasing the volume decreases concentrations and slows the release of halogens. Choosing an appropriate volume of the liquid fraction that represents natural snow reasonably is an obstacle in models. Melting point depression by impurities and geometric constraints might be used at temperatures above the eutectic point. At lower temperatures, models often use the thickness of the disordered interface. This is also problematic, because measurements do not give a consistent picture yet (Sect. 3.3) and this parameter needs thus to be assumed so that simulation results match observations. Interestingly, a recent re-run of a specific nitrate snow-chemistry model where the liquid fraction was reduced by a factor of up to 100 showed that the overall results were surprisingly robust and only slightly sensitive to the assumed volume of the liquid fraction, when other parameters - such as solubility limits were accounted for and concentrations adjusted (Bock and Jacobi, 2010; Jacobi, 2011).
Using an approach similar to Michalowski et al. (2000), Boxe and Saiz-Lopez (2008) applied a 0-D multiphase model to study $\mathrm{NO}_{\mathrm{x}}$ emissions to the boundary layer resulting from photolysis of nitrate $\left(\mathrm{NO}_{3}^{-}\right)$and nitrite $\left(\mathrm{NO}_{2}^{-}\right)$impurities in snow. In order to calculate volume fluxes (a surface flux distributed throughout the boundary layer) the model also utilised a volumetric factor $\left(1.22 \times 10^{3}\right)$ which they described as a reaction rate enhancement factor. The calculated fluxes from the 0-D model were then used in a 1-D model to predict the $\mathrm{NO}$ and $\mathrm{NO}_{2}$ vertical profiles as a function of height above the snowpack. While this study did not include a description of snow physics, the volume fluxes predicted from the model are in good agreement with prior work in Antarctica (Jones et al., 2011) and provided an initial step towards understanding the feasibility of predicting the measured fluxes using a model.

The first full 1-D model of air-snow interactions was presented by Thomas et al. $(2011,2012)$. While simple and reasonable in the representation of snow physics, the model included the most sophisticated reaction mechanism for airsnow interactions involving $\mathrm{NO}_{\mathrm{x}}$ to date. The model was used to understand both $\mathrm{NO}$ and $\mathrm{BrO}$ measurements at Summit, Greenland, during a three-day focus period of summer 2008. For the purposes of their study, Thomas et al. (2011) used primarily aqueous-phase chemistry to describe the liquid layer and varied the initial nitrate concentrations in the liquid volume so that the model results matched measured NO concentrations in the boundary layer. The remaining fraction of nitrate was treated as unavailable for photochemistry. This was motivated, in part, by an observed fractionation of nitrate between the ice surface and interior reservoirs in a recent laboratory study (Wren and Donaldson, 2011). If nitrate, in fact, is more concentrated in the liquid layer, then it is possible that nitrate reacts via different pathways in environmental snow, for example with precipitates or with organic molecules. For halogens, this study included all of the measured halide ions in melted surface snow $(\mathrm{Br}$ and $\mathrm{Cl})$ in the reactive liquid volume. The concentrations for formaldehyde and $\mathrm{H}_{2} \mathrm{O}_{2}$ were initialised according to their aqueous Henry's law equilibrium concentrations. Mass transfer was treated according to Schwartz (1986), including diffusionlimited Henry's law equilibrium to the liquid fraction and the interstitial air. In the snowpack photolysis rates varied with depth according to measured e-folding depth for nitrate at Summit. This study showed that reactions in the liquid layer followed by transfer to the interstitial air and venting of the snowpack (by wind pumping and diffusion) can explain the levels of NO and BrO measured at Summit. However, it required the assumption that not the entire nitrate is available for photolysis to match field observations. Therefore, either reaction rates in the snow are indeed different from those in the liquid, or nitrate preferentially does not accumulate in the liquid fraction of snow. The use of other aqueous-phase parameters, such as Henry law's constant and 
acid-base equilibrium, or the location of the reactive liquid could also affect the model.

More recently, Toyota et al. (2013b, a) have developed a snow-boundary layer 1-D model of bromine, ozone, and mercury chemistry (PHANTAS) that was used to study ozone depletion events in the Arctic (Toyota et al., 2013b). The model uses a similar approach to that of Thomas et al. (2011) for modelling the snowpack, with a few notable exceptions. In PHANTAS, the concentration of chloride in the snow liquid fraction is given as a function of temperature according to Cho et al. (2002). In addition, the model includes vertical diffusion in the condensed phase of the snowpack for species dissolved in the liquid fraction. This study suggests that bromine release from the snowpack is sufficient to lead to an ozone depletion event, which is in agreement with recent experiments by Pratt et al. (2013). They also investigated the role of snowpack photochemistry in contributing to atmospheric mercury depletion events (Toyota et al., 2013a). Given that this is the first 1-D model used to investigate whether snowpack chemistry can initiate and sustain bromine explosion events, which cause complete ozone depletion in the polar boundary layer, it is clear that future work will be needed to fully understand the connection between snowpack photochemistry and Arctic atmospheric chemistry. Future work on appropriate parameterisations and representation of snow chemistry in models should clarify the uncertainty associated with how these processes are represented.

\subsection{Conclusions about chemistry}

Chemistry in ice and at ice surfaces under conditions relevant to the troposphere is a relatively new area of study. The work discussed above reflects the complexity of ice and snow as a host for chemical reactions. Nevertheless, important insight into the chemical fate of atmospheric species in frozen aqueous media can be summarised as follows.

1. A very important factor in the apparent rate of chemical reactions in environmental snow is the presence of a multiphase system, where liquid solutions and ice coexist. Many chemical reactions investigated so far proceed more efficiently in the presence of a liquid phase as compared to the ice matrix. In particular, the freeze-concentration effect results in significant acceleration of observed rates. This is of importance for a number of reactive systems because reactions that are negligible in dilute solutions may become important in snow-liquid multiphase systems due to increased concentrations in the brine and, on occasion, freeze-potential effects. Aqueous-phase kinetics describe the concentration-dependent chemistry well. This has been shown for heterogeneous reactions such as bromide ozonation, as well as for reactions that occur within bulk regions of ice such as micro-veins and pockets. Variables such as temperature and total solute concentration will determine the liquid content of the snow and the reagent concentrations and, thus, the observed reaction rates. This underlines the importance of identifying the presence of liquid or brine in laboratory ice samples and in ice in environmental settings.

2. Some reactions were found to be moderately accelerated in ice compared to aqueous samples. By analogy with the freeze-concentration effect, the higher apparent rates can be understood as a consequence of high local reagent concentrations. Other types of reactions were found to proceed with similar or even reduced apparent rates in ice compared to the liquid phase. This shows that factors other than local concentration can influence the observed reactivity. Changes in mechanism, local chemical environment, and the local physical environment were discussed, but more studies are needed to develop a quantitative understanding of chemistry in snow. In particular, unimolecular reactions such as direct photolysis show similar quantum yields and reaction rates in ice as in aqueous solution. Parameterising these reactions based on aqueousphase reaction rates might thus be justified.

3. Heterogeneous chemistry at the ice surface was found to be uniquely different from that in the bulk water and on water surfaces. In these instances, parameterisation based on aqueous-phase chemistry is not appropriate. First-order heterogeneous rate coefficients specific to ice surfaces should be used. Unfortunately, only a few rate coefficients for reactions at ice surfaces have been measured and more work is needed. How the surface disorder that occurs naturally on snow crystals is an important outstanding issue.

As is the case for many areas of environmental study, the measurement of reaction kinetics and products at environmentally relevant reagent concentrations is technically challenging. As analytical techniques gain sensitivity, revisiting important reactions at environmentally relevant reagent concentrations will provide links between laboratory experiments and field observations. A second critical difference between laboratory studies and settings in the field is that in laboratory studies the ice matrix is often frozen from liquid solutions, whereas environmental snow forms mostly by water vapour condensation. Thus reactions that occur during the freezing process might be of relevance for wet snow, but not for dry snow at colder temperatures. Little is known about the reactivity in environmental snow in liquid compartments in dry snow. Impurities will lead to the formation of small amounts of highly concentrated solutions above the specific eutectic temperatures. Whether these brines also represent reservoirs for other impurities, or whether different impurities mix there to foster reactivity, is unknown.

Despite the challenges involved, these advances are essential for developing correct descriptions of environmental 
processes used in models. Reactive species are localised in a liquid environment with a constant volume that takes concentration enhancements due to the reduced volume of this liquid fraction into account. A similar approach was used to reproduce laboratory experiments investigating the photolysis of nitrate in snow (Honrath et al., 2000; Dubowski et al., 2002; Jacobi and Hilker, 2007; Bock and Jacobi, 2010; Jacobi, 2011). Over time the applied chemical mechanisms were upgraded from very simplified mechanisms as presented by Liao and Tan (2008) to the most advanced model to date presented by Thomas et al. (2011). The most advanced model extended an existing atmospheric 1-D chemistry model including gas-phase, aqueous-phase, and heterogeneous chemistry using additional layers to represent chemical processes in the snow. Nevertheless, a full representation of the distinct compartments (bulk ice, grain boundaries, ice surface, liquid brine, solid precipitates) and the different physicochemical processes has not yet been attempted, in part due to the difficulty in treating the non-equilibrium chemical processes in these complex environments. Significant developments in modelling these processes will be needed in the future, but will require close cooperation between laboratory scientists, measurement campaigns, and a corresponding development of an interdisciplinary model community capable of including these complex processes in models.

\section{Synthesis and outlook}

Snow is of great interest in a number of scientific disciplines ranging from fundamental materials science to applied environmental science (Bartels-Rausch et al., 2012). In this review, we focus on atmospheric and cryospheric science of the polar regions, where chemistry and physical processes in snow have a far-ranging environmental impact (Grannas et al., 2013). The focus was placed on studies that showed the interplay of impurities with snow and ice and that characterised the structural environment down to a molecular level. It was demonstrated that the structural and chemical environment of impurities varies significantly depending on their location within the snowpack and that for their fate the knowledge of the distribution of impurities between individual compartments and the description of chemical and physical processes therein is crucial. For example, a sound parameterisation has been developed based on well-defined laboratory studies for the uptake of a number of atmospherically relevant trace gases to ice surfaces. Chemical reactivity studies focused mainly on photochemical reactions and on bimolecular reactions in freezing systems. The chemistry during freezing and in partially frozen multiphase systems seems to be well understood taking concentrations in the remaining liquid phase into account. For the chemistry in ice a detailed parameterisation cannot yet be given; apparent rates show large deviations for individual studies. Important fac- tors explaining the observed reaction rates are local concentration, physical and chemical environment, and mechanism changes. Clearly, more studies are needed in particular at low reagent concentrations. Previous modelling attempts in snow chemistry have addressed specific questions such as the conservation of $\mathrm{H}_{2} \mathrm{O}_{2}$ and formaldehyde in snow, firn, and ice or the release of reactive species from the snowpack to the atmosphere. The objectives of the respective studies have determined the degree of the complexity of the physical and chemical parts of the snow models: simulation of snow and firn profiles of $\mathrm{H}_{2} \mathrm{O}_{2}$ and formaldehyde have emphasised the role of long-term physical and meteorological processes (e.g. accumulation, compaction, exchange between the gas phase and the bulk solid), while the studies of the nitrate photolysis concentrated on a sophisticated representation of fast chemical processes and the transport in the firn air. So far neither of the models has included fully coupled snow physics and chemistry in which the physical properties of the snowpack and its changes over time were fully simulated to deliver a consistent frame for the modelling of the chemical processes in the snowpack.

Understanding and modelling chemistry in snow will remain difficult since our current knowledge of many crucial components is still very limited. A key issue is the distribution of impurities. For example, most of the described models including chemical reactions assume that these reactions take place in a liquid environment in the snow matrix (Michalowski et al., 2000; Boxe and Saiz-Lopez, 2008; Bock and Jacobi, 2010; Thomas et al., 2012). This approach seems well justified when liquid brine is present. Laboratory work has clearly shown that even small amounts of aqueous solution can dominate the chemical reactivity, exchange of trace gases, and distribution of impurities in snow. This induced melting and brine formation is one way of how impurities can change the structure and composition of snow. Some experiments indicated that the concentrations in such a brine fraction can be deduced assuming a simple thermodynamic equilibrium approach using ideal behaviour of the solutes (Cho et al., 2002). Therefore, such an approach to define initial concentration of solutes in a given volume of brine has been used by Boxe and Saiz-Lopez (2008) and during further studies based on laboratory experiments (Jacobi and Hilker, 2007; Bock and Jacobi, 2010; Jacobi, 2011). A recent study refined this approach, taking into account the non-ideal behaviour of the solutes in the highly concentrated brine (Kuo et al., 2011), leading to a better agreement with previous laboratory experiments. Open issues in this treatment remain the precipitation of solutes when solubility limits are reached (Jacobi, 2011), the solubility of impurities in the ice crystal, and the trapping of impurities in solid deposits, such as aerosols, within the snow.

While thermodynamics predict the concentration of brine for a given amount of impurities in a snow sample, uncertainties with this approach stem from unpredictable fractionation of impurities between the air-ice interface and the bulk ice 
phase. Further, such brine in snow does not necessarily form one connected phase, and little is known about the mixing of impurities, which is essential for efficient reactivity. For example, Thomas et al. (2012) found best agreement between simulations and observations if a fraction of only $6 \%$ of the measured nitrate in the snow was present at the surface of the snow crystals. As the fractionation of solutes between the surface and interior of snow crystals is highly concentrationdependent, it remains unclear whether a similar fractionation of nitrate can also be applied to a snowpack with different nitrate or sea salt concentrations or at different temperatures. Alternatively this may indicate that reaction rates in the liquid fraction of snow differ from those in aqueous solutions. This is an inherent problem of snow-chemistry models: with the increase in complexity needed to capture observations, they become less confined. In principle, this thermodynamic approach holds only down to the temperature of the eutectic point, at which all components form a solid phase. Nevertheless, a concentrated liquid fraction has been observed well below the eutectic temperature of a bulk ice sample (Cho et al., 2002). Surface-sensitive spectroscopy, on the other hand, gave no indication of liquid below the eutectic (Křepelová et al., 2010a). Possibly, the liquid observed in the bulk sample was located in nanometre-sized micro-pockets that formed during the rapid freezing of the highly concentrated solutions used in that study. Just as in small aerosol droplets, freezing might be inhibited by steric reasons in such small compartments. Projections to environmental snow might thus be highly questionable. Precise knowledge of the location of impurities is thus important and a unifying theory describing the liquid fraction of ice covering the range of temperatures and impurity concentrations observed in natural snow still needs to be developed.

Modelling and interpretation of laboratory results have been based on the existence of a disordered interface on ice with properties similar to liquid water. This very simplified picture to describe the disordered interface has been used successfully in thermodynamic frameworks, and is somehow supported by water diffusion measurements on ice surfaces. Also molecular dynamics simulations indicate that in a very thick disordered interface the upper part has structural features approaching those of a supercooled liquid. However, describing the surface disorder as a homogeneous liquid-like phase contradicts direct observations showing distinct structural differences between the disordered interface and a liquid phase. Further, the properties of such a layer, such as thickness and volume, and their dependence on temperature remain poorly defined. However, most studies on pure ice indicate that the disordered interface remains rather thin with structural features highly influenced by the underlying solid crystal. This and the widespread presence of impurities in the field make this disordered interface less relevant for understanding snow chemistry in polar regions. It is clear that impurities increase the thickness of the disorder. Recent simulations and direct observations, however, indicate that the impact of impurities on the hydrogen-bonding network at the ice surface is limited to their vicinity where they form a hydration shell. This means that the impurity experiences an environment similar to an aqueous solution even when the disordered interface is very thin and that the molecular structure at the ice surface may be very heterogeneous. Further studies are needed for a larger set of impurities and with different methods. How the local disorder induced by some impurities influences the uptake, distribution and chemistry of other impurities is an essential open issue. Approaching the melting point, the lack of knowledge of the surface disorder even increases, as the number of studies investigating the surface disorder and its effects just below the melting point are limited.

It is generally assumed that no reactions take place in the solid phase of the snow grains due to the reduced mobility of the products or because these reactions are too slow. Nevertheless, this portion can constitute an important reservoir for reactive species like $\mathrm{H}_{2} \mathrm{O}_{2}$ and possibly also for nitrate. In these cases, adsorption, desorption and solid-state diffusion need to be considered for the successful modelling of concentration profiles in snow, firn, and ice on longer timescales (Hutterli et al., 2003).

The potential role of aerosol deposits as a host of impurities and of chemical reactions has not been investigated in laboratory or modelling studies (Domine and Shepson, 2002; Domine et al., 2013).

For the description of chemical processes in models - including photochemical reactions, adsorption and desorption on the grain surfaces, diffusion inside the grains, and transport in the interstitial air - physical snow properties like temperature, density, grain shape and structure are crucial. In many models, the physical properties have been assumed to be constant and were based on observations. Such an approach is reasonable for the structural parameters like density and grain shape if the simulations are restricted to shorter periods like several days and excluding fresh snow. However, even on this timescale the snow temperature undergoes variations linked to diurnal cycles in radiation or rapid changes in the air temperatures, so that an explicit description of the evolution of the temperature will be needed. Recent advances in X-ray-computed microtomography have enabled us to observe the changes in the structure of a snow sample in situ under such temperature gradients. These studies have revealed huge water mass fluxes on timescales of days (Pinzer and Schneebeli, 2009b; Pinzer et al., 2012). An explicit description of the evolution of the temperature will be needed in future simulations for longer periods (weeks to multi-annual cycles), and changes in the snowpack properties due to metamorphism and compaction need to be considered. Moreover, the fate of impurities during this movement of water molecules and the restructuring of the snow structure is an essential, yet open, issue. Laboratory experiments with growing ice showed that particularly strong acids are buried by growing ice films, leading to an enhanced uptake 
from the gas phase. More studies are needed to asses the fate of impurities in snow that is not in equilibrium with the water-vapour pressure. The rate and timing of snow accumulation are important factors determining the direct input and the release of volatile impurities to the snow in the case of $\mathrm{H}_{2} \mathrm{O}_{2}$ and formaldehyde (Hutterli et al., 2003). Furthermore, even in polar regions fresh snow can undergo rapid changes, contributing to an enhancement of the release of incorporated but volatile species like formaldehyde (Jacobi et al., 2002). Snow physics models with varying complexities exist to reproduce the development of snow properties (Schwander, 1989; Brun et al., 1989; McConnell et al., 1998; Hutterli et al., 1999; Bartelt and Lehning, 2002; Lehning et al., 2002). Although some of these models were developed to contribute to the forecasting of avalanches in the Alps, further studies have shown their general applicability also to other snowpack types (e.g. Lejeune et al., 2007; Jacobi et al., 2010) and even to the simulation of snowpack properties on the top of the large ice sheet (Genthon et al., 2001; Brun et al., 2011). Although the existing snow physics models still contain simplified parameterisation of important processes (e.g. Etchevers et al., 2004) and need to be developed further, such models can constitute a useful physical frame for the simulation of chemical processes in the snow in a 1-D model on different timescales.

Acknowledgements. This review was initiated and planned during the 3rd Workshop on Air-Ice Chemical Interactions held in June 2011, in New York, NY. The workshop was sponsored in part by IGAC and the Columbia University School of Engineering and Applied Sciences. T. Bartels-Rausch and M. Ammann appreciate support by the Swiss National Science Foundation (grants $121857,125179,140400$, and 149629) and valuable input to this review by Sepp Schreiber. H.-W. Jacobi acknowledges support by the LEFE-CHAT program of INSU-CNRS. E. S. Thomson and J. B. C. Pettersson benefit from the scientific support of the Swedish Research Council and the Nordic top-level research initiative CRAICC. M. H. Kuo, V. F. McNeill, and S. G. Moussa acknowledge a NSF CAREER award for V. F. McNeill (ATM0845043). M. Roeselová acknowledges support from the Czech Science Foundation (grant P208/10/1724) and RVO 61388963. P. Klán and D. Heger appreciate support by the Czech Science Foundation (P503/10/0947), and the project CETOCOEN (CZ.1.05/2.1.00/01.0001) granted by the European Regional Development Fund. M. I. Guzmán thanks the U.S. National Science Foundation for a CAREER award (CHE-1255290). F. Domine thanks the French Polar Institute (IPEV) for continuous support. H. Bluhm acknowledges support from the Director, Office of Science, Office of Basic Energy Sciences, and by the Division of Chemical Sciences, Geosciences, and Biosciences of the U.S. Department of Energy under Contract Nr. DE-AC02-05CH11231. J. T. Newberg acknowledges support from an NSF Postdoctoral Fellowship (ANT-1019347).

Edited by: E. Wolff

\section{References}

Abbatt, J. P. D.: Interaction of $\mathrm{HNO}_{3}$ with water-ice surfaces at temperatures of the free troposphere, Geophys. Res. Lett., 24, 14791482, doi:10.1029/97GL01403, 1997.

Abbatt, J. P. D.: Interactions of atmospheric trace gases with ice surfaces: Adsorption and reaction, Chem. Rev., 103, 4783-4800, doi:10.1021/Cr0206418, 2003.

Abbatt, J.: Atmospheric chemistry: Arctic snowpack bromine release, Nature Geosci, 6, 331-332, doi:10.1038/ngeo1805, 2013.

Abbatt, J. P. D., Beyer, K. D., Fucaloro, A. F., McMahon, J. R., Wooldridge, P. J., Zhang, R., and Molina, M. J.: Interaction of $\mathrm{HCl}$ vapor with water-ice - Implications for the stratosphere, J. Geophys. Res., 97, 15819-15826, doi:10.1029/92JD01220, 1992.

Abbatt, J. P. D., Bartels-Rausch, T., Ullerstam, M., and Ye, T. J.: Uptake of acetone, ethanol and benzene to snow and ice: Effects of surface area and temperature, Environ. Res. Lett., 3, 045008, doi:10.1088/1748-9326/3/4/045008, 2008.

Abbatt, J. P. D., Thomas, J. L., Abrahamsson, K., Boxe, C., Granfors, A., Jones, A. E., King, M. D., Saiz-Lopez, A., Shepson, P. B., Sodeau, J., Toohey, D. W., Toubin, C., von Glasow, R., Wren, S. N., and Yang, X.: Halogen activation via interactions with environmental ice and snow in the polar lower troposphere and other regions, Atmos. Chem. Phys., 12, 6237-6271, doi:10.5194/acp-12-6237-2012, 2012.

Abida, O. and Osthoff, H. D.: On the $\mathrm{pH}$ dependence of photoinduced volatilization of nitrogen oxides from frozen solutions containing nitrate, Geophys. Res. Lett., 38, L16808, doi:10.1029/2011GL048517, 2011.

Aguzzi, A., Fluckiger, B., and Rossi, M.: The nature of the interface and the diffusion coefficient of $\mathrm{HCl} /$ ice and $\mathrm{HBr}$ /ice in the temperature range 190-205 K, Phys. Chem. Chem. Phys., 5, 41574169, doi:10.1039/b308422c, 2003.

Allouche, A. and Bahr, S.: Acetic acid-water interaction in solid interfaces, J. Phys. Chem. B, 110, 8640-8648, doi:10.1021/jp0559736, 2006.

Alsayed, A., Islam, M., Zhang, J., Collings, P., and Yodh, A.: Premelting at defects within bulk colloidal crystals, Science, 309, 1207-1210, doi:10.1126/science.1112399, 2005.

Anastasio, C. and Chu, L.: Photochemistry of nitrous acid (HONO) and nitrous acidium ion $\left(\mathrm{H}_{2} \mathrm{ONO}^{+}\right)$in aqueous solution and ice, Environ. Sci. Technol., 43, 1108-1114, doi:10.1021/es802579a, 2009.

Anastasio, C., Galbavy, E., Hutterli, M., Burkhart, J., and Friel, D.: Photoformation of hydroxyl radical on snow grains at Summit, Greenland, Atmos. Environ., 41, 5110-5121, doi:10.1016/J.Atmosenv.2006.12.011, 2007.

Anklin, M. and Bales, R. C.: Recent increase in $\mathrm{H}_{2} \mathrm{O}_{2}$ concentration at Summit, Greenland, J. Geophys. Res., 102, 19099-19104, doi:10.1029/97JD01485, 1997.

Aristov, Y. I., Marco, G., Tokarev, M. M., and Parmon, V. N.: Selective water sorbents for multiple applications, $3 . \mathrm{CaCl}_{2}$ solution confined in micro- and mesoporous silica gels: Pore size effect on the 'solidification-melting' diagram, React. Kinet. Catal. L., 61, 147-154, doi:10.1007/BF02477527, 1997.

Arons, E. M. and Colbeck, S. C.: Geometry of heat and masstransfer in dry snow - a review of theory and experiment, Rev. Geophys., 33, 463-493, doi:10.1029/95RG0207, 1995. 
Baker, I., Cullen, D., and Iliescu, D.: The microstructural location of impurities in ice, Can. J. Phys., 81, 1-9, doi:10.1139/p03-030, 2003.

Baker, M. and Dash, J. G.: Comment on: Surface layers on ice by CA Knight., J. Geophys. Res., 101, 12929-12936, doi:10.1029/96JD00555, 1996.

Ballenegger, V., Picaud, S., and Toubin, C.: Molecular dynamics study of diffusion of formaldehyde in ice, Chem. Phys. Lett., 432, 78-83, doi:10.1016/j.cplett.2006.10.014, 2006.

Barnes, P. and Wolff, E.: Distribution of soluble impurities in cold glacial ice, J. Glaciol., 50, 311-324, doi:10.3189/172756504781829918, 2004.

Barnes, P., Mulvaney, R., Robinson, K., and Wolff, E.: Observations of polar ice from the holocene and the glacial period using the scanning electron microscope, Ann. Glaciol., 35, 559-566, doi:10.3189/172756402781816735, 2002.

Barret, M., Domine, F., Houdier, S., Gallet, J.-C., Weibring, P., Walega, J., Fried, A., and Richter, D.: Formaldehyde in the Alaskan Arctic snowpack: Partitioning and physical processes involved in air - snow exchanges, J. Geophys. Res., 116, D00R03, doi:10.1029/2011JD016038, 2011a.

Barret, M., Houdier, S., and Domine, F.: Thermodynamics of the formaldehyde - water and formaldehyde - ice systems for atmospheric applications, J. Phys. Chem. A, 115, 307-317, doi:10.1021/jp108907u, 2011b.

Bartels-Rausch, T., Guimbaud, C., Gäggeler, H. W., and Ammann, M.: The partitioning of acetone to different types of ice and snow between 198 and 223 K, Geophys. Res. Lett., 31, L16110, doi:10.1029/2004g1020070, 2004.

Bartels-Rausch, T., Huthwelker, T., Gäggeler, H. W., and Ammann, M.: Atmospheric pressure coated-wall flow-tube study of acetone adsorption on ice, J. Phys. Chem. A, 109, 4531-4539, doi:10.1021/Jp0451871, 2005.

Bartels-Rausch, T., Brigante, M., Elshorbany, Y., Ammann, M., D’Anna, B., George, C., Stemmler, K., Ndour, M., and Kleffmann, J.: Humic acid in ice: Photo-enhanced conversion of nitrogen dioxide into nitrous acid, Atmos. Environ., 44, 5443-5450, doi:10.1016/j.atmosenv.2009.12.025, 2010.

Bartels-Rausch, T., Krysztofiak, G., Bernhard, A., Schläppi, M., Schwikowski, M., and Ammann, M.: Photoinduced reduction of divalent mercury in ice by organic matter, Chemosphere, 82 , 199-203, doi:10.1016/j.chemosphere.2010.10.020, 2011.

Bartels-Rausch, T., Bergeron, V., Cartwright, J. H. E., Escribano, R., Finney, J. L., Grothe, H., Gutierrez, P. J., Haapala, J., Kuhs, W. F., Pettersson, J. B. C., Price, S. D., Sainz-Diaz, C. I., Stokes, D. J., Strazzulla, G., Thomson, E. S., Trinks, H., and Uras-Aytemiz, N.: Ice structures, patterns, and processes: A view across the icefields, Rev. Mod. Phys., 84, 885-944, doi:10.1103/RevModPhys.84.885, 2012.

Bartels-Rausch, T., Wren, S. N., Schreiber, S., Riche, F., Schneebeli, M., and Ammann, M.: Diffusion of volatile organics through porous snow: Impact of surface adsorption and grain boundaries, Atmos. Chem. Phys., 13, 6727-6739, doi:10.5194/acp-13-6727-2013, 2013.

Bartelt, P. and Lehning, M.: A physical SNOWPACK model for the Swiss avalanche warning part I: Numerical model, Cold Reg. Sci. Technol., 35, 123-145, 2002.

Bauerecker, S., Ulbig, P., Buch, V., Vrbka, L., and Jungwirth, P.: Monitoring ice nucleation in pure and salty water via high-speed imaging and computer simulations, J. Phys. Chem. C, 112, 76317636, doi:10.1021/jp711507f, 2008.

Beaglehole, D.: Surface melting of small particles, and the effects of surface impurities, J. Cryst. Growth, 112, 663-669, doi:10.1016/0022-0248(91)90123-M, 1991.

Beine, H. and Anastasio, C.: The photolysis of flash-frozen dilute hydrogen peroxide solutions, J. Geophys. Res., 116, D14302, doi:10.1029/2010JD015531, 2011.

Beine, H. J., Anastasio, C., Esposito, G., Patten, K., Wilkening, E., Domine, F., Voisin, D., Barret, M., Houdier, S., and Hall, S.: Soluble, light-absorbing species in snow at Barrow, Alaska, J. Geophys. Res., 116, D00R05, doi:10.1029/2011JD016181, 2011.

Benatov, L. and Wettlaufer, J.: Abrupt grain boundary melting in ice, Phys. Rev. E, 70, 061606, doi:10.1103/PhysRevE.70.061606, 2004.

Birkeland, K. W., Johnson, R. F., and Schmidt, D. S.: Near-surface faceted crystals formed by diurnal recrystallization: A case study of weak layer formation in the mountain snowpack and its contribution to snow avalanches, Arctic Alpine Res., 30, 200-204, 1998.

Bishop, C. L., Pan, D., Liu, L.-M., Tribello, G. A., Michaelides, A., Wang, E. G., and Slater, B.: On thin ice: Surface order and disorder during pre-melting, Faraday Discuss., 141, 277-292, doi:10.1039/b807377p, 2009.

Blackford, J. R.: Sintering and microstructure of ice: A review, J. Phys. D Appl. Phys., 40, R355-R385, doi:10.1088/00223727/40/21/R02, 2007.

Blackford, J. R., Jeffree, C. E., Noake, D. F. J., and Marmo, B. A.: Microstructural evolution in sintered ice particles containing $\mathrm{NaCl}$ observed by low-temperature scanning electron microscope, P. I. Mech. Eng. L - J. Mat., 221, 151-156, doi:10.1243/14644207JMDA134, 2007.

Bláha, L., Klánová, J., Klán, P., Janošek, J., Škarek, M., and Růžička, R.: Toxicity increases in ice containing monochlorophenols upon photolysis: Environmental consequences, Environ. Sci. Technol., 38, 2873-2878, doi:10.1021/es035076k, pMID: 15212262, 2004.

Blicks, H., Dengel, O., and Riehl, N.: Diffusion von Protonen (Tritonen) in reinen und dotierten Eis-Einkristallen, Phys. kondens. Materie, 4, 375-381, doi:10.1007/BF02422755, 1966.

Bluhm, H., Ogletree, D. F., Fadley, C. S., Hussain, Z., and Salmeron, M.: The premelting of ice studied with photoelectron spectroscopy, J. Phys.: Condens. Matter, 14, L227-L233, doi:10.1088/0953-8984/14/8/108, 2002.

Bock, J. and Jacobi, H.-W.: Development of a mechanism for nitrate photochemistry in snow, J. Phys. Chem. A, 114, 1790-1796, doi:10.1021/jp909205e, 2010.

Bogdan, A.: Double freezing of $\left(\mathrm{NH}_{4}\right)_{2} \mathrm{SO}_{4} / \mathrm{H}_{2} \mathrm{O}$ droplets below the eutectic point and the crystallization of $\left(\mathrm{NH}_{4}\right)_{2} \mathrm{SO}_{4}$ to the ferroelectric phase, J. Phys. Chem. A, 114, 10135-10139, doi:10.1021/jp105699s, 2010.

Bolton, K. and Pettersson, J. B. C.: A molecular dynamics study of the long-time ice Ih surface dynamics, J. Phys. Chem. B, 104, 1590-1595, doi:10.1021/jp9934883, 2000.

Boxe, C. S. and Saiz-Lopez, A.: Multiphase modeling of nitrate photochemistry in the quasi-liquid layer (QLL): implications for $\mathrm{NO}_{\mathrm{x}}$ release from the Arctic and coastal Antarctic snowpack, Atmos. Chem. Phys., 8, 4855-4864, doi:10.5194/acp-8-4855-2008, 2008. 
Bronshteyn, V. and Chernov, A.: Freezing potentials arising on solidification of dilute aqueous solutions of electrolytes, J. Cryst. Growth, 112, 129-145, doi:10.1016/0022-0248(91)90918-U, 1991.

Brun, E., Martin, E., Simon, V., Gendre, C., and Coleou, C.: An energy and mass model of snow cover suitable for operational avalanche forecasting, J. Glaciol., 35, 333-342, 1989.

Brun, E., David, P., Sudul, M., and Brunot, G.: A numerical-model to simulate snow-cover stratigraphy for operational avalanche forecasting, J. Glaciol., 38, 13-22, 1992.

Brun, E., Six, D., Picard, G., Vionnet, V., Arnaud, L., Bazile, E., Boone, A., Bouchard, A., Genthon, C., Guidard, V., Le Moigne, P., Rabier, F., and Seity, Y.: Snow/atmosphere coupled simulation at Dome C, Antarctica, J. Glaciol., 57, 721-736, 2011.

Burkhart, J. F., Hutterli, M. A., and Bales, R. C.: Partitioning of formaldehyde between air and ice at $-35^{\circ} \mathrm{C}$ to $-5^{\circ} \mathrm{C}$, Atmos. Environ., 36, 2157-2163, doi:10.1016/S1352-2310(02)00221-2, 2002.

Carignano, M. A., Baskaran, E., Shepson, P. B., and Szleifer, I.: Molecular dynamics simulation of ice growth from supercooled pure water and from salt solution, Ann. Glaciol., 44, 113-117, doi:10.3189/172756406781811646, 2006.

Carignano, M. A., Shepson, P. B., and Szleifer, I.: Ions at the ice/vapor interface, Chem. Phys. Lett., 436, 99-103, doi:10.1016/j.cplett.2007.01.016, 2007.

Cheng, J., Hoffmann, M. R., and Colussi, A. J.: Confocal fluorescence microscopy of the morphology and composition of interstitial fluids in freezing electrolyte solutions, J. Phys. Chem. Lett., 1, 374-378, doi:10.1021/jz9000888, 2010.

Cho, H., Shepson, P. B., Barrie, L. A., Cowin, J. P., and Zaveri, R.: NMR investigation of the quasi-brine layer in ice/brine mixtures, J. Phys. Chem. B, 106, 11226-11232, doi:10.1021/jp020449+, 2002.

Christenson, H. K.: Confinement effects on freezing and melting, J. Phys.: Condens. Matter, 13, R95-R133, doi:10.1088/09538984/13/11/201, 2001

Chu, L. and Anastasio, C.: Quantum yields of hydroxyl radical and nitrogen dioxide from the photolysis of nitrate on ice, J. Phys. Chem. A, 107, 9594-9602, doi:10.1021/jp0349132, 2003.

Chu, L. and Anastasio, C.: Formation of hydroxyl radical from the photolysis of frozen hydrogen peroxide, J. Phys. Chem. A, 109, 6264-6271, doi:10.1021/jp051415f, 2005.

Chu, L. and Anastasio, C.: Temperature and wavelength dependence of nitrite photolysis in frozen and aqueous solutions, Environ. Sci. Technol., 41, 3626-3632, doi:10.1021/es062731q, 2007.

Clapsaddle, C. and Lamb, D.: The sorption behavior of $\mathrm{SO}_{2}$ on ice at temperatures between $-30{ }^{\circ} \mathrm{C}$ and $-5^{\circ} \mathrm{C}$, Geophys. Res. Lett., 16, 1173-1176, doi:10.1029/GL016i010p01173, 1989.

Clarke, D. R.: On the equilibrium thickness of intergranular glass phases in ceramic materials, J. Am. Ceram. Soc., 70, 15-22, doi:10.1111/j.1151-2916.1987.tb04846.x, 1987.

Clegg, S. M. and Abbatt, J. P. D.: Uptake of gas-phase $\mathrm{SO}_{2}$ and $\mathrm{H}_{2} \mathrm{O}_{2}$ by ice surfaces: dependence on partial pressure, temperature, and surface acidity, J. Phys. Chem. A, 105, 6630-6636, doi:10.1021/jp010062r, 2001.

Cobb, A. and Gross, G.: Interfacial electrical effects observed during the freezing of dilute electrolytes in water, J. Electrochem. Soc., 116, 796-804, 1969.
Cohen, S. R., Weissbuch, I., PopovitzBiro, R., Majewski, J., Mauder, H. P., Lavi, R., Leiserowitz, L., and Lahav, M.: Spontaneous assembly in organic thin films spread on aqueous subphase: A scanning force microscope (SFM) study, Isr. J. Chem., 36, 97-110, 1996.

Compoint, M., Toubin, C., Picaud, S., Hoang, P. N. M., and Girardet, C.: Geometry and dynamics of formic and acetic acids adsorbed on ice, Chem. Phys. Lett., 365, 1-7, doi:10.1016/S00092614(02)01413-6, 2002.

Conde, M. M., Vega, C., and Patrykiejew, A.: The thickness of a liquid layer on the free surface of ice as obtained from computer simulation, J. Chem. Phys., 129, 014702, doi:10.1063/1.2940195, 2008.

Conklin, M. H. and Bales, R. C.: $\mathrm{SO}_{2}$ uptake on ice spheres - liquid nature of the ice-air interface, J. Geophys. Res., 98, 1685116855, doi:10.1029/93JD0120, 1993.

Conklin, M. H., Sigg, A., Neftel, A., and Bales, R. C.: Atmospheresnow transfer-function for $\mathrm{H}_{2} \mathrm{O}_{2}-$ microphysical considerations, J. Geophys. Res., 98, 18367-18376, doi:10.1029/93JD01194, 1993.

Cox, R., Fernandez, M., Symington, A., Ullerstam, M., and Abbatt, J. P. D.: A kinetic model for uptake of $\mathrm{HNO}_{3}$ and $\mathrm{HCl}$ on ice in a coated wall flow system, Phys. Chem. Chem. Phys., 7, 3434 3442, doi:10.1039/b506683b, 2005.

Crowley, J. N., Ammann, M., Cox, R. A., Hynes, R. G., Jenkin, M. E., Mellouki, A., Rossi, M. J., Troe, J., and Wallington, T. J.: Evaluated kinetic and photochemical data for atmospheric chemistry: Volume V - Heterogeneous reactions on solid substrates, Atmos. Chem. Phys., 10, 9059-9223, doi:10.5194/acp-10-90592010, 2010.

Cullen, D. and Baker, I.: Observation of impurities in ice, Microsc. Res. Tech., 55, 198-207, doi:10.1002/jemt.10000, 2001.

Dadic, R., Schneebeli, M., Lehning, M., Hutterli, M. A., and Ohmura, A.: Impact of the microstructure of snow on its temperature: A model validation with measurements from Summit, Greenland, J. Geophys. Res., 113, D14303, doi:10.1029/2007JD009562, 2008.

Dash, J. G., Fu, H. Y., and Wettlaufer, J. S.: The premelting of ice and its environmental consequences, Rep. Prog. Phys., 58, 115167, doi:10.1088/0034-4885/58/1/003, 1995.

Dash, J. G., Rempel, A. W., and Wettlaufer, J.: The physics of premelted ice and its geophysical consequences, Rev. Mod. Phys., 78, 695-741, doi:10.1103/RevModPhys.78.695, 2006.

Davis, D., Nowak, J. B., Chen, G., Buhr, M., Arimoto, R., Hogan, A., Eisele, F., Mauldin, L., Tanner, D., Shetter, R., Lefer, B., and McMurry, P.: Unexpected high levels of NO observed at South Pole, Geophys. Res. Lett., 28, 3625-3628, doi:10.1029/2000GL012584, 2001.

Davis, D., Chen, G., Buhr, M., Crawford, J., Lenschow, D., Lefer, B., Shetter, R., Eisele, F., Mauldin, L., and Hogan, A.: South Pole $\mathrm{NO}_{\mathrm{x}}$ chemistry: An assessment of factors controlling variability and absolute levels, Atmos. Environ., 38, 5375-5388, doi:10.1016/J.Atmosenv.2004.04.039, 2004.

De Angelis, M. and Legrand, M.: Origins and variations of fluoride in Greenland precipitation, J. Geophys. Res., 99, 1157-1172, doi:10.1029/93JD02660, 1994.

Delibaltas, P., Dengel, O., Helmreich, D., Riehl, N., and Simon, H.: Diffusion von ${ }^{18} \mathrm{O}$ in Eis-Einkristallen, Phys. kondens. Materie, 5, 166, doi:10.1007/BF02422709, 1966. 
Devlin, J. P. and Buch, V.: Evidence for the surface origin of point defects in ice: Control of interior proton activity by adsorbates, J. Chem. Phys., 127, 091101, doi:10.1063/1.2768517, 2007.

Dieckmann, G. S., Nehrke, G., Papadimitriou, S., Göttlicher, J., Steininger, R., Kennedy, H., Wolf-Gladrow, D., and Thomas, D. N.: Calcium carbonate as ikaite crystals in Antarctic sea ice, Geophys. Res. Lett., 35, L08501, doi:10.1029/2008g1033540, 2008.

Dolinová, J., Ružička, R., Kurková, R., Klánová, J., and Klán, P.: Oxidation of aromatic and aliphatic hydrocarbons by $\mathrm{OH}$ radicals photochemically generated from $\mathrm{H}_{2} \mathrm{O}_{2}$ in ice, Environ. Sci. Technol., 40, 7668-7674, doi:10.1021/es0605974, 2006.

Domine, F. and Rauzy, C.: Influence of the ice growth rate on the incorporation of gaseous HCl, Atmos. Chem. Phys., 4, 2513-2519, doi:10.5194/acp-4-2513-2004, 2004.

Domine, F. and Shepson, P. B.: Air-snow interactions and atmospheric chemistry, Science, 297, 1506-1510, doi:10.1126/science.1074610, 2002.

Domine, F. and Thibert, E.: Mechanism of incorporation of trace gases in ice grown from the gas phase, Geophys. Res. Lett., 23, 3627-3630, 1996.

Domine, F., Thibert, E., Vanlandeghem, F., Silvente, E., and Wagnon, P.: Diffusion and solubility of $\mathrm{HCl}$ in ice - preliminaryresults, Geophys. Res. Lett., 21, 601-604, 1994.

Domine, F., Cabanes, A., Taillandier, A. S., and Legagneux, L.: Specific surface area of snow samples determined by $\mathrm{CH}_{4}$ adsorption at $77 \mathrm{~K}$ and estimated by optical, microscopy and scanning electron microscopy, Environ. Sci. Technol., 35, 771-780, doi:10.1021/es001168n, 2001.

Domine, F., Sparapani, R., Ianniello, A., and Beine, H. J.: The origin of sea salt in snow on Arctic sea ice and in coastal regions, Atmos. Chem. Phys., 4, 2259-2271, doi:10.5194/acp-4-2259-2004, 2004.

Domine, F., Albert, M., Huthwelker, T., Jacobi, H.-W., Kokhanovsky, A. A., Lehning, M., Picard, G., and Simpson, W. R.: Snow physics as relevant to snow photochemistry, Atmos. Chem. Phys., 8, 171-208, doi:10.5194/acp-8-171-2008, 2008.

Domine, F., Bock, J., Voisin, D., and Donaldson, D. J.: Can we model snow photochemistry? Problems with the current approaches., J. Phys. Chem. A, 117, 4733-4749, doi:10.1021/jp3123314, 2013.

Dommergue, A. 1., Ferrari, C. P., Gauchard, P.-A., Boutron, C. F., Poissant, L., Pilote, M., Jitaru, P., and Adams, F.: The fate of mercury species in a sub-Arctic snowpack during snowmelt, Geophys. Res. Lett., 30, 1621-1624, doi:10.1029/2003g1017308, 2003.

Döppenschmidt, A. and Butt, H. J.: Measuring the thickness of the liquid-like layer on ice surfaces with atomic force microscopy, Langmuir, 16, 6709-6714, doi:10.1021/la990799w, 2000.

Douglas, T. A., Sturm, M., Simpson, W. R., Blum, J. D., AlvarezAviles, L., Keeler, G. J., Perovich, D. K., Biswas, A., and Johnson, K.: Influence of snow and ice crystal formation and accumulation on mercury deposition to the Arctic, Environ. Sci. Technol., 42, 1542-1551, doi:10.1021/es070502d, 2011.

Dubowski, Y. and Hoffmann, M.: Photochemical transformations in ice: Implications for the fate of chemical species, Geophys. Res. Lett., 27, 3321-3324, doi:10.1029/2000GL011701, 2000.
Dubowski, Y., Colussi, A. J., and Hoffmann, M. R.: Nitrogen dioxide release in the $302 \mathrm{~nm}$ band photolysis of spray-frozen aqueous nitrate solutions. Atmospheric implications, J. Phys. Chem. A, 105, 4928-4932, doi:10.1021/jp0042009, 2001.

Dubowski, Y., Colussi, A. J., Boxe, C., and Hoffmann, M. R.: Monotonic increase of nitrite yields in the photolysis of nitrate in ice and water between 238 and 294 K, J. Phys. Chem. A, 106, 6967-6971, doi:10.1021/jp0142942, 2002.

Durnford, D. and Dastoor, A.: The behavior of mercury in the cryosphere: A review of what we know from observations, J. Geophys. Res., 116, D06305, doi:10.1029/2010JD014809, 2011.

Eichler, A., Schwikowski, M., and Gäggeler, H. W.: Meltwaterinduced relocation of chemical species in Alpine firn, Tellus B 53, 192-203, doi:10.1034/j.1600-0889.2001.d01-15.x, 2001.

Eisele, F., Davis, D. D., Helmig, D., Oltmans, S. J., Neff, W., Huey, G., Tanner, D., Chen, G., Crawford, J., Arimoto, R., Buhr, M., Mauldin, L., Hutterli, M., Dibb, J., Blake, D., Brooks, S. B., Johnson, B., Roberts, J. M., Wang, Y. H., Tan, D., and Flocke, F.: Antarctic tropospheric chemistry investigation (ANTCI) 2003 overview, Atmos. Environ., 42, 2749-2761, doi:10.1016/J.Atmosenv.2007.04.013, 2008.

Elbaum, M., Lipson, S., and Dash, J. G.: Optical study of surface melting on ice, J. Cryst. Growth, 129, 491-505, doi:10.1016/0022-0248(93)90483-D, 1993.

Etchevers, P., Martin, E., Brown, R., Fierz, C., Lejeune, Y., Bazile, E., Boone, A., Dai, Y., Essery, R., Fernandez, A., Gusev, Y., Jordan, R., Koren, V., Kowalcyzk, E., Nasonova, N. O., Pyles, R. D., Schlosser, A., Shmakin, A. B., Smirnova, T. G., Strasser, U., Verseghy, D., Yamazaki, T., and Yang, Z. L.: Validation of the energy budget of an alpine snowpack simulated by several snow models (SNOWMIP project), Ann. Glaciol., 38, 150-158, doi:10.3189/172756404781814825, 2004.

Finnegan, W.: Redox reactions in growing single ice crystals: A mechanistic interpretation of experimental results, J. Colloid Interface Sci., 242, 373-377, doi:10.1006/jcis.2001.7825, 2001.

Finnegan, W. and Pitter, R.: Ion-induced charge separations in growing single ice crystals: Effects on growth and interaction processes, J. Colloid Interface Sci., 189, 322-327, doi:10.1006/jcis.1997.4829, 1997.

Freitag, J., Wilhelms, F., and Kipfstuhl, S.: Microstructuredependent densification of polar firn derived from X-ray microtomography, J. Glaciol., 50, 243-250, doi:10.3189/172756504781830123, 2004.

Frenkel, J.: Kinetic theory of liquids, Clarendon, Oxford, 1946.

Frenken, J. W. and van der Veen, J. F.: Observation of surface melting, Phys. Rev. Lett., 54, 134-137, doi:10.1103/PhysRevLett.54.134, 1985.

Frey, M. M., Stewart, R. W., McConnell, J. R., and Bales, R. C.: Atmospheric hydroperoxides in west Antarctica: Links to stratospheric ozone and atmospheric oxidation capacity, J. Geophys. Res., 110, D23301, doi:10.1029/2005JD006110, 2005.

Frey, M. M., Bales, R. C., and McConnell, J. R.: Climate sensitivity of the century-scale hydrogen peroxide $\left(\mathrm{H}_{2} \mathrm{O}_{2}\right)$ record preserved in 23 ice cores from West Antarctica, J. Geophys. Res., 111, D21301, doi:10.1029/2005JD006816, 2006.

Frey, M. M., Brough, N., France, J. L., Anderson, P. S., Traulle, O., King, M. D., Jones, A. E., Wolff, E. W., and Savarino, J.: The diurnal variability of atmospheric nitrogen oxides (NO and $\mathrm{NO}_{2}$ ) above the Antarctic Plateau driven by atmospheric stabil- 
ity and snow emissions, Atmos. Chem. Phys., 13, 3045-3062, doi:10.5194/acp-13-3045-2013, 2013.

Fries, E., Starokozhev, E., Haunold, W., Jaeschke, W., Mitra, S. K., Borrmann, S., and Schmidt, M. U.: Laboratory studies on the uptake of aromatic hydrocarbons by ice crystals during vapor depositional crystal growth, Atmos. Environ., 41, 6156-6166, doi:10.1016/j.atmosenv.2007.04.028, 2007.

Fuhrer, K., Neftel, A., Anklin, M., and Maggi, V.: Continuous measurements of hydrogen-peroxide, formaldehyde, calcium and ammonium concentrations along the new grip ice core from Summit, central Greenland, Atmos. Environ., 27, 1873-1880, doi:10.1016/0960-1686(93)90292-7, 1993.

Fukazawa, H., Sugiyama, K., Mae, S., Narita, H., and Hondoh, T.: Acid ions at triple junction of Antarctic ice observed by raman scattering, Geophys. Res. Lett., 25, 2845-2848, doi:10.1029/98GL02178, 1998.

Furukawa, Y. and Nada, H.: Anisotropic surface melting of an ice crystal and its relationship to growth forms, J. Phys. Chem. B, 101, 6167-6170, doi:10.1021/jp9631700, 1997.

Furukawa, Y., Yamamoto, M., and Kuroda, T.: Ellipsometric study of the transition layer on the surface of an ice crystal, J. Cryst. Growth, 82, 665-677, doi:10.1016/s00220248(87)80012-x, 1987

Galbavy, E. S., Ram, K., and Anastasio, C.: 2-nitrobenzaldehyde as a chemical actinometer for solution and ice photochemistry, J. Photoch. Photobio. A, 209, 186-192, doi:10.1016/j.jphotochem.2009.11.013, 2010.

Gao, S. S. and Abbatt, J. P. D.: Kinetics and mechanism of $\mathrm{OH}$ oxidation of small organic dicarboxylic acids in ice: Comparison to behavior in aqueous solution, J. Phys. Chem. A, 115, $9977-$ 9986, doi:10.1021/jp202478w, 2011.

Geil, B., Kirschgen, T., and Fujara, F.: Mechanism of proton transport in hexagonal ice, Phys. Rev. B, 72, 014304, doi:10.1103/PhysRevB.72.014304, 2005.

Genthon, C., Fily, M., and Martin, E.: Numerical simulations of Greenland snowpack and comparison with passive microwave spectral signatures, Ann. Glaciol., 32, 109-115, doi:10.3189/172756401781819094, 2001.

George, I. J. and Abbatt, J. P. D.: Heterogeneous oxidation of atmospheric aerosol particles by gas-phase radicals, Nature Chem., 2, 713-722, doi:10.1038/nchem.806, 2010.

Giannelli, V., Thomas, D. N., Haas, C., Kattner, G., Kennedy, H., and Dieckmann, G. S.: Behaviour of dissolved organic matter and inorganic nutrients during experimental sea-ice formation, Ann. Glaciol., 33, 317-321, 2001.

Gillen, K. T., Douglass, D. C., and Hoch, M. J. R.: Selfdiffusion in liquid water to $-31^{\circ} \mathrm{C}$, J. Chem. Phys., 57, 5117, doi:10.1063/1.1678198, 1972.

Girardet, C. and Toubin, C.: Molecular atmospheric pollutant adsorption on ice: A theoretical survey, Surf. Sci. Rep., 44, 163238, doi:10.1016/S0167-5729(01)00016-4, 2001.

Gladich, I., Pfalzgraff, W., Maršálek, O., Jungwirth, P., Roeselová, M., and Neshyba, S.: Arrhenius analysis of anisotropic surface self-diffusion on the prismatic facet of ice, Phys. Chem. Chem. Phys., 13, 19960-19969, doi:10.1039/c1cp22238d, 2011.

Goertz, M. P., Zhu, X. Y., and Houston, J. E.: Exploring the liquid-like layer on the ice surface, Langmuir, 25, 6905-6908, doi:10.1021/la9001994, 2009.
Golden, K. M., Eicken, H., Heaton, A. L., Miner, J., Pringle, D. J., and Zhu, J.: Thermal evolution of permeability and microstructure in sea ice, Geophys. Res. Lett., 34, L16501, doi:10.1029/2007GL030447, 2007.

Golecki, I. and Jaccard, C.: Intrinsic surface disorder in ice near the melting point, J. Phys. C Solid State, 11, 4229-4237, doi:10.1088/0022-3719/11/20/018, 1978.

Goto, K., Hondoh, T., and Higashi, A.: Determination of diffusioncoefficients of self-interstitials in ice with a new method of observing climb of dislocations by X-Ray topography, Jpn. J. Appl. Phys. 1, 25, 351-357, doi:10.1143/JJAP.25.351, 1986.

Grannas, A. M., Bausch, A. R., and Mahanna, K. M.: Enhanced aqueous photochemical reaction rates after freezing, J. Phys Chem. A, 111, 11043-11049, doi:10.1021/jp073802q, 2007a.

Grannas, A. M., Jones, A. E., Dibb, J., Ammann, M., Anastasio, C., Beine, H. J., Bergin, M., Bottenheim, J., Boxe, C. S., Carver, G., Chen, G., Crawford, J. H., Dominé, F., Frey, M. M., Guzmán, M. I., Heard, D. E., Helmig, D., Hoffmann, M. R., Honrath, R. E., Huey, L. G., Hutterli, M., Jacobi, H. W., Klán, P., Lefer, B., McConnell, J., Plane, J., Sander, R., Savarino, J., Shepson, P. B., Simpson, W. R., Sodeau, J. R., von Glasow, R., Weller, R., Wolff, E. W., and Zhu, T.: An overview of snow photochemistry: Evidence, mechanisms and impacts, Atmos. Chem. Phys., 7, 43294373, doi:10.5194/acp-7-4329-2007, 2007b.

Grannas, A. M., Bogdal, C., Hageman, K. J., Halsall, C., Harner, T., Hung, H., Kallenborn, R., Klán, P., Klánová, J., Macdonald, R. W., Meyer, T., and Wania, F.: The role of the global cryosphere in the fate of organic contaminants, Atmos. Chem. Phys., 13, 32713305, doi:10.5194/acp-13-3271-2013, 2013.

Grecea, M. L., Backus, E. H. G., Fraser, H. J., Pradeep, T., Kleyn, A. W., and Bonn, M.: Mobility of haloforms on ice surfaces, Chem. Phys. Lett., 385, 244-248, doi:10.1016/j.cplett.2003.12.085, 2004.

Gross, G. W., Gutjahr, A., and Caylor, K.: Recent experimental work on solute redistribution at the ice water interface - Implications for electrical-properties and interface processes, J. Phys.Paris, 48, 527-533, doi:10.1051/jphyscol:1987172, 1987.

Guzmán, M. I., Hildebrandt, L., Colussi, A. J., and Hoffmann, M. R.: Cooperative hydration of pyruvic acid in ice, J. Am. Chem. Soc., 128, 10621-10624, doi:10.1021/ja062039v, 2006.

Guzmán, M. I., Hoffmann, M. R., and Colussi, A. J.: Photolysis of pyruvic acid in ice: Possible relevance to $\mathrm{CO}$ and $\mathrm{CO}_{2}$ ice core record anomalies, J. Geophys. Res., 112, D10123, doi:10.1029/2006JD007886, 2007.

Halde, R.: Concentration of impurities by progressive freezing, Water Res., 14, 575-580, doi:10.1016/0043-1354(80)90115-3, 1980.

Harrison, J. D.: Measurements of brine droplet migration in ice, J. Appl. Phys., 36, 3811-3815, doi:10.1063/1.1713953, 1965.

Heger, D. and Klán, P.: Interactions of organic molecules at grain boundaries in ice: A solvatochromic analysis, J. Photoch. Photobio. A, 187, 275-284, doi:10.1016/j.jphotochem.2006.10.012, 2007.

Heger, D., Jirkovsky, J., and Klán, P.: Aggregation of methylene blue in frozen aqueous solutions studied by absorption spectroscopy, J. Phys. Chem. A, 109, 6702-6709, doi:10.1021/jp050439j, 2005. 
Heger, D., Klánová, J., and Klán, P.: Enhanced protonation of cresol red in acidic aqueous solutions caused by freezing, J. Phys. Chem. B, 110, 1277-1287, doi:10.1021/jp0553683, 2006.

Heggli, M., Köchle, B., Matzl, M., Pinzer, B. R., Riche, F., Steiner, S., Steinfeld, D., and Schneebeli, M.: Measuring snow in 3-D using X-ray tomography: Assessment of visualization techniques, Ann. Glaciol., 52, 231-236, doi:10.3189/172756411797252202, 2011.

Hellebust, S., Roddis, T., and Sodeau, J. R.: Potential role of the nitroacidium ion on HONO emissions from the snowpack, J. Phys. Chem. A, 111, 1167-1171, doi:10.1021/jp068264g, 2007.

Hellebust, S., O'Sullivan, D., and Sodeau, J. R.: Protonated nitrosamide and its potential role in the release of HONO from snow and ice in the dark, J. Phys. Chem. A, 114, 11632-11637, doi:10.1021/jp104327a, 2010.

Henson, B. and Robinson, J.: Dependence of quasiliquid thickness on the liquid activity: A bulk thermodynamic theory of the interface, Phys. Rev. Lett., 92, 246107, doi:10.1103/PhysRevLett.92.246107, 2004.

Henson, B. F., Voss, L. F., Wilson, K. R., and Robinson, J. M.: Thermodynamic model of quasiliquid formation on $\mathrm{H}_{2} \mathrm{O}$ ice: Comparison with experiment, J. Chem. Phys., 123, 144707, doi:10.1063/1.2056541, 2005.

Herbert, B. M. J., Halsall, C. J., Jones, K. C., and Kallenborn, R.: Field investigation into the diffusion of semi-volatile organic compounds into fresh and aged snow, Atmos. Environ., 40, 1385-1393, doi:10.1016/j.atmosenv.2005.10.055, 2006.

Hirashima, H., Yamaguchi, S., Sato, A., and Lehning, M.: Numerical modeling of liquid water movement through layered snow based on new measurements of the water retention curve, Cold Reg. Sci. Technol., 64, 94-103, doi:10.1016/j.coldregions.2010.09.003, 2010.

Hobbs, P. V.: Ice physics, Oxford classic texts in the physical sciences, Oxford University Press, 2010.

Hoekstra, P. and Osterkamp, T. E.: The migration of liquid inclusions in single ice crystals, J. Geophys. Res., 70, 5035, doi:10.1029/JZ070i020p05035, 1965.

Honrath, R. E., Guo, S., Peterson, M. C., Dziobak, M. P., Dibb, J. E., and Arsenault, M. A.: Photochemical production of gas phase $\mathrm{NO}_{\mathrm{x}}$ from ice crystal $\mathrm{NO}_{3}^{-}$, J. Geophys. Res., 105, 2418324190, doi:10.1029/2000JD900361, 2000.

Huthwelker, T., Lamb, D., Baker, M., Swanson, B., and Peter, T.: Uptake of $\mathrm{SO}_{2}$ by polycrystalline water ice, J. Colloid Interface Sci., 238, 147-159, doi:10.1006/jcis.2001.7507, 2001.

Huthwelker, T., Krieger, U. K., Weers, U., Peter, T., and Lanford, W. A.: RBS analysis of trace gas uptake on ice, Nucl. Instrum. Meth. B, 190, 47-53, doi:10.1016/S0168-583X(01)01265-4, 2002.

Huthwelker, T., Malmström, M. E., Helleis, F., Moortgat, G. K., and Peter, T.: Kinetics of $\mathrm{HCl}$ uptake on ice at 190 and $203 \mathrm{~K}$ : Implications for the microphysics of the uptake process, J. Phys. Chem. A, 108, 6302-6318, doi:10.1021/jp0309623, 2004.

Huthwelker, T., Ammann, M., and Peter, T.: The uptake of acidic gases on ice, Chem. Rev., 106, 1375-1444, doi:10.1021/Cr020506v, 2006.

Hutterli, M. A., Röthlisberger, R., and Bales, R. C.: Atmosphere-to-snow-to-firn transfer studies of $\mathrm{HCHO}$ at Summit, Greenland, Geophys. Res. Lett., 26, 1691-1694, doi:10.1029/1999GL900327, 1999.
Hutterli, M. A., McConnell, J. R., Bales, R. C., and Stewart, R. W.: Sensitivity of hydrogen peroxide $\left(\mathrm{H}_{2} \mathrm{O}_{2}\right)$ and formaldehyde $(\mathrm{HCHO})$ preservation in snow to changing environmental conditions: Implications for ice core records, J. Geophys. Res., 108, 4023, doi:10.1029/2002JD002528, 2003.

Hynes, R. G., Fernandez, M. A., and Cox, R. A.: Uptake of $\mathrm{HNO}_{3}$ on water-ice and coadsorption of $\mathrm{HNO}_{3}$ and $\mathrm{HCl}$ in the temperature range 210-235 K, J. Geophys. Res., 107, 4797, doi:10.1029/2001JD001557, 2002.

Ikeda-Fukazawa, T. and Kawamura, K.: Molecular-dynamics studies of surface of ice Ih, J. Chem. Phys., 120, 1395-1401, doi:10.1063/1.1634250, 2004.

Israelachvili, J. N.: Intermolecular and surface forces, Academic Press, Oxford, doi:10.1016/B978-0-12-375182-9.10026-0, 1991.

Jacobi, H. W.: Correction to 'Development of a mechanism for nitrate photochemistry in snow', J. Phys. Chem. A, 115, 1471714719, doi:10.1021/Jp209750d, 2011.

Jacobi, H.-W. and Hilker, B.: A mechanism for the photochemical transformation of nitrate in snow, J. Photoch. Photobio. A, 185, 371-382, doi:10.1016/j.jphotochem.2006.06.039, 2007.

Jacobi, H. W., Frey, M. M., Hutterli, M. A., Bales, R. C., Schrems, O., Cullen, N. J., Steffen, K., and Koehler, C.: Measurements of hydrogen peroxide and formaldehyde exchange between the atmosphere and surface snow at Summit, Greenland, Atmos. Environ., 36, 2619-2628, doi:10.1016/S1352-2310(02)00106-1, 2002.

Jacobi, H. W., Annor, T., and Quansah, E.: Investigation of the photochemical decomposition of nitrate, hydrogen peroxide, and formaldehyde in artificial snow, J. Photoch. Photobio. A, 179, 330-338, doi:10.1016/j.jphotochem.2005.09.001, 2006.

Jacobi, H. W., Domine, F., Simpson, W. R., Douglas, T. A., and Sturm, M.: Simulation of the specific surface area of snow using a one-dimensional physical snowpack model: Implementation and evaluation for subarctic snow in Alaska, Cryosphere, 4, 35-51, doi:10.5194/tc-4-35-2010, 2010.

Jones, A. E., Wolff, E. W., Ames, D., Bauguitte, S. J.-B., Clemitshaw, K. C., Fleming, Z., Mills, G. P., Saiz-Lopez, A., Salmon, R. A., Sturges, W. T., and Worton, D. R.: The multi-seasonal $\mathrm{NO}_{\mathrm{y}}$ budget in coastal Antarctica and its link with surface snow and ice core nitrate: Results from the CHABLIS campaign, Atmos. Chem. Phys., 11, 9271-9285, doi:10.5194/acp-11-92712011, 2011.

Journet, E., Le Calvé, S. p., and Mirabel, P.: Adsorption study of acetone on acid-doped ice surfaces between 203 and $233 \mathrm{~K}$, J. Phys. Chem. B, 109, 14112-14117, doi:10.1021/jp051524u, 2005.

Jung, K. H., Park, S. C., Kim, J. H., and Kang, H.: Vertical diffusion of water molecules near the surface of ice, J. Chem. Phys., 121, 2758-2764, doi:10.1063/1.1770518, 2004.

Kahan, T. F. and Donaldson, D. J.: Photolysis of polycyclic aromatic hydrocarbons on water and ice surfaces, J. Phys. Chem. A, 111, 1277-1285, doi:10.1021/jp066660t, 2007.

Kahan, T. F. and Donaldson, D. J.: Heterogeneous ozonation kinetics of phenanthrene at the air-ice interface, Environ. Res. Lett., 3, 045006, doi:10.1088/1748-9326/3/4/045006, 2008.

Kahan, T. F. and Donaldson, D. J.: Benzene photolysis on ice: Implications for the fate of organic contaminants in the winter, Environ. Sci. Technol., 44, 3819-3824, doi:10.1021/es100448h, 2010 . 
Kahan, T. F., Reid, J. P., and Donaldson, D. J.: Spectroscopic probes of the quasi-liquid layer on ice, J. Phys. Chem. A, 111, 1100611012, doi:10.1021/jp074551o, 2007.

Kahan, T. F., Kwamena, N.-O. A., and Donaldson, D. J.: Different photolysis kinetics at the surface of frozen freshwater vs. frozen salt solutions, Atmos. Chem. Phys., 10, 10917-10922, doi:10.5194/acp-10-10917-2010, 2010a.

Kahan, T. F., Zhao, R., and Donaldson, D. J.: Hydroxyl radical reactivity at the air-ice interface, Atmos. Chem. Phys., 10, 843-854, doi:10.5194/acp-10-843-2010, 2010b.

Kahan, T. F., Zhao, R., Jumaa, K. B., and Donaldson, D. J.: Anthracene photolysis in aqueous solution and ice: Photon flux dependence and comparison of kinetics in bulk ice and at the air-ice interface, Environ. Sci. Technol., 44, 1302-1306, doi:10.1021/es9031612, 2010c.

Karcher, B. and Basko, M. M.: Trapping of trace gases in growing ice crystals, J. Geophys. Res., 109, D22204, doi:10.1029/2004JD005254, 2004.

Kawada, S.: Dielectric anisotropy in ice Ih, J. Phys. Soc. Jpn., 44, 1881-1886, doi:10.1143/JPSJ.44.1881, 1978.

Kerbrat, M., Le Calvé, S., and Mirabel, P.: Uptake measurements of ethanol on ice surfaces and on supercooled aqueous solutions doped with nitric acid between 213 and 243 K, J. Phys. Chem. A, 111, 925-931, doi:10.1021/jp0635011, 2007.

Kerbrat, M., Huthwelker, T., Bartels-Rausch, T., Gäggeler, H. W., and Ammann, M.: Co-adsorption of acetic acid and nitrous acid on ice, Phys. Chem. Chem. Phys., 12, 7194-7202, doi:10.1039/b924782c, 2010a.

Kerbrat, M., Huthwelker, T., Gäggeler, H. W., and Ammann, M.: Interaction of nitrous acid with polycrystalline ice: Adsorption on the surface and diffusion into the bulk, J. Phys. Chem. C, 114, 2208-2219, doi:10.1021/jp909535c, 2010b.

Kim, K. and Choi, W.: Enhanced redox conversion of chromate and arsenite in ice, Environ. Sci. Technol., 45, 2202-2208, doi:10.1021/es103513u, 2011.

Kim, K., Choi, W., Hoffmann, M. R., Yoon, H.-I., and Park, B.K.: Photoreductive dissolution of iron oxides trapped in ice and its environmental implications, Environ. Sci. Technol., 44, 41424148, doi:10.1021/es9037808, 2010.

Klán, P. and Holoubek, I.: Ice (photo)chemistry. Ice as a medium for long-term (photo)chemical transformations - Environmental implications, Chemosphere, 46, 1201-1210, doi:10.1016/S00456535(01)00285-5, 2002.

Klán, P., Ansorgová, A., del Favero, D., and Holoubek, I.: Photochemistry of chlorobenzene in ice, Tetrahedron Lett., 41, 77857789, doi:10.1016/S0040-4039(00)01336-8, 2000.

Klán, P., del Favero, D., Ansorgová, A., Klánová, J., and Holoubek, I.: Photodegradation of halobenzenes in water ice, Environ. Sci. Pollut. Res., 8, 195-200, doi:10.1007/BF02987385, 2001.

Klánová, J., Klán, P., Heger, D., and Holoubek, I.: Comparison of the effects of $\mathrm{UV}, \mathrm{H}_{2} \mathrm{O}_{2} / \mathrm{UV}$ and gamma-irradiation processes on frozen and liquid water solutions of monochlorophenols, Photochem. Photobiol. Sci., 2, 1023-1031, doi:10.1039/b303483f, 2003a.

Klánová, J., Klán, P., Nosek, J., and Holoubek, I.: Environmental ice photochemistry: Monochlorophenols, Environ. Sci. Technol., 37, 1568-1574, doi:10.1021/es025875n, 2003b.

Knight, C. A.: Reply, J. Geophys. Res., 101, 12933-12936, doi:10.1029/96JD00556, 1996a.
Knight, C. A.: Surface layers on ice, J. Geophys. Res., 101, 1292112928, doi:10.1029/96JD00554, 1996 b.

Koch, T. G., Holmes, N. S., Roddis, T. B., and Sodeau, J. R.: Low-temperature reflection/absorption IR study of thin films of nitric acid hydrates and ammonium nitrate adsorbed on gold foil, J. Chem. Soc. Farad. T. I, 92, 4787-4792, doi:10.1039/ft9969204787, 1996.

Kolb, C. E., Cox, R. A., Abbatt, J. P. D., Ammann, M., Davis, E. J., Donaldson, D. J., Garrett, B. C., George, C., Griffiths, P. T., Hanson, D. R., Kulmala, M., McFiggans, G., Pöschl, U., Riipinen, I., Rossi, M. J., Rudich, Y., Wagner, P. E., Winkler, P. M., Worsnop, D. R., and O' Dowd, C. D.: An overview of current issues in the uptake of atmospheric trace gases by aerosols and clouds, Atmos. Chem. Phys., 10, 10561-10605, doi:10.5194/acp-10-10561-2010, 2010.

Koop, T., Kapilashrami, A., Molina, L. T., and Molina, M. J.: Phase transitions of sea-salt/water mixtures at low temperatures: Implications for ozone chemistry in the polar marine boundary layer, J. Geophys. Res., 105, 26393-26402, doi:10.1029/2000JD900413, 2000.

Kopp, M., Barnaal, D. E., and Lowe, I. J.: Measurement by NMR of diffusion rate of HF in ice, J. Chem. Phys., 43, 2965-2971, doi:10.1063/1.1697258, 1965.

Krieger, U. K., Huthwelker, T., Daniel, C., Weers, U., Peter, T., and Lanford, W. A.: Rutherford backscattering to study the nearsurface region of volatile liquids and solids, Science, 295, 10481050, doi:10.1126/science.1066654, 2002.

Kuo, M. H., Moussa, S. G., and McNeill, V. F.: Modeling interfacial liquid layers on environmental ices, Atmos. Chem. Phys., 11, 9971-9982, doi:10.5194/acp-11-9971-2011, 2011.

Kurková, R., Ray, D., Nachtigallová, D., and Klán, P.: Chemistry of small organic molecules on snow grains: The applicability of artificial snow for environmental studies, Environ. Sci. Technol., 45, 3430-3436, doi:10.1021/es104095g, 2011.

Křepelová, A., Huthwelker, T., Bluhm, H., and Ammann, M.: Surface chemical properties of eutectic and frozen $\mathrm{NaCl}$ solutions probed by XPS and NEXAFS, Chem. Phys. Chem., 11, 38593866, doi:10.1002/cphc.201000461, 2010a.

Křepelová, A., Newberg, J. T., Huthwelker, T., Bluhm, H., and Ammann, M.: The nature of nitrate at the ice surface studied by XPS and NEXAFS, Phys. Chem. Chem. Phys., 12, 8870-8880, doi:10.1039/c0cp00359j, 2010b.

Křepelová, A., Bartels-Rausch, T., Brown, M. A., Bluhm, H., and Ammann, M.: Adsorption of acetic acid on ice studied by ambient-pressure XPS and partial-electron-yield NEXAFS spectroscopy at 230-240 K, J. Phys. Chem. A, 117, 401-409, doi:10.1021/jp3102332, 2013.

Lalonde, J. D., Poulain, A. J., and Amyot, M.: The role of mercury redox reactions in snow on snow-to-air mercury transfer, Environ. Sci. Technol., 36, 174-178, doi:10.1021/es010786g, 2002.

Lamarque, J.-F., McConnell, J. R., Shindell, D. T., Orlando, J. J., and Tyndall, G. S.: Understanding the drivers for the 20th century change of hydrogen peroxide in Antarctic ice-cores, Geophys. Res. Lett., 38, L04810, doi:10.1029/2010GL045992, 2011.

Lee, C. W., Lee, P. R., Kim, Y. K., and Kang, H.: Mechanistic study of proton transfer and H/D exchange in ice films at low temperatures (100-140 K), J. Chem. Phys., 127, 084701, doi:10.1063/1.2759917, 2007. 
Legrand, M. and Mayewski, P.: Glaciochemistry of polar ice cores: A review, Rev. Geophys., 35, 219-243, doi:10.1029/96RG03527, 1997.

Lehning, M., Bartelt, P., Brown, B., Fierz, C., and Satyawali, P.: A physical snowtack model for the Swiss avalanche warning part II: Snow microstructure, Cold Reg. Sci. Technol., 35, 147-167, 2002.

Lejeune, Y., WAGNON, P., Bouilloud, L., Chevallier, P., Etchevers, P., Martin, E., Sicart, J. E., and Habets, F.: Melting of snow cover in a tropical mountain environment in Bolivia: Processes and modeling, J. Hydrometeo., 8, 922-937, doi:10.1175/Jhm590.1, 2007.

Li, Y. and Somorjai, G. A.: Surface premelting of ice, J. Phys. Chem. C, 111, 9631-9637, doi:10.1021/jp071102f, 2007.

Li, Z., Friedl, R., Moore, S., and Sander, S.: Interaction of peroxynitric acid with solid $\mathrm{H}_{2} \mathrm{O}$ ice, J. Geophys. Res., 101, 6795-6802, doi:10.1029/96JD00065, 1996.

Liao, W. and Tan, D.: 1-D Air-snowpack modeling of atmospheric nitrous acid at South Pole during ANTCI 2003, Atmos. Chem. Phys., 8, 7087-7099, doi:10.5194/acp-8-7087-2008, 2008.

Lied, A., Dosch, H., and Bilgram, J. H.: Glancing angle X-ray scattering from single crystal ice surfaces, Physica B, 198, 92-96, doi:10.1016/0921-4526(94)90135-X, 1994.

Livingston, F. and George, S.: Effect of sodium on $\mathrm{HCl}$ hydrate diffusion in ice: Evidence for anion-cation trapping, J. Phys. Chem. A, 106, 5114-5119, doi:10.1021/jp0145309, 2002.

Livingston, F., Smith, J., and George, S.: Depth-profiling and diffusion measurements in ice films using infrared laser resonant desorption, Anal. Chem., 72, 5590-5599, doi:10.1021/ac000724t, 2000.

Liyana-Arachchi, T., Valsaraj, K., and Hung, F.: Ice growth from supercooled aqueous solutions of reactive oxygen species, Theor. Chem. Acc., 132, 1-13, doi:10.1007/s00214-012-1309-5, 2012a.

Liyana-Arachchi, T. P., Valsaraj, K. T., and Hung, F. R.: Ice growth from supercooled aqueous solutions of benzene, naphthalene, and phenanthrene, J. Phys. Chem. A, 116, 8539-8546, doi:10.1021/jp304921c, 2012b.

Lodge, J. P., Baker, M. L., and Pierrard, J. M.: Observations on ion separation in dilute solutions by freezing, J. Chem. Phys., 24, 716-719, doi:10.1063/1.1742596, 1956.

Lomonaco, R., Albert, M., and Baker, I.: Microstructural evolution of fine-grained layers through the firn column at Summit, Greenland, J. Glaciol., 57, 755-762, doi:10.3189/002214311797409730, 2011.

Long, Y., Chaumerliac, N., Deguillaume, L., Leriche, M., and Champeau, F.: Effect of mixed-phase cloud on the chemical budget of trace gases: A modeling approach, Atmos. Res., 97, 540554, doi:10.1016/j.atmosres.2010.05.005, 2010.

Lu, H., McCartney, S. A., and Sadtchenko, V.: H/D exchange kinetics in pure and $\mathrm{HCl}$ doped polycrystalline ice at temperatures near its melting point: Structure, chemical transport, and phase transitions at grain boundaries, J. Chem. Phys., 130, 054501054511, doi:10.1063/1.3039077, 2009.

Luo, J. and Chiang, Y.-M.: Wetting and Prewetting on Ceramic Surfaces, Annu. Rev. Mater. Res., 38, 227-249, doi:10.1146/annurev.matsci.38.060407.132431, 2008.

Mader, H. M.: The thermal-behavior of the water-vein system in polycrystalline ice, J. Glaciol., 38, 359-374, 1992.
Mantz, Y. A., Geiger, F. M., Molina, L. T., Molina, M. J., and Trout, B. L.: First-principles molecular-dynamics study of surface disordering of the (0001) face of hexagonal ice, J. Chem. Phys., 113, 10733-10743, doi:10.1063/1.1323959, 2000.

Mantz, Y. A., Geiger, F. M., Molina, L. T., Molina, M. J., and Trout, B. L.: First-principles theoretical study of molecular $\mathrm{HCl}$ adsorption on a hexagonal ice (0001) surface, J. Phys. Chem. A, 105, 7037-7046, doi:10.1021/jp010817u, 2001a.

Mantz, Y. A., Geiger, F. M., Molina, L. T., Molina, M. J., and Trout, B. L.: The interaction of $\mathrm{HCl}$ with the (0001) face of hexagonal ice studied theoretically via car-parrinello molecular dynamics, Chem. Phys. Lett., 348, 285-292, doi:10.1016/S00092614(01)01103-4, 2001b.

Matykiewiczová, N., Klánová, J., and Klán, P.: Photochemical degradation of PCBs in snow, Environ. Sci. Technol., 41, 83088314, doi:10.1021/es0714686, 2007a.

Matykiewiczová, N., Kurková, R., Klánová, J., and Klán, P.: Photochemically induced nitration and hydroxylation of organic aromatic compounds in the presence of nitrate or nitrite in ice, J. Photoch. Photobio. A, 187, 24-32, doi:10.1016/j.jphotochem.2006.09.008, 2007b.

McConnell, J., Winterle, J., Bales, R., Thompson, A., and Stewart, R.: Physically based inversion of surface snow concentrations of $\mathrm{H}_{2} \mathrm{O}_{2}$ to atmospheric concentrations at south pole, Geophys. Res. Lett., 24, 441-444, doi:10.1029/97GL00183, 1997.

McConnell, J. R., Bales, R. C., Stewart, R. W., Thompson, A. M., Albert, M. R., and Ramos, R.: Physically based modelling of atmosphere-to-snow-to-firn transfer of $\mathrm{H}_{2} \mathrm{O}_{2}$ at South Pole, J. Geophys. Res., 103, 10561-10570, doi:10.1029/98JD00460, 1998.

McDonald, S. A., Marone, F., Hintermüller, C., Mikuljan, G., David, C., and Stampanoni, M.: Phase contrast Xray tomographic microscopy for biological and materials science applications, Adv. Eng. Mater., 13, 116-121, doi:10.1002/adem.201000219, 2011.

McNeill, V. F., Loerting, T., Geiger, F. M., Trout, B. L., and Molina, M. J.: Hydrogen chloride-induced surface disordering on ice, P. Natl Acad. Sci. USA, 103, 9422-9427, doi:10.1073/pnas.0603494103, 2006.

McNeill, V. F., Geiger, F. M., Loerting, T., Trout, B. L., Molina, L. T., and Molina, M. J.: Interaction of hydrogen chloride with ice surfaces: The effects of grain size, surface roughness, and surface disorder, J. Phys. Chem. A, 111, 6274-6284, doi:10.1021/Jp068914g, 2007.

McNeill, V. F., Grannas, A. M., Abbatt, J. P. D., Ammann, M., Ariya, P., Bartels-Rausch, T., Domine, F., Donaldson, D. J., Guzman, M. I., Heger, D., Kahan, T. F., Klán, P., Masclin, S., Toubin, C., and Voisin, D.: Organics in environmental ices: Sources, chemistry, and impacts, Atmos. Chem. Phys., 12, 9653-9678, doi:10.5194/acp-12-9653-2012, 2012.

Meyer, T. and Wania, F.: Organic contaminant amplification during snowmelt, Water Res., 42, 1847-1865, doi:10.1016/j.watres.2007.12.016, 2008.

Michalowski, B. A., Francisco, J. S., Li, S. M., Barrie, L. A., Bottenheim, J. W., and Shepson, P. B.: A computer model study of multiphase chemistry in the Arctic boundary layer during Polar sunrise, J. Geophys. Res., 105, 15131-15145, doi:10.1029/2000JD900004, 2000. 
Mitchell, D. L. and Lamb, D.: Influence of riming on the chemicalcomposition of snow in winter orographic storms, J. Geophys. Res., 94, 14831-14840, doi:10.1029/JD094iD12p14831, 1989.

Mizuno, Y. and Hanafusa, N.: Studies of surface properties of ice using nuclear magnetic resonance, J. Phys.-Paris, 48, 511-517, doi:10.1051/jphyscol:1987170, 1987.

Molinero, V. and Moore, E. B.: Water modeled as an intermediate element between carbon and silicon, J. Phys. Chem. B, 113, 4008-4016, doi:10.1021/jp805227c, 2009.

Morin, S., Marion, G. M., von Glasow, R., Voisin, D., Bouchez, J., and Savarino, J.: Precipitation of salts in freezing seawater and ozone depelition: A status report, Atmos. Chem. Phys., 8, $7317-$ 7324, doi:10.5194/acp-8-7317-2008, 2008.

Moussa, S. G., Kuo, M. H., and McNeill, V. F.: Nitric acid-induced surface disordering on ice, Phys. Chem. Chem. Phys., 15, 1098910995, doi:10.1039/c3cp50487e, 2013.

Muchová, E., Gladich, I., Picaud, S., Hoang, P. N. M., and Roeselová, M.: The ice-vapor interface and the melting point of ice Ih for the polarizable POL3 water model, J. Phys. Chem. A, 115, 5973-5982, doi:10.1021/jp110391q, 2011.

Mullins, W. W.: Theory of thermal grooving, J. Appl. Phys., 28, 333-339, doi:10.1063/1.1722742, 1957.

Mulvaney, R., Wolff, E. W., and Oates, K.: Sulphuric acid at grain boundaries in Antarctic ice, Nature, 331, 247-249, doi:10.1038/331247a0, 1988.

Murphy, E. J.: Generation of electromotive forces during freezing of water, J. Colloid Interface Sci., 32, 1-11, doi:10.1016/00219797(70)90094-9, 1970.

Murshed, M. M., Klapp, S. A., Enzmann, F., Szeder, T., Huthwelker, T., Stampanoni, M., Marone, F., Hintermüller, C., Bohrmann, G., Kuhs, W. F., and Kersten, M.: Natural gas hydrate investigations by synchrotron radiation X-ray cryo-tomographic microscopy (SRXCTM), Geophys. Res. Lett., 35, L23612, doi:10.1029/2008GL035460, 2008.

Nada, H. and Furukawa, Y.: Anisotropy in structural phase transitions at ice surfaces: A molecular dynamics study, Appl. Surf. Sci., 121-122, 445-447, doi:10.1016/S0169-4332(97)00324-3, 1997.

Nasello, O. B., Di Prinzio, C. L., and Guzmán, P. G.: Temperature dependence of pure ice grain boundary mobility, Acta Mater., 53, 4863-4869, doi:10.1016/J.Actamat.2005.06.002, 2005.

Nasello, O. B., Navarro de Juarez, S., and Di Prinzio, C. L.: Measurement of self-diffusion on ice surface, Scripta Mater., 56, 1071-1073, doi:10.1016/j.scriptamat.2007.02.023, 2007.

Neftel, A., Bales, R. C., and Jacob, D. J.: $\mathrm{H}_{2} \mathrm{O}_{2}$ and HCHO in polar snow and their relation to atmospheric chemistry, pp. 249264, Proceedings of the NATO advanced research workshop "Ice score studies of global biogeochemical cycles", Springer, Berlin, 1995.

Neshyba, S., Nugent, E., Roeselová, M., and Jungwirth, P.: Molecular dynamics study of ice-vapor interactions via the quasi-liquid layer, J. Phys. Chem. C, 113, 4597-4604, doi:10.1021/jp810589a, 2009.

Nye, J. and Frank, F.C.: Hydrology of the intergranular veins in a temperate glacier, Symposium on the Hydrology of Glaciers, 95, 157-161, 1973.

Nye, J. F.: Thermal-behavior of glacier and laboratory ice, J. Glaciol., 37, 401-413, 1991.
Obbard, R. W., Iliescu, D., Cullen, D., Chang, J., and Baker, I.: SEM/EDS comparison of polar and seasonal temperate ice, Microsc. Res. Tech., 62, 49-61, doi:10.1002/jemt.10381, 2003.

Obbard, R. W., Troderman, G., and Baker, I.: Imaging brine and air inclusions in sea ice using micro-X-ray computed tomography, J. Glaciol., 55, 1113-1115, 2009.

O'Concubhair, R. and Sodeau, J. R.: Freeze-induced formation of bromine/chlorine interhalogen species from aqueous halide ion solutions, Environ. Sci. Technol., 46, 10589-10596, doi:10.1021/es301988s, 2012.

O'Concubhair, R. and Sodeau, J. R.: The effect of freezing on reactions with environmental impact, Acc. Chem. Res., 46, 27162724, doi:10.1021/ar400114e, 2013.

O'Concubhair, R., O’Sullivan, D., and Sodeau, J. R.: Dark oxidation of dissolved gaseous mercury in polar ice mimics, Environ. Sci. Technol., 46, 4829-4836, doi:10.1021/es300309n, 2012.

O'Driscoll, P., Minogue, N., Takenaka, N., and Sodeau, J.: Release of nitric oxide and iodine to the atmosphere from the freezing of sea-salt aerosol components, J. Phys. Chem. A, 112, 1677-1682, doi:10.1021/Jp710464c, 2008.

Oltmans, S. J., Schnell, R. C., Sheridan, P. J., Peterson, R. E., Li, S. M., Winchester, J. W., Tans, P. P., Sturges, W. T., Kahl, J. D., and Barrie, L. A.: Seasonal surface ozone and filterable bromine relationship in the high Arctic, Atmos. Environ., 23, 2431-2441, doi:10.1016/0004-6981(89)90254-0, 1989.

O'Sullivan, D. and Sodeau, J. R.: Freeze-induced reactions: Formation of iodine- bromine interhalogen species from aqueous halide ion solutions, J. Phys. Chem. A, 114, 12208-12215, doi:10.1021/jp104910p, 2010.

Paesani, F. and Voth, G. A.: Quantum effects strongly influence the surface premelting of ice, J. Phys. Chem. C, 112, 324-327, doi:10.1021/jp710640e, 2008.

Park, S.-C., Moon, E.-S., and Kang, H.: Some fundamental properties and reactions of ice surfaces at low temperatures, Phys. Chem. Chem. Phys., 12, 12000-12011, doi:10.1039/C003592K, 2010.

Pasteur, E. C. and Mulvaney, R.: Migration of methane sulphonate in Antarctic firn and ice, J. Geophys. Res., 105, 11525-11534, doi:10.1029/2000jd900006, 2000.

Pereyra, R. G. and Carignano, M. A.: Ice nanocolumns: A molecular dynamics study, J. Phys. Chem. C, 113, 12699-12705, doi:10.1021/jp903404n, 2009.

Petitjean, M., Mirabel, P., and Calvé, S. L.: Uptake measurements of acetaldehyde on solid ice surfaces and on solid/liquid supercooled mixtures doped with $\mathrm{HNO}_{3}$ in the temperature range 203-253 K, J. Phys. Chem. A, 113, 5091-5098, doi:10.1021/jp810131f, 2009.

Petrenko, V. F. and Whitworth, R. W.: Physics of ice, Oxford University Press, New York, 1999.

Pfalzgraff, W. C., Hulscher, R. M., and Neshyba, S. P.: Scanning electron microscopy and molecular dynamics of surfaces of growing and ablating hexagonal ice crystals, Atmos. Chem. Phys., 10, 2927-2935, doi:10.5194/acp-10-2927-2010, 2010.

Pfalzgraff, W. C., Neshyba, S., and Roeselová, M.: Comparative molecular dynamics study of vapor-exposed basal, prismatic and pyramidal surfaces of ice, J. Phys. Chem. A, 115, 6184-6193, doi:10.1021/jp111359, 2011.

Picaud, S.: Dynamics of TIP5P and TIP4P/ice potentials, J. Chem. Phys., 125, 174712, doi:10.1063/1.2370882, 2006. 
Picaud, S., Hoang, P. N. M., Peybernès, N., Le Calvé, S., and Mirabel, P.: Adsorption of acetic acid on ice: Experiments and molecular dynamics simulations, J. Chem. Phys., 122, 194707, doi:10.1063/1.1888368, 2005.

Pincock, R. E.: Reactions in frozen systems, Acc. Chem. Res., 2, 97-103, doi:10.1021/ar50016a001, 1969.

Pinzer, B. and Schneebeli, M.: Breeding snow: An instrumented sample holder for simultaneous tomographic and thermal studies, Meas. Sci. Technol., 20, 095705, doi:10.1088/09570233/20/9/095705, 2009a.

Pinzer, B. and Schneebeli, M.: Snow metamorphism under alternating temperature gradients: Morphology and recrystallization in surface snow, Geophys. Res. Lett., 36, L23503, doi:10.1029/2009GL039618, 2009b.

Pinzer, B., Kerbrat, M., Huthwelker, T., Gäggeler, H. W., Schneebeli, M., and Ammann, M.: Diffusion of $\mathrm{NO}_{\mathrm{x}}$ and $\mathrm{HONO}$ in snow: A laboratory study, J. Geophys. Res., 115, D03304, doi:10.1029/2009JD012459, 2010.

Pinzer, B. R., Schneebeli, M., and Kaempfer, T. U.: Vapor flux and recrystallization during dry snow metamorphism under a steady temperature gradient as observed by time-lapse microtomography, The Cryosphere, 6, 1141-1155, doi:10.5194/tc-61141-2012, 2012.

Pittenger, B., Fain, S., Cochran, M., Donev, J., Robertson, B., Szuchmacher, A., and Overney, R.: Premelting at icesolid interfaces studied via velocity-dependent indentation with force microscope tips, Phys. Rev. B, 63, 134102, doi:10.1103/PhysRevB.63.134102, 2001.

Poulida, O., Schwikowski, M., Baltensperger, U., Staehelin, J., and Gäggeler, H. W.: Scavenging of atmospheric constituents in mixed phase clouds at the High-Alpine site Jungfraujoch Part II. Influence of riming on the scavenging of particulate and gaseous chemical species, Atmos. Environ., 32, 3985-4000, doi:10.1016/S1352-2310(98)00131-9, 1998.

Pouvesle, N., Kippenberger, M., Schuster, G., and Crowley, J. N.: The interaction of $\mathrm{H}_{2} \mathrm{O}_{2}$ with ice surfaces between 203 and 233 K, Phys. Chem. Chem. Phys., 12, 15544-15550, doi:10.1039/C0cp01656j, 2010.

Pratt, K. A., Custard, K. D., Shepson, P. B., Douglas, T. A., Pohler, D., General, S., Zielcke, J., Simpson, W. R., Platt, U., Tanner, D. J., Gregory Huey, L., Carlsen, M., and Stirm, B. H.: Photochemical production of molecular bromine in Arctic surface snowpacks, Nature Geosci., 6, 351-356, 2013.

Price, W. S., Ide, H., and Arata, Y.: Self-diffusion of supercooled water to $238 \mathrm{~K}$ using PGSE NMR diffusion measurements, J. Phys. Chem. A, 103, 448-450, doi:10.1021/jp9839044, 1999.

Ram, K. and Anastasio, C.: Photochemistry of phenanthrene, pyrene, and fluoranthene in ice and snow, Atmos. Environ., 43, 2252-2259, doi:10.1016/j.atmosenv.2009.01.044, 2009.

Ramseier, R. O.: Self-diffusion of tritium in natural and synthetic ice monocrystals, J. Appl. Phys., 38, 2553, doi:10.1063/1.1709948, 1967.

Ray, D., Kurková, R., Hovorková, I., and Klán, P.: Determination of the specific surface area of snow using ozonation of 1,1-diphenylethylene, Environ. Sci. Technol., 45, 10061-10067, doi:10.1021/es202922k, 2011.

Ray, D., Malongwe, J. K., and Klán, P.: Rate acceleration of the heterogeneous reaction of ozone with a model alkene at the air-ice interface at low temperatures, Environ. Sci. Technol., 47, 67736780, doi:10.1021/es304812t, 2013.

Rempel, A. W., Waddington, E. D., Wettlaufer, J. S., and Worster, M. G.: Possible displacement of the climate signal in ancient ice by premelting and anomalous diffusion, Nature, 411, 568-571, doi:10.1038/35079043, 2001.

Rempel, A. W., Wettlaufer, J. S., and Waddington, E. D.: Anomalous diffusion of multiple impurity species: Predicted implications for the ice core climate records, J. Geophys. Res., 107, 2330, doi:10.1029/2002jb001857, 2002.

Richardson, C.: Phase relationsships in sea ice as a function of temperature, J. Glaciol., 17, 507-519, 1976.

Riche, F., Bartels-Rausch, T., Schreiber, S., Ammann, M., and Schneebeli, M.: Temporal evolution of surface and grain boundary area in artificial ice beads and implications for snow chemistry, J. Glaciol., 58, 815-817, doi:10.3189/2012JoG12J058, 2012.

Riordan, E., Minogue, N., Healy, D., O'Driscol, P., and Sodeau, J. R.: Spectroscopic and optimization modeling study of nitrous acid in aqueous solution, J. Phys. Chem. A, 109, 779-786, doi:10.1021/jp040269v, 2005.

Roberts, J. L., van Ommen, T. D., Curran, M. A. J., and Vance, T. R.: Methanesulphonic acid loss during ice-core storage: Recommendations based on a new diffusion coefficient, J. Glaciol., 55, 784-788, 2009.

Robinson, C., Boxe, C., Guzmán, M., Colussi, A., and Hoffmann, M.: Acidity of frozen electrolyte solutions, J. Phys. Chem. B, 110, 7613-7616, doi:10.1021/jp061169n, 2006.

Roth, C. M., Goss, K., and Schwarzenbach, R. P.: Sorption of diverse organic vapors to snow, Environ. Sci. Technol., 38, 40784084, doi:10.1021/es0350684, 2004.

Rothlisberger, R., Hutterli, M. A., Wolff, E. W., Mulvaney, R., Fischer, H., Bigler, M., Goto-Azuma, K., Hansson, M. E., Ruth, U., Siggaard-Andersen, M. L., and Steffensen, J. P.: Nitrate in Greenland and Antarctic ice cores: A detailed description of post-depositional processes, in: International Symposium on Ice Cores and Climate, edited by Wolff, E., vol. 000182023600035 , pp. 209-216, Annals of Glaciology, Kangerlussuaq, Greenland, doi:10.3189/172756402781817220, 2001.

Ružička, R., Baráková, L., and Klán, P.: Photodecarbonylation of dibenzyl ketones and trapping of radical intermediates by copper(II) chloride in frozen aqueous solutions, J. Phys. Chem. B, 109, 9346-9353, doi:10.1021/jp044661k, 2005.

Sander, R., Burrows, J., and Kaleschke, L.: Carbonate precipitation in brine - A potential trigger for tropospheric ozone depletion events, Atmos. Chem. Phys., 6, 4653-4658, doi:10.5194/acp-64653-2006, 2006.

Satoh, K., Uchida, T., Hondoh, T., and Mae, S.: Diffusion coefficients and solubility measurements of noble gases in ice crystals, Proceedings of the NIPR Symposium on Polar Meteorology and Glaciology, 10, 73-81, 1996.

Sazaki, G., Zepeda, S., Nakatsubo, S., Yokomine, M., and Furukawa, Y.: Quasi-liquid layers on ice crystal surfaces are made up of two different phases, P. Natl. Acad. Sci. USA, 109, 10521055, doi:10.1073/pnas.1116685109, 2012.

Schneebeli, M. and Sokratov, S. A.: Tomography of temperature gradient metamorphism of snow and associated changes in heat conductivity, Hydrol. Process, 18, 3655-3665, doi:10.1002/hyp.5800, 2004. 
Schwander, J.: The transformation of snow to ice and the occlusion of gases, Environmental Record in Glaciers and Ice Sheets, 8, 53-67, 1989.

Schwartz, S. E.: Mass-transport considerations pertinent to aqueous-phase reactions of gases in liquid-water clouds, vol. G6 of Chemistry of Multiphase Atmospheric Systems, Springer Verlag, NATO ASI Series, New York, 1986.

Seok, B., Helmig, D., Williams, M. W., Liptzin, D., Chowanski, K., and Hueber, J.: An automated system for continuous measurements of trace gas fluxes through snow: An evaluation of the gas diffusion method at a subalpine forest site, Niwot Ridge, Colorado, Biogeochemistry, 95, 95-113, doi:10.1007/s10533-0099302-3, 2009

Shepherd, T. D., Koc, M. A., and Molinero, V.: The quasi-liquid layer of ice under conditions of methane clathrate formation, J. Phys. Chem. C, 116, 12172-12180, doi:10.1021/jp303605t, 2012.

Shiraiwa, M., Pfrang, C., and Pöschl, U.: Kinetic multi-layer model of aerosol surface and bulk chemistry (KM-SUB): The influence of interfacial transport and bulk diffusion on the oxidation of oleic acid by ozone, Atmos. Chem. Phys., 10, 3673-3691, doi:10.5194/acp-10-3673-2010, 2010.

Sigg, A., Staffelbach, T., and Neftel, A.: Gas-phase measurements of hydrogen-peroxide in Greenland and their meaning for the interpretation of $\mathrm{H}_{2} \mathrm{O}_{2}$ records in ice cores, J. Atmos. Chem., 14, 223-232, doi:10.1007/BF00115235, 1992.

Simpson, W. R., von Glasow, R., Riedel, K., Anderson, P., Ariya, P., Bottenheim, J., Burrows, J., Carpenter, L. J., Frieß, U., Goodsite, M. E., Heard, D., Hutterli, M., Jacobi, H.-W., Kaleschke, L., Neff, B., Plane, J., Platt, U., Richter, A., Roscoe, H., Sander, R., Shepson, P., Sodeau, J., Steffen, A., Wagner, T., and Wolff, E.: Halogens and their role in polar boundary-layer ozone depletion, Atmos. Chem. Phys., 7, 4375-4418, doi:10.5194/acp-74375-2007, 2007.

Smith, M. and Pounder, E. R.: Impurity concentration profiles in ice by an anthrone method, Can. J. Phys., 38, 354-368, doi:10.1139/p60-037, 1960.

Snider, J. R. and Huang, J.: Factors influencing the retention of hydrogen peroxide and molecular oxygen in rime ice, J. Geophys. Res., 103, 1405-1415, doi:10.1029/97jd02847, 1998.

Sokolov, O. and Abbatt, J. P. D.: Competitive adsorption of atmospheric trace gases onto ice at $228 \mathrm{~K}: \mathrm{HNO}_{3} / \mathrm{HCl}, 1-$ butanol/acetic acid and 1-butanol/HCl, Geophys. Res. Lett., 29, 1851, doi:10.1029/2002g1014843, 2002.

Sola, M. I. and Corti, H. R.: Freezing induced electric potentials and $\mathrm{pH}$ changes in aqueous-solutions of electrolytes, An. Asoc. Quim. Argent., 81, 483-498, 1993.

Sommer, S., Appenzeller, C., Röthlisberger, R., Hutterli, M. A., Stauffer, B., Wagenbach, D., Oerter, H., Wilhelms, F., Miller, H., and Mulvaney, R.: Glacio-chemical study spanning the past $2 \mathrm{kyr}$ on three ice cores from dronning maud land, Antarctica 1. Annually resolved accumulation rates, J. Geophys. Res., 105, 29411-29421, doi:10.1029/2000JD900449, 2000.

Sommerfeld, R. A. and Lamb, D.: Preliminary measurements of $\mathrm{SO}_{2}$ adsorbed on ice, Geophys. Res. Lett., 13, 349-351, doi:10.1029/GL013i004p00349, 1986.

Spaulding, N. E., Meese, D. A., and Baker, I.: Advanced microstructural characterization of four east Antarctic firn/ice cores, J. Glaciol., 57, 796-810, 2011.
Staffelbach, T., Neftel, A., Stauffer, B., and Jacob, D.: A record of the atmospheric methane sink from formaldehyde in polar ice cores, Nature, 349, 603-605, doi:10.1038/349603a0, 1991.

Starr, D. E., Pan, D., Newberg, J. T., Ammann, M., Wang, E. G., Michaelides, A., and Bluhm, H.: Acetone adsorption on ice investigated by X-ray spectroscopy and density functional theory, Phys. Chem. Chem. Phys., 13, 19988-19996, doi:10.1039/C1CP21493D, 2011.

Steffen, A., Douglas, T., Amyot, M., Ariya, P., Aspmo, K., Berg, T., Bottenheim, J., Brooks, S., Cobbett, F., Dastoor, A., Dommergue, A., Ebinghaus, R., Ferrari, C., Gardfeldt, K., Goodsite, M. E., Lean, D., Poulain, A. J., Scherz, C., Skov, H., Sommar, J., and Temme, C.: A synthesis of atmospheric mercury depletion event chemistry in the atmosphere and snow, Atmos. Chem. Phys., 8, 1445-1482, doi:10.5194/acp-8-1445-2008, 2008.

Strauss, H. L., Chen, Z., and Loong, C. K.: The diffusion of $\mathrm{H}_{2}$ in hexagonal ice at low temperatures, J. Chem. Phys., 101, 71777180, doi:10.1063/1.468303, 1994.

Symington, A., Cox, R. A., and Fernandez, M. A.: Uptake of organic acids on ice surfaces: Evidence for surface modification and hydrate formation, Z. Phys. Chem., 224, 1219-1245, doi:10.1524/zpch.2010.6149, 2010.

Szabo, D. and Schneebeli, M.: Subsecond sintering of ice, Appl. Phys. Lett., 90, 151916, doi:10.1063/1.2721391, 2007.

Takenaka, N. and Bandow, H.: Chemical kinetics of reactions in the unfrozen solution of ice, J. Phys. Chem. A, 111, 8780-8786, doi:10.1021/jp0738356, 2007.

Takenaka, N., Ueda, A., and Maeda, Y.: Acceleration of the rate of nitrite oxidation by freezing in aqueous solution, Nature, 358 , 736-738, doi:10.1038/358736a0, 1992.

Takenaka, N., Ueda, A., Daimon, T., Bandow, H., Dohmaru, T., and Maeda, Y.: Acceleration mechanism of chemical reaction by freezing: The reaction of nitrous acid with dissolved oxygen, J. Phys. Chem., 100, 13874-13884, doi:10.1021/jp9525806, 1996.

Takenaka, N., Furuya, S., Sato, K., Bandow, H., Maeda, Y., and Furukawa, Y.: Rapid reaction of sulfide with hydrogen peroxide and formation of different final products by freezing compared to those in solution, Int. J. Chem. Kinet., 35, 198-205, doi:10.1002/kin.10118, 2003.

Tasaki, Y. and Okada, T.: Adsorption-partition switching of retention mechanism in ice chromatography with $\mathrm{NaCl}$-doped waterice, Anal. Sci., 25, 177-181, doi:10.2116/analsci.25.177, 2009.

Thibert, E. and Domine, F.: Thermodynamics and kinetics of the solid solution of $\mathrm{HCl}$ in ice, J. Phys. Chem. B, 101, 3554-3565, doi:10.1021/jp962115o, 1997.

Thibert, E. and Domine, F.: Thermodynamics and kinetics of the solid solution of $\mathrm{HNO}_{3}$ in ice, J. Phys. Chem. B, 102, 4432 4439, doi:10.1021/jp980569a, 1998.

Thomas, D. N. and Dieckmann, G. S.: Sea ice, Wiley-Blackwell, New York, 2 edn., 2009.

Thomas, J. L., Stutz, J., Lefer, B., Huey, L. G., Toyota, K., Dibb, J. E., and von Glasow, R.: Modeling chemistry in and above snow at Summit, Greenland - Part 1: Model description and results, Atmos. Chem. Phys., 11, 4899-4914, doi:10.5194/acp-11-48992011, 2011.

Thomas, J. L., Dibb, J. E., Huey, L. G., Liao, J., Tanner, D., Lefer, B., von Glasow, R., and Stutz, J.: Modeling chemistry in and above snow at Summit, Greenland - Part 2: Impact of snowpack chemistry on the oxidation capacity of the boundary layer, 
Atmos. Chem. Phys., 12, 6537-6554, doi:10.5194/acp-12-65372012, 2012.

Thompson, A. M.: Photochemical modeling of chemical cycles: Issues related to the interpretation of ice core data, 265-297, Springer Verlag, NATO ASI Series I, New York, 1995.

Thomson, E.: Erratum: Abrupt grain boundary melting in ice [phys. Rev. E 70, 061606 (2004)], Phys. Rev. E, 82, 039907(E), doi:10.1103/PhysRevE.82.039907, 2010.

Thomson, E. S., Hansen-Goos, H., Wettlaufer, J. S., and Wilen, L. A.: Grain boundary melting in ice, J. Chem. Phys., 138, 124707, doi:10.1063/1.4797468, 2013.

Toubin, C., Picaud, S., Hoang, P. N. M., Girardet, C., Demirdjian, B., Ferry, D., and Suzanne, J.: Dynamics of ice layers deposited on $\mathrm{MgO}(001)$ : Quasielastic neutron scattering experiments and molecular dynamics simulations, J. Chem. Phys., 114, 63716381, doi:10.1063/1.1355238, 2001.

Toyota, K., Dastoor, A. P., and Ryzhkov, A.: Air-snowpack exchange of bromine, ozone and mercury in the springtime Arctic simulated by the 1-D model PHANTAS - Part 2: Mercury and its speciation, Atmos. Chem. Phys. Discuss., 13, 22151-22220, doi:10.5194/acpd-13-22151-2013, 2013a.

Toyota, K., McConnell, J. C., Staebler, R. M., and Dastoor, A. P.: Air-snowpack exchange of bromine, ozone and mercury in the springtime Arctic simulated by the 1-D model PHANTAS - Part 1: In-snow bromine activation and its impact on ozone, Atmos. Chem. Phys. Discuss., 13, 20341-20418, doi:10.5194/acpd-1320341-2013, 2013b.

Traversi, R., Becagli, S., Castellano, E., Marino, F., Rugi, F., Severi, M., De Angelis, M., Fischer, H., Hansson, M., Stauffer, B., Steffensen, J. P., Bigler, M., and Udisti, R.: Sulfate spikes in the deep layers of EPICA-Dome C ice core: Evidence of glaciological artifacts, Environ. Sci. Technol., 43, 8737-8743, doi:10.1021/es901426y, 2009.

Ullerstam, M. and Abbatt, J. P. D.: Burial of gas-phase $\mathrm{HNO}_{3}$ by growing ice surfaces under tropospheric conditions, Phys. Chem. Chem. Phys., 7, 3596-3600, doi:10.1039/b507797d, 2005.

Ullerstam, M., Thornberry, T., and Abbatt, J. P. D.: Uptake of gasphase nitric acid to ice at low partial pressures: Evidence for unsaturated surface coverage, Faraday Discuss., 130, 211-226, doi:10.1039/b417418f, 2005.

Ulrich, T., Ammann, M., Leutwyler, S., and Bartels-Rausch, T.: The adsorption of peroxynitric acid on ice between $230 \mathrm{~K}$ and $253 \mathrm{~K}$, Atmos. Chem. Phys., 12, 1833-1845, doi:10.5194/acp-12-18332012, 2012.

Vega, C. and Abascal, J. L. F.: Simulating water with rigid nonpolarizable models: A general perspective, Phys. Chem. Chem. Phys., 13, 19663-19688, doi:10.1039/C1CP22168J, 2011.

Vega, C., Martin-Conde, M., and Patrykiejew, A.: Absence of superheating for ice Ih with a free surface: A new method of determining the melting point of different water models, Mol. Phys., 104, 3583-3592, doi:10.1080/00268970600967948, 2006.

Vega, C., Abascal, J. L. F., Conde, M. M., and Aragones, J. L.: What ice can teach us about water interactions: A critical comparison of the performance of different water models, Faraday Discuss., 141, 251-276, doi:10.1039/b805531a, 2009.

Verdaguer, A., Sacha, G. M., and Salmeron, M.: Molecular structure of water at interfaces: Wetting at the nanometer scale, Chem. Rev., 106, 1478-1510, doi:10.1021/cr0403761, 2006.
Voisin, D., Jaffrezo, J.-L., Houdier, S., Barret, M., Cozic, J., King, M. D., France, J. L., Reay, H. J., Grannas, A., Kos, G., Ariya, P. A., Beine, H. J., and Domine, F.: Carbonaceous species and humic like substances (HULIS) in Arctic snowpack during OASIS field campaign in Barrow, J. Geophys. Res., 117, D00R19, doi:10.1029/2011JD0166122012, 2012.

von Hessberg, P., Pouvesle, N., Winkler, A. K., Schuster, G., and Crowley, J. N.: Interaction of formic and acetic acid with ice surfaces between 187 and $227 \mathrm{~K}$. Investigation of single species- and competitive adsorption, Phys. Chem. Chem. Phys., 10, 23452355, doi:10.1039/B800831k, 2008.

Vrbka, L. and Jungwirth, P.: Brine rejection from freezing salt solutions: A molecular dynamics study, Phys. Rev. Lett., 95, 148501 , doi:10.1103/PhysRevLett.95.148501, 2005.

Waff, H. S. and Bulau, J. R.: Equilibrium fluid distribution in an ultramafic partial melt under hydrostatic stress conditions, J Geophys. Res., 84, 6109-6114, doi:10.1029/JB084iB11p06109, 1979.

Wang, S. Y.: Photochemical reactions in frozen solutions, Nature, 190, 690-694, doi:10.1038/190690a0, 1961.

Wang, S. Y.: The mechanism for frozen aqueous solution irradiation of pyrimidines, Photochem. Photobiol., 3, 395-398, doi:10.1111/j.1751-1097.1964.tb08161.x, 1964.

Wania, F., Hoff, J. T., Jia, C. Q., and Mackay, D.: The effects of snow and ice on the environmental behaviour of hydrophobic organic chemicals, Environ. Pollut., 102, 25-41, doi:10.1016/S0269-7491(98)00073-6, 1998.

Weber, J., Kurková, R., Klánová, J., Klán, P., and Halsall, C.: Photolytic degradation of methyl-parathion and fenitrothion in ice and water: Implications for cold environments, Environ. Pollut., 157, 3308-3313, doi:10.1016/j.envpol.2009.05.045, 2009.

Weeks, W. F. and Ackley, S. F.: The growth, structure and properties of sea ice, 9-164, Plenum Press, New York, 1986.

Wei, X., Miranda, P., and Shen, Y.: Surface vibrational spectroscopic study of surface melting of ice, Phys. Rev. Lett., 86, 1554 1557, doi:10.1103/PhysRevLett.86.1554, 2001.

Wettlaufer, J. S.: Impurity effects in the premelting of ice, Phys. Rev. Lett., 82, 2516-2519, doi:10.1103/PhysRevLett.82.2516, 1999.

Wilson, P. W. and Haymet, A. D. J.: Workman-Reynolds freezing potential measurements between ice and dilute salt solutions for single ice crystal faces, J. Phys. Chem. B, 112, 11750-11755, doi:10.1021/jp804047x, 2008.

Wolff, E. W.: Nitrate in polar ice, Ice Core Studies of Global Biogeochemical Cycles, 30, 195-224, 1995.

Workman, E. and Reynolds, S.: Electrical phenomena occurring during the freezing of dilute aqueous solutions and their possible relationship to thunderstorm electricity, Phys. Rev., 78, 254-259, doi:10.1103/PhysRev.78.254, 1950.

Wren, S. N. and Donaldson, D. J.: Exclusion of nitrate to the airice interface during freezing, J. Phys. Chem. Let., 2, 1967-1971, doi:10.1021/Jz2007484, 2011.

Wren, S. N. and Donaldson, D. J.: How does deposition of gas phase species affect $\mathrm{pH}$ at frozen salty interfaces?, Atmos. Chem. Phys., 12, 10065-10073, doi:10.5194/acp-12-100652012, 2012a.

Wren, S. N. and Donaldson, D. J.: Laboratory study of $\mathrm{pH}$ at the air-ice interface, J. Phys. Chem. C, 116, 10171-10180, doi:10.1021/jp3021936, 2012b. 
Wren, S., Kahan, T. F., Jumaa, K., and Donaldson, D. J.: Spectroscopic studies of the heterogeneous reaction between $\mathrm{O}_{3}(\mathrm{~g})$ and halides at the surface of frozen salt solutions, J. Geophys. Res., 115, D16309, doi:10.1029/2010JD013929, 2010.
Zhu, C., Xiang, B., Chu, L. T., and Zhu, L.: $308 \mathrm{~nm}$ photolysis of nitric acid in the gas phase, on aluminum surfaces, and on ice films, J. Phys. Chem. A, 114, 2561-2568, doi:10.1021/jp909867a, 2010. 